\title{
Problema de corte bidimensional guilhotinado e restrito em 2-estágios
}

\author{
Maria Cristina Nogueira Gramani
}

Orientador: Prof. Dr. Marcos Nereu Arenales

Dissertação apresentada ao Instituto de Ciências Matemáticas de São Carlos, da Universidade de São Paulo, como parte dos requisitos para obtenção do título de Mestre em Ciências - Área: "Ciências da Computação e Matemática Computacional”.

São Carlos - S.P.

Setembro de 1997 
À minha família. 


\title{
Problema de corte bidimensional guilhotinado e restrito em 2-estágios
}

\author{
Maria Cristina Nogueira Gramani
}

Orientador: Prof. Dr. Marcos Nereu Arenales

Dissertação apresentada ao Instituto de Ciências Matemáticas de São Carlos, da Universidade de São Paulo, como parte dos requisitos para obtenção do título de Mestre em Ciências - Área: "Ciências da Computação e Matemática Computacional".

São Carlos - S.P.

Setembro de 1997 


\title{
RESUMO
}

Uma placa de dimensões $(L, W)$ deve ser cortada para produzir $m$ peças de dimensões $\left(l_{i}, w_{i}\right)$, às quais estão associados valores de utilidade $v_{i}$ e um limite máximo $b_{i}$ (problema restrito), $i=1, \ldots, m$. Os cortes são do tipo guilhotinado e limitados a 2-estágios. O problema consiste em maximizar o valor de utilidade total. Neste trabalho estendemos a abordagem clássica de Gilmore e Gomory para problemas irrestritos, onde apresentamos um modelo matemático de otimização inteira não-linear, e propomos métodos de solução baseados na relaxação lagrangeana e heurísticas. Resultados computacionais são apresentados ao final.

\begin{abstract}
Consider a plate of dimensions $(L, W)$ to be cut in order to produce $m$ pieces of dimensions $\left(l_{i}, w_{i}\right)$, to which are associated utility values $v_{i}$ and upper bounds $b_{i}$ (constraint problem), $i=1, \ldots, m$. The cuts are guillotine typed and limited by 2 -stages. The problem consists of maximizing the total utility value. In this work we extend the classical approach of Gilmore and Gomory for unconstrained problems, through modeling the problem as a nonlinear integer programe, for which we devise a lagrangean method and heuristics. Finally, computational experiments are presented.
\end{abstract}




\section{ÍNDICE}

Introdução

Introdução

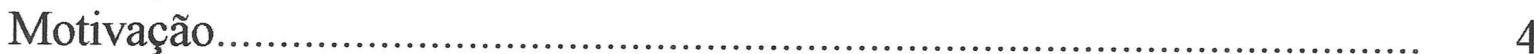

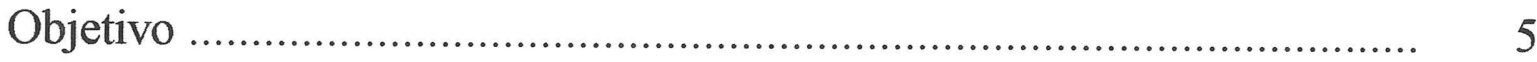

Organização da Dissertação .................................................................... 5

\section{PARTE I : Revisão da Literatura}

\section{CAPÍTULO 1 Problema de Corte de Estoque Unidimensional}

1.1. Introdução

1.2. Problema de Corte de Estoque Unidimensional ............................. 10

1.3. Problema da Mochila ..................................................................... 13

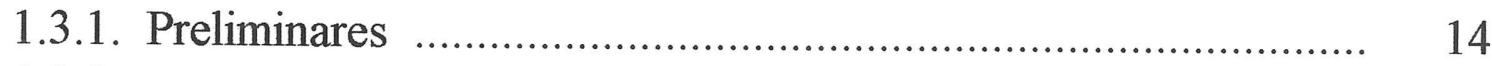

1.3.2. Programação Dinâmica ....................................................... 15

1.3.3. Método de Enumeração Implícita ......................................... 16

1.3.4. Comentários Adicionais ...................................................... 18

CAPÍTULO 2 Problema de Corte Bidimensional ................................. 19

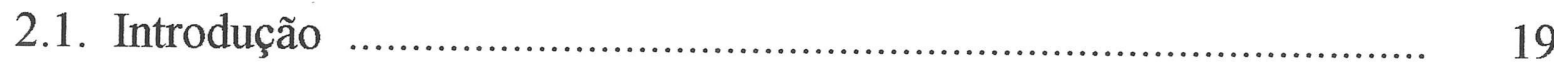

2.2. Programação Dinâmica ........................................................... 21

2.3. Uma Abordagem em Grafo E/OU ............................................... 22

2.3.1. Representação de Padrões de Corte por Grafo E/OU ..................... 22

2.3.2. Padrão $k$-Estagiado ................................................................. 24

2.3.3. Padrão Restrito .................................................................... 25 
2.3.4. Estratégia de Busca

2.4. Problema de Corte Bidimensional Guilhotinado e Irrestrito em 2-Estágios

2.4.2. Modelo Matemático

2.4.3. Método de Resolução 30

\section{PARTE II : Problema de Corte Bidimensional Guilhotinado e Restrito em 2-Estágios.}

CAPÍTULO 3 Formulação Matemática e Um Método de Resolução ...

3.1. Introdução

3.2. Modelagem Matemática ........................................................... 34

3.3. Relaxação Lagrangeana e Método do Subgradiente ....................... 38

3.4. Algoritmo do Problema de Corte Bidimensional Guilhotinado e 42 Restrito em 2-Estágios

\section{CAPÍTULO 4 Heurísticas para Obtenção de Uma Solução Factível} Inicial

4.1. Introdução

4.2. Heurística Gulosa por Peça (G/P)

4.3. Heurística Gulosa por Faixa (G/F)

4.3.1 Modelo matemático

4.3.2. Funcionamento de G/F 48

4.4. Heurística Gulosa de Substituição (G/S)

4.5. Heurística Em Grafo E/OU

4.6. Comparação entre $\mathrm{G} / \mathrm{P}, \mathrm{G} / \mathrm{F}$ e G/S

5.1. Introdução

5.2. Heurística Lagrangeana

5.3. Comparações Entre as Heurísticas Em Grafo E/OU e a Lagrangeana 


\section{PARTE III : Conclusões}

CAPÍTULO 6 Resultados dos Testes Computacionais …...................... 64

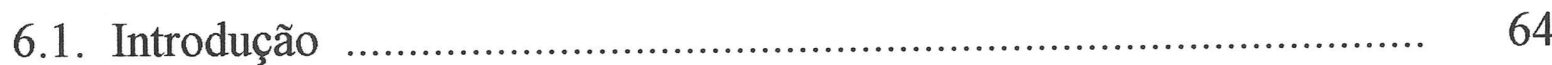

6.2. Resultados a Partir de Cada Heurística ........................................ 66

6.3. Resultados a Partir da Melhor Heurística ....................................... 69

6.3.1. Exemplos Pequenos .............................................................. 69

Valores de Utilidade Dados pela Área ........................................ 69

Valores de Utilidade Gerados Aleatoriamente ............................ 72

6.3.2. Exemplos Grandes .......................................................... 74

Valores de Utilidade Dados pela Área ........................................ 74

Valores de Utilidade Gerados Aleatoriamente ............................. $\quad 77$

6.4. Exemplos da Literatura .............................................................. 81

6.4.1. Valores de Utilidade Dados pela Área ................................. 81

6.4.2. Valores de Utilidade Gerados Aleatoriamente ........................ 85

CAPÍTULO 7 Conclusões e Perspectivas Futuras …….......................... 92

APÊNDICE $\quad$ O Método do Subgradiente ............................................ 95

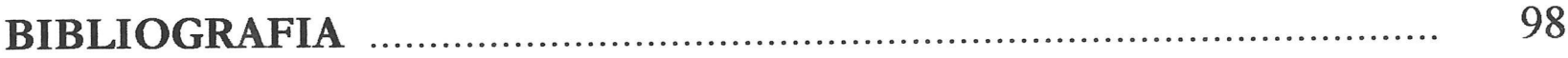




\section{INTRODUÇÃO}

\section{Introdução}

Muitos processos industriais para a produção de peças encomendadas (itens), com dimensões e quantidades especificadas, têm um importante módulo que consiste em cortar peças maiores (objetos), que podem estar disponíveis em estoque, bem como podem ser produzidas ou adquiridas de terceiros, em dimensões impostas por restrições técnicas ou de mercado, podendo ainda existir ou não limites sobre as quantidades dos objetos.

Este módulo de cortagem, por sua vez, tem um subproblema interessante que exige a definição de como os itens devem ser obtidos em cada objeto a ser cortado. A esta definição chamamos de padrão de corte. Observe que a geometria aqui é determinante, isto é, as formas e as medidas dos itens e objetos determinarão os possíveis padrões de corte. A figura 1 ilustra um possível padrão de corte para um objeto e itens retangulares.

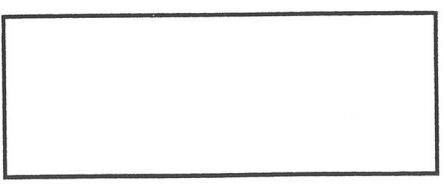

(a)

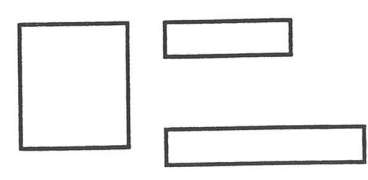

(b)

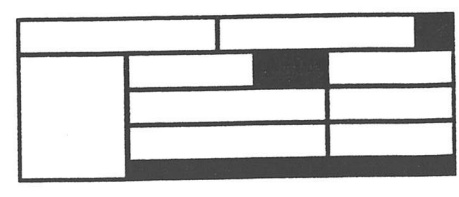

(c)
figura 1:
a. peça retangular a ser cortada (objeto)
b. peças retangulares de encomenda (itens)
c. um padrão de corte 
$\mathrm{Na}$ definição dos padrões de corte podemos associar valores de utilidade aos itens, e desta forma temos um problema de otimização combinatória que consiste em definir o padrão de corte com o maior valor de utilidade (soma dos valores de utilidade dos itens no padrão). Esforços têm sido feitos na resolução deste problema combinatório (onde a geometria dos itens e objetos definem as restrições do problema), que é o componente principal dos métodos de resolução de problemas de corte.

Dependendo da aplicação em estudo, algumas regras são necessárias para definição de um padrão de corte, tais como, cortes do tipo guilhotinados (onde cada corte sempre produz dois novos retângulos), limitação de itens (cortes restritos ou irrestritos) e número de estágios (um corte é dito 2-estágios quando apenas uma mudança no sentido dos cortes guilhotinados é permitida: vertical / horizontal ou horizontal / vertical, isto é, primeiro fazemos cortes guilhotinados verticais (ou horizontais) na placa, e depois fazemos apenas cortes horizontais (ou verticais) nos retângulos obtidos).

Podemos também ter algumas classificações dos problemas em relação à dimensão:

- Problemas Unidimensionais: onde apenas uma das dimensões é relevante para o processo de cortagem. Esta situação ocorre, por exemplo, no corte do comprimento de barras de aço, como podemos ver na figura 2 .

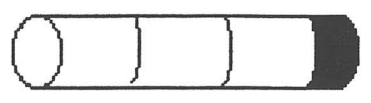

figura 2: Corte unidimensional.

- Problemas Bidimensionais: duas dimensões são relevantes para a solução do problema. A figura 3 ilustra uma placa retangular que deverá ser cortada em peças menores. A área hachurada representa o material inutilizado (pode representar a perda). Duas dimensões (comprimento e largura) são relevantes. 


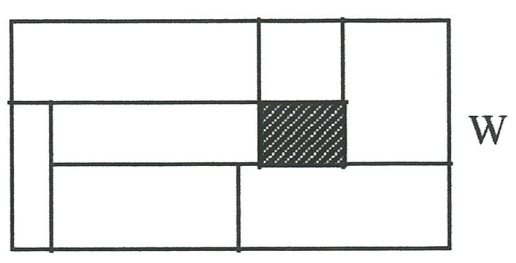

L

figura 3: Placa com dimensões $(\mathrm{L}, \mathrm{W})$.

- Problemas 1.5-dimensionais: têm duas dimensões relevantes para a solução, porém uma é variável, por exemplo, no corte de peças de vestuário.

- Problemas 2.5-dimensionais: têm três dimensões relevantes sendo uma delas variável, por exemplo, o problema de se efetuar o carregamento de unidades dentro de caixas abertas, ou seja, as bases estão definidas, mas a altura deverá ser definida.

- O problema tridimensional, onde as três dimensões são relevantes para a solução. Basicamente, trata-se de arranjar caixas espaciais, sem sobrepô-las, dentro de contêineres, comumente chamado, Problema do Carregamento de Contêineres (veja figura 4).

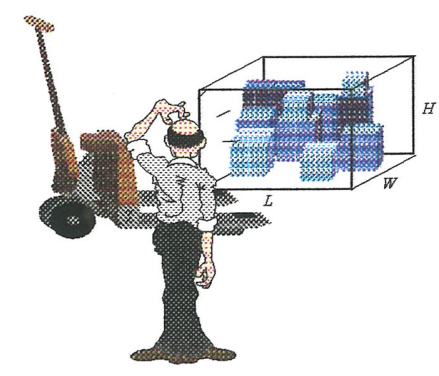

figura 4: Carregamento de contêiner com dimensões $(L, W, H)$.

Estamos preocupados com problemas bidimensionais, guilhotinados restritos em 2estágios, como mostra a figura 5.

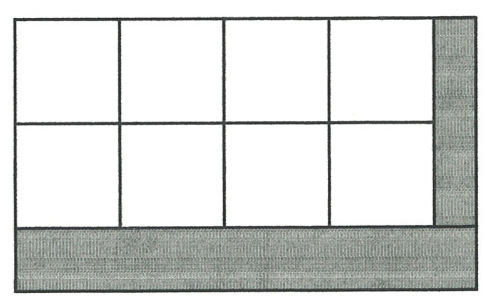

figura 5: Padrão de corte bidimensional guilhotinado em 2-estágios. 


\section{Motivação}

A importância prática e relevância econômica da otimização nos processos de corte vem sendo constatada há vários anos. Indústrias de papel têm aplicado a otimização no processo de cortes de bobinas de papel (problema unidimensional) objetivando a perda mínima; indústrias de móveis, onde placas retangulares de madeira são cortadas para produção de peças também retangulares (problema bidimensional), se deparam com o problema de escolher no mercado os tipos e as quantidades das placas a comprar, pois estas têm preços diferenciados. O objetivo é então minimizar os custos. $\mathrm{O}$ problema de corte unidimensional vem sendo usado também na construção civil, onde barras de aço devem ser cortadas, etc.

Embora o potencial de aplicações de otimização nos processos de corte no Brasil seja enorme, são poucos ainda os exemplos de utilização de metodologias específicas. Obviamente, a otimização baseada no conhecimento e habilidade humana é largamente utilizada.

A importância prática associada à dificuldade de resolução do problema de corte tem motivado vários pesquisadores a estudarem este problema e, como destacou $\mathrm{K}$. Dowsland e W.Dowsland (1992), os problemas industriais têm sido abordados através de um ponto de vista científico, isto é, um corpo matemático com definições, teoremas e corolários têm sido usado para formulação e resolução dos problemas. Durante a conferência da IFORS (International Federation of Research Societes) em 1987, na Grécia, um grupo de estudiosos organizaram o SICUP (Special Interest Group on Cutting and Packing Problems), com o objetivo de reunir e difundir os trabalhos na área. (SICUP está disponível na Internet na página http://prodlog.wiwi.uni-halle.de/sicup/).

É interessante destacar que problemas com diferentes motivações podem ser vistos sob a ótica de corte/empacotamento, ampliando ainda mais o interesse pela área. O livro de Dyckoff e Finke (1992) (Cutting and Packing in Production and Distribution: Typology 
and Bibliography) reúne os trabalhos publicados (nas línguas inglesa e alemã) até o início de 1992 objetivando, principalmente, uma classificação dos problemas de corte e empacotamento.

$\mathrm{O}$ interesse pelos problemas de corte cresceu substancialmente a partir dos trabalhos de Gilmore e Gomory no início dos anos 60. Eles propuseram métodos de determinação de padrões de corte (hoje o bem conhecido problema da mochila para o caso unidimensional) para geração de colunas de um modelo de programação linear. Os resultados excelentes obtidos ainda hoje por esse processo de geração de colunas, fazem dos trabalhos pioneiros de Gilmore e Gomory os mais importantes na área. Naturalmente esta abordagem tem suas limitações.

\section{Objetivo}

O objetivo principal deste trabalho é desenvolver uma metodologia para a resolução do problema de corte bidimensional guilhotinado e restrito em 2-estágios (estudado no Capítulo 3). Este problema foi pouco explorado na literatura e a abordagem por Grafo E/OU (estudada no capítulo 2) pode ser usada para soluções heurísticas porém ainda pouco testada.

\section{Organização da Dissertação}

Esta dissertação está dividida em 7 capítulos.

No Capítulo 1 o problema de corte de estoque unidimensional foi abordado. Veremos neste primeiro capítulo que o problema de corte de estoque unidimensional quando expresso como um programa inteiro, torna-se computacionalmente inviável pelo grande número de variáveis envolvidas. Para superar essa dificuldade Gilmore e Gomory, 1963 propuseram uma técnica de geração de colunas baseada na resolução do problema da 
mochila. Veremos também dois métodos de resolução do problema da mochila: programação dinâmica e o método de enumeração implícita.

Vale observar que a partir do Capítulo2, estudaremos o problema de corte que envolve apenas a descoberta do melhor padrão de corte para uma única placa, diferentemente do Capítulo 1 onde estudamos o problema de corte de estoque que envolve o corte de várias placas associados à demanda.

Apresentamos no Capítulo 2 o problema de corte bidimensional Mostraremos nesse capítulo três métodos de resolução para o problema de corte bidimensional guilhotinado:

- programação dinâmica para problemas irrestritos e não estagiados;

- abordagem por Grafo E/OU para problemas restritos e estagiados;

- método proposto por Gilmore e Gomory, 1965 para problemas irrestritos em 2-estágios.

O método de Gilmore e Gomory, 1965 baseia-se em estender a técnica de geração de colunas (estudada no Capítulo 1) para problemas de corte bidimensional. Como no caso unidimensional, a dificuldade em resolver este problema de corte é o imenso número de colunas (variáveis) que podem ocorrer na matriz. Se como no caso unidimensional aplicarmos a técnica de geração de colunas, obtemos um certo "problema da mochila generalizado", cujas restrições correspondem ao padrão de corte encaixando peças retangulares em uma placa retangular. Esta proposta de solução é baseada na resolução de no máximo $m+1$ problemas da mochilas.

No Capítulo 3 estudamos o objetivo do nosso trabalho: o problema de corte bidimensional guilhotinado e restrito em 2-estágios. Para o caso restrito, temos uma certa dificuldade, pois o modelo matemático apresenta restrições não-lineares. Uma abordagem de resolução consiste em relaxar as restrições complicadas, isto é, as restrições nãolineares, através da Relaxação Lagrangeana produzindo subproblemas irrestritos. 
Definimos então o dual lagrangeano e, para resolvê-lo utilizamos o Método do Subgradiente apresentado no Apêndice. Apresentamos também nesse capítulo o algoritmo implementado.

Durante a implementação do algoritmo acima mencionado notamos a necessidade de produzir uma solução factível inicial, assim, no Capítulo 4, propusemos três heurísticas para esse cálculo e alguns resultados computacionais comparando essas duas heurísticas. Também neste capítulo apresentamos um método heurístico, denominada heurística em Grafo E/OU, baseada em Hifi et al, 1997 para problemas de corte bidimensional guilhotinado restrito em 2-estágios.

No Capítulo 5, propusemos uma Heurística Lagrangeana, para factibilizar soluções provenientes da resolução do problema relaxado (irrestrito). Apresentamos alguns resultados computacionais comparando o desempenho do algoritmo proposto no capítulo 3 utilizando a heurística lagrangeana com a heurística em grafo E/OU.

No Capítulo 6, apresentamos alguns resultados dos testes computacionais do algoritmo implementado no capítulo 3.

Finalmente apresentamos nossas conclusões e as considerações finais desta dissertação no Capítulo 7. 


\section{CAPÍTULO 1}

\section{Problema de corte de estoque unidimensional}

\subsection{Introdução}

O problema de corte de estoque é um problema onde um conjunto de peças encomendadas deve ser produzido a partir da cortagem de peças em estoque de modo que uma demanda conhecida das peças encomendadas seja atendida e que uma certa função seja otimizada. Este problema foi estudado por Gilmore e Gomory (1961, 1963, 1965) onde propuseram uma abordagem de geração de colunas para o Método Simplex. O problema consiste em determinar padrões de corte de peças em estoque para obtenção de itens demandados em quantidades especificadas. O modelo mais difundido é :

$$
\begin{gathered}
\min \sum_{j=1}^{n} c_{j} x_{j} \\
\sum_{j=1}^{n} a_{i j} x_{j}=N_{i} \quad i=1, \ldots, m \\
x_{j} \geq 0
\end{gathered}
$$


onde $x_{j}$ (incógnita ) é a quantidade de peças cortadas segundo um padrão $j ; c_{j}$ é o custo de cortar uma peça segundo o padrão $j ; a_{i j}$ é o número peças encomendadas do tipo $i$ obtidos no padrão $j$ e $N_{i}$ é a quantidade demandada de itens do tipo $i$. (Por simplificação de notação, apenas um tipo de placa em estoque é suposto). Como $n$ (número total de padrões de corte) é muito grande, na ordem de vários milhões ou bilhões em casos práticos, as colunas $\left(a_{1 j}, a_{2 j}, \ldots, a_{m j}\right)$ - correspondendo a padrões de cortes - são geradas a cada iteração simplex, pois têm uma lei de formação (semelhante ao método de Dantzig-Wolfe). A geração de uma coluna corresponde a um "subproblema de otimização combinatória" o qual determina como uma peça deve ser cortada, isto é, determina um "padrão de corte". Este subproblema é chamado de "problema de corte" que surge a cada iteração do método de geração de colunas de Gilmore e Gomory (bem como na maioria dos algoritmos heurísticos) e é definido por :

$$
\begin{array}{r}
\max \pi_{1} y_{1}+\pi_{2} y_{2}+\ldots+\pi_{m} y_{m} \\
\text { sujeito a }:\left(y_{1}, y_{2}, \ldots, y_{m}\right)-\text { corresponde a um padrão de corte } \\
\text { sobre a peça disponível em estoque. }
\end{array}
$$

A função objetivo (1.1) depende dos multiplicadores simplex e as restrições (1.2) nem sempre podem ser explicitadas matematicamente através de sistemas algébricos de equações. Em particular, se apenas uma dimensão for relevante (problema unidimensional) para o processo de cortagem então (1.2) pode ser descrita por :

$$
\sum_{i=1}^{m} l_{i} y_{i} \leq L \quad y_{i} \geq 0 \quad \text { inteiro }
$$

onde $L$ : dimensão relevante da peça em estoque e $l_{i}$ dimensão do item $i$ demandado, $i=1, \ldots, m$.

Veremos na próxima seção a técnica de geração de colunas, o problema da mochila, e dois métodos de resolução deste último. 


\subsection{Problema de corte de estoque unidimensional}

Em Gilmore e Gomory (1961) o problema unidimensional foi abordado, onde o modelo proposto por Eisemann (1957) foi reformulado e desenvolveu-se um processo de geração de colunas para superar a dificuldade na formulação do problema de programação linear.

$$
\left\{\begin{array}{cl}
\min & c_{1} x_{1}+c_{2} x_{2}+\ldots+c_{n} x_{n} \\
\text { sujeito } a: & a_{i 1} x_{1}+a_{i 2} x_{2}+\ldots+a_{i n} x_{n} \geq N_{i} \quad i=1,2, \ldots, m \\
& x_{j} \geq 0 \text { e inteiros } j=1,2, \ldots, n
\end{array}\right.
$$

Introduzindo variáveis de folga $x_{n+1}, \ldots, x_{n+m}$ o problema de corte de estoque pode ser descrito como um problema de encontrar inteiros $x_{1}, \ldots, x_{n+m}$ satisfazendo:

$$
\begin{gathered}
a_{i 1} x_{1}+a_{i 2} x_{2}+\ldots+a_{i n} x_{n}-x_{n+i}=N_{i} \quad i=1,2, \ldots, m \\
x_{j} \geq 0 \quad j=1,2, \ldots, n+m
\end{gathered}
$$

para o qual (1.3) é mínimo.

Existem dois fatores contribuindo para fazer essa formulação do problema de corte de estoque impraticável: Primeiro a restrição de integralidade, e o segundo fator, o tamanho de $n$ que pode ser enorme.

Com relação a restrição de integralidade, podemos relaxá-la quando a demanda é suficientemente alta, de modo que o número de peças em estoque a serem cortadas seja grande.

Embora as variáveis de folga, quando removemos a restrição de integralidade possam ser omitidas, existem vantagens de não omiti-las. Sem as variáveis de folga toda solução para o problema terá exatamente $m$ padrões, enquanto que com as variáveis de folga uma solução pode ser obtida com menos que $m$ padrões. 
Em relação ao segundo fator, quando no método simplex chega-se no estágio de procurar uma nova coluna ou padrão que irá melhorar a solução, ao invés de procurar sobre uma vasta coleção de colunas (que torna o problema impraticável pelo grande número de variáveis envolvidas), simplesmente cria-se uma coluna útil resolvendo um problema auxiliar, que será de programação inteira, mas de um tipo especial, o problema da mochila, que pode ser resolvido por vários métodos, como, programação dinâmica ou método de enumeração implícita. Isto pode ser observado pela aplicação do método simplex ao problema (1.3)-(1.5):

O custo relativo de uma coluna $j$ é:

$$
c_{j}-\pi^{t} a_{j}=c_{j}-\pi_{1}^{t} a_{1 j}-\pi_{2}^{t} a_{2 j}-\ldots-\pi_{m}^{t} a_{m j}
$$

A coluna a ser escolhida a entrar na base (pelo critério de Dantzig) é:

$$
\min c_{j}-\pi^{t} a_{j}=\min c_{j}-\pi_{1}^{t} a_{1 j}-\pi_{2}^{t} a_{2 j}-\ldots-\pi_{m}^{t} a_{m j}
$$

como a j-ésima coluna deve corresponder a um padrão de corte tem-se:

$$
\begin{aligned}
& l_{1} a_{1 j}+l_{2} a_{2 j}+\ldots+l_{m} a_{m j} \leq L \\
& a_{i j} \geq 0 \text { e inteiros } i=1,2, \ldots, m
\end{aligned}
$$

onde $L$ é o comprimento das peças em estoque e $l_{i}$ o comprimento das peças demandadas, $i=1,2, \ldots, m$.

Supondo por simplicidade que todas as peças em estoque sejam idênticas e a função objetivo seja $x_{1}+x_{2}+\ldots+x_{n}\left(c_{j}=1\right)$, a escolha da coluna corresponde a resolver o seguinte problema:

$$
\begin{array}{cl}
\max & \pi_{1} y_{1}+\pi_{2} y_{2}+\ldots+\pi_{m} y_{m,} \\
\text { sujeito } a: & l_{1} y_{1}+l_{2} y_{2}+\ldots+l_{m} y_{m} \leq L \\
& y_{i} \geq 0 \text { inteiros } i=1,2, \ldots, m
\end{array}
$$

onde uma coluna $a=\left(y_{1}, y_{2}, \ldots, y_{m}\right)^{t}$ significa que $y_{i}$ peças demandadas de comprimento $l_{i}$ foram produzidas no correspondente padrão de corte. Se $1-\sum_{i=1}^{m} \pi_{i} y_{i} \geq 0$ então estamos na solução ótima do problema. Caso contrário, determine a coluna que vai sair da base e 
reinicialize o processo do método simplex com a nova base. Temos então o seguinte algoritmo para o problema de corte de estoque unidimensional:

\section{$\underline{\text { Algoritmo }}$}

Passo 1: PARE=Falso, IT=1 (iteração atual). Gerar $B$, base inicial construída a partir da solução homogênea, isto é:

$$
B=\left(\begin{array}{l|lllll}
\left\lfloor\frac{L}{l_{1}}\right\rfloor & 0 & 0 & 0 & \ldots & 0 \\
0 & \left\lfloor\frac{L}{l_{2}}\right\rfloor & 0 & 0 & \ldots & 0 \\
\ldots & & & & & \\
0 & 0 & \ldots & & & \left.\frac{L}{l_{m}}\right\rfloor
\end{array}\right)
$$

Passo 2: Enquanto PARE=Falso, faça:

\{início da iteração simplex\}

2.1.: \{cálculo da solução básica corrente\} Resolva $B x=b$

2.2.: \{cálculo dos custos relativos\} Resolva $B^{t} \pi=c_{B}$.

2.3.: \{problema da mochila\} Resolva

$$
\begin{array}{cl}
\max & \pi_{1} y_{1}+\pi_{2} y_{2}+\ldots+\pi_{m} y_{m,} \\
\text { sujeito } a: & l_{1} y_{1}+l_{2} y_{2}+\ldots+l_{m} y_{m} \leq L \\
& y_{i} \geq 0 \text { int eiros } i=1,2, \ldots, m
\end{array}
$$

2.4.: $\{$ Teste de otimalidade $\}$

Se $1-\sum_{i=1}^{m} \pi_{i} y_{i} \geq 0$ então PARE=Verdadeiro. $\{$ solução corrente é ótima\}

Senão \{determine as coordenadas básicas da direção simplex $d$ \} 
resolva $B d=-y \quad(y=$ coluna a entrar na base $)$

2.5.: Determine $r$ tal que :

$$
\frac{-x_{r}}{d_{r}}=\min \left\{\frac{-x_{i}}{d_{i}} / d_{i}<0\right\}
$$

2.6.: Atualize a base:

$$
B=[\ldots \ldots y . \ldots . . ., y \text { entra na } r \text {-ésima posição. }
$$

$\mathrm{IT}=\mathrm{IT}+1$

\{Fim da iteração simplex.\}

\subsection{Problema da Mochila}

O problema (1.6), descrito na seção anterior, é conhecido na literatura como problema da mochila e deve ser resolvido a cada iteração simplex, determinando uma coluna (ou um padrão de corte) a entrar na base.

O problema da mochila é assim chamado por modelar a seguinte situação hipotética:

Um muambeiro pode carregar em sua mochila uma carga que não pode superar $R \$ L$ (digamos, uma restrição alfandegária). Tem a opção de escolher entre $m$ produtos. Cada produto $i$ vale $l_{i}$ e dará ao muambeiro um retorno de $\pi_{i}, i=1,2, \ldots, m$. Definindo-se $y_{i}$ a quantidade escolhida do produto $i$, o problema (1.6) modela a escolha de máximo retorno.

Vejamos agora dois métodos de resolução do problema da mochila. 


\subsubsection{Preliminares}

- Observe que o problema da mochila pode ser resolvido por uma seqüência de decisões, que consiste em incluir uma peça por vez, dentre os $m$ tipos de peças disponíveis.

- A mochila inicialmente está vazia e, portanto, o espaço disponível é $L$. Num primeiro estágio, podemos incluir uma peça do tipo $i, i=1,2, \ldots, m$ e por conseguinte, restará um espaço de $L-l_{i}$ a ser preenchido. Em seguida num segundo estágio, o espaço $L-l_{i}$ pode ser preenchido da mesma maneira, escolhendo-se uma peça do tipo $j$, restando um espaço de $L-l_{i}-l_{j}$. Este processo pode ser repetido até que o espaço resultante não seja mais suficiente para a inclusão de qualquer outra peça. Se todas as possibilidades de inclusão de peças em cada estágio forem percorridas, teremos gerado todas as possíveis soluções do problema da mochila. Essas possíveis decisões podem ser representadas numa árvore, onde cada nó representa o espaço ainda a ser preenchido e cada arco a decisão a ser tomada.

- árvore de decisões:

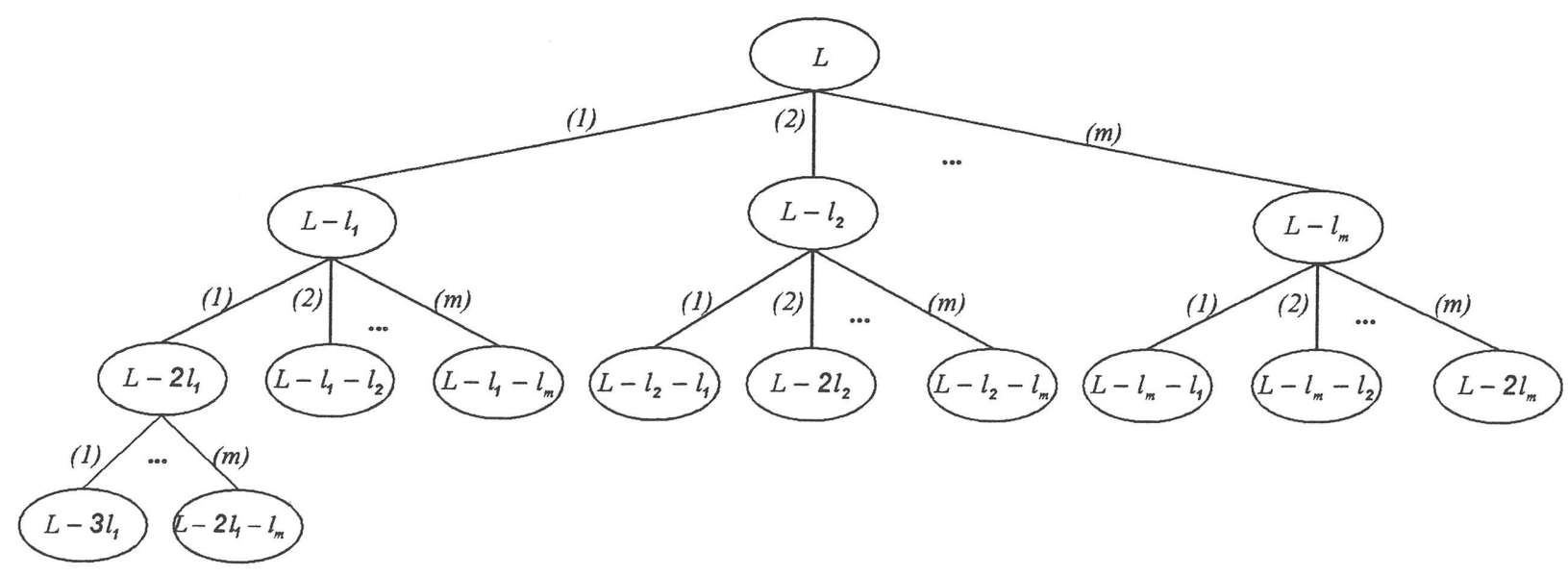

Para cada nó da árvore de decisões, uma seqüência de decisões já foram tomadas e sejam $\hat{y}_{1}, \hat{y}_{2}, \ldots, \hat{y}_{m}$ os números de peças $1,2, \ldots, m$ incluídas, respectivamente. $\mathrm{O}$ espaço livre na mochila é dado por: $X=L-l_{1} \hat{y}_{1}-l_{2} \hat{y}_{2}-\ldots-l_{m} \hat{y}_{m}$. Resta então o problema: 


$$
\mathrm{G}(\mathrm{X})=\begin{array}{ll}
\max & \pi_{1} y_{1}+\pi_{2} y_{2}+\ldots+\pi_{m} y_{m} \\
\text { sujeito } a: & l_{1} y_{1}+l_{2} y_{2}+\ldots+l_{m} y_{m} \leq X \\
& y_{i} \geq 0 \text { int eiros } i=1,2, \ldots, m
\end{array}
$$

O valor de $G(X)$, assim definido, é o valor ótimo da mochila de tamanho $X$. Observe que $\mathrm{G}(\mathrm{L})$ corresponde ao problema da mochila original.

\subsubsection{Programação Dinâmica (Gilmore e Gomory, 1961).}

A programação dinâmica propõe uma fórmula recursiva para a resolução do problema que implementa uma estratégia de percorrer a árvore de decisões:

A solução de um nó representando um espaço vazio $X$ (mochila de tamanho $X$ ) é determinada assim que os nós sucessores: $X-l_{1}, X-l_{2}, \ldots, X-l_{m}$ estiverem resolvidos, isto é,

Se conhecemos $\mathrm{G}\left(X-l_{1}\right), \mathrm{G}\left(X-l_{2}\right), \ldots, \mathrm{G}\left(X-l_{m}\right)$ então podemos determinar $\mathrm{G}(X)$.

A figura a seguir ilustra esta forma de percorrer a árvore. A decisão tomada, incluir a peça $k$, deve ser guardada.

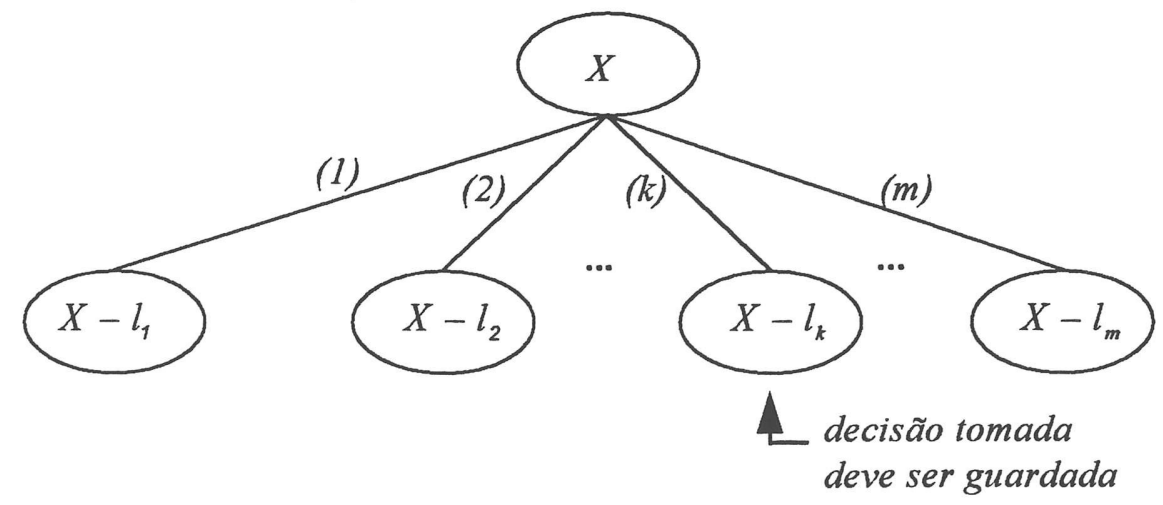

Logo, podemos escrever 


$$
\begin{aligned}
& l_{o}=\min \left\{l_{i}, i=1,2, \ldots, m\right\} \\
& G(X)=0, X=0,1, \ldots, l_{o}-1 \\
& G(X)=\pi_{k}+G\left(X-l_{k}\right)=\max \left\{\pi_{i}+G\left(X-l_{i}\right), i=1,2, \ldots, m\right\}, X=l_{0}, l_{0}+1, \ldots, L \\
& \operatorname{Decis\tilde {a}o}(X)=k
\end{aligned}
$$

Observe que esta fórmula recursiva exige que todos os estados sejam resolvidos. Os estados possíveis podem ser reduzidos a uma combinação dos comprimentos $l_{i}$, $i=1,2, \ldots, m$. Heurísticas podem ser desenvolvidas por considerar um subconjunto dos estados possíveis.

\subsubsection{Um método de enumeração implícita (branch and bound) implementado pela estratégia de busca em profundidade primeiro (Gilmore e Gomory, 1963).}

Percorrer todas as possíveis soluções do problema da mochila, isto é, enumerar explicitamente todos os caminhos na árvore de decisão, é, em geral, computacionalmente impraticável para problemas de tamanhos moderados. As soluções podem, entretanto, ser implicitamente enumeradas, isto é, podemos descartar soluções (caminhos na árvore de decisão) sem perder a solução ótima do problema. Isto é feito com o uso de limitantes do problema.

\section{$\underline{\text { Algoritmo }}$}

Passo 1: Para cada peça do tipo $i$ (à qual estão associados um valor $\pi_{i}$ e um comprimento $l_{i}$ ) definimos $v_{i}=\pi_{i} / l_{i}, i=1,2, \ldots, m$. As peças mais valiosas são aquelas com os maiores valores de $v_{i}$, logo, ordene as peças segundo os valores $v_{i}$, isto é, $v_{1} \geq v_{2} \geq \ldots \geq v_{m}$ 
Passo 2: Uma solução inicial (factível) pode ser facilmente obtida pela solução homogênea - busca em profundidade primeiro, logo, faça:

$$
y_{1}=\left\lfloor\frac{L}{l_{1}}\right\rfloor, \ldots, y_{k+1}=\left\lfloor\frac{L-\sum_{i=1}^{k} l_{i} y_{i}}{l_{k+1}}\right\rfloor, k=1,2, \ldots, m-1
$$

Passo 3: Avaliação da solução corrente e armazenamento da mais valiosa.

Determine

$$
g(y)=\sum_{i=1}^{m} \pi_{i} y_{i}
$$

Se $\underline{G}<g(y)$ (considere inicialmente $\underline{G}=0$ ) então faça: $\underline{G}=g(y)$

e guarde a solução correspondente:

$$
\underline{y}=y \text {. }
$$

Passo 4: teste de otimalidade e cálculo de limite superior:

Determine $k$ o maior índice tal que $y_{k} \neq 0$.

Se $y=0$ então PARE, a melhor solução guardada em $\underline{y}$, é uma solução ótima.

Caso contrário, calcule: (se $k=m$, considere $\pi_{m+1}=0$ e $l_{m+1}=1$ )

$$
\bar{G}=\pi_{1} y_{1}+\pi_{2} y_{2}+\ldots+\pi_{k}\left(y_{k}-1\right)+\frac{\pi_{k+1}}{l_{k+1}}\left(L-l_{1} y_{1}-l_{2} y_{2}-\ldots-l_{k}\left(y_{k}-1\right)\right)
$$

Passo 5: backtracking

5.1: retorno longo

Se $\bar{G} \leq \underline{G}$ faça $y_{k}=0$ e volte ao passo 4 .

5.2: retorno ao nó precedente e nova busca em profundidade

Se $\bar{G}>\underline{G}$ então faça $y_{k} \leftarrow y_{k}-1$ e defina a nova solução $y$ :

$$
y_{j+1}=\left\lfloor\frac{L-\sum_{i=1}^{m} l_{i} y_{i}}{l_{j+1}}\right\rfloor, j=k, \ldots, m-1
$$

e volte ao passo 3 . 


\subsubsection{Comentários Adicionais}

- Na introdução deste capítulo supomos apenas um tipo de peça em estoque por simplificação de notação. Mas também poderíamos ter problemas com peças de diferentes comprimentos em estoque, $L_{1}, L_{2}, \ldots, L_{k}$. Portanto o problema de escolher uma nova coluna no procedimento simplex para o problema de corte de estoque pode ser expressado como um problema de encontrar uma solução para $k$ problemas auxiliares, ou problemas da mochila (um para cada peça em estoque, $L_{1}, L_{2}, \ldots, L_{k}$ ), cada um desses sendo um problema de programação inteira. Esses $k$ problemas da mochila são resolvidos quando a mochila da peça maior for resolvida, isto é, seja $L=\max \left\{L_{1}, L_{2}, \ldots, L_{k}\right\}$, então o cálculo de $G(L)$ pressupõe que $G\left(L_{i}\right), i=1,2, \ldots, k$, tenham sido calculados.

- Para a resolução do problema da mochila, a técnica mais comumente utilizada é a programação dinâmica. Morábito (1992) em sua Tese de Doutorado descreveu que para problemas relativamente pequenos rotinas de programação dinâmica tem um bom desempenho e são facilmente programáveis em computador. Para problemas maiores, a utilização dessas rotinas são limitadas geralmente pela disponibilidade de memória computacional e outras abordagens podem ser mais adequadas. Por exemplo o método de enumeração implícita (ou método branch and bound) em Akinc (1983) eficaz na solução de problemas com até 5000 variáveis . 


\section{CAPÍTULO 2}

\section{Problema de corte bidimensional}

\subsection{Introdução}

Considere uma placa retangular de largura $W$ e comprimento $L$ e peças retangulares de comprimentos $l_{i}$ e larguras $w_{i}, i=1,2, \ldots, m$. Um problema de corte bidimensional consiste em cortar a placa retangular em peças retangulares menores de modo que uma certa função seja otimizada.

Diferentemente do caso unidimensional, regras do processo de cortagem devem ser agora definidas, tais como cortes guilhotinados e não-guilhotinados, estagiado e multiestagiado, etc. Observemos que no capítulo anterior estudamos o problema de corte de estoque e nos próximos capítulos daremos enfoque ao problema de corte.

Definição 2.1.: Dizemos que um corte é do tipo guilhotinado se aplicado a um retângulo produzir dois novos retângulos. Chamamos esses retângulos de pares. Um padrão de corte é do tipo guilhotinado se é obtido por cortes guilhotinados sucessivos. 


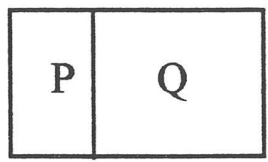

(a)

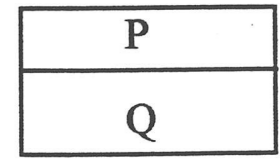

(b)

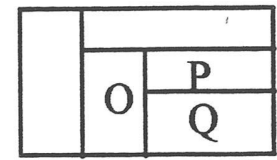

(c)

figura 2.1: (a) corte vertical guilhotinado

(b) corte horizontal guilhotinado

(c) padrão de corte guilhotinado

Definição 2.2.: Um padrão de corte é irrestrito quando não há limitação no número de itens por padrão de corte, caso contrário, o padrão de corte é restrito.

Definição 2.3.: Um corte é dito 2-estágios quando apenas uma mudança no sentido dos cortes guilhotinados é permitida: vertical / horizontal ou horizontal / vertical, isto é, primeiro fazemos cortes guilhotinados verticais (ou horizontais) na placa, e depois fazemos apenas cortes horizontais (ou verticais) nos retângulos obtidos. Se não há limite no número de estágios, então chama-se multiestágios ou não-estagiado.

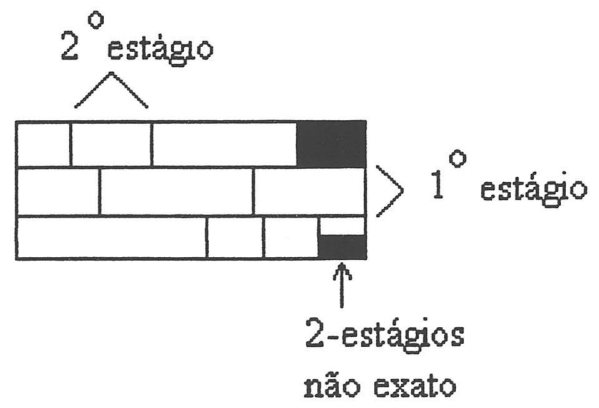

cortes guilhotinados

figura 2.2.: Corte guilhotinado 2-estágios.

Observe que na figura acima temos um corte guilhotinado 2-estágios não-exato, isto é, quando é permitimos um estágio posterior somente para fazer a última apara na direção perpendicular à direção dos cortes do estágio anterior (trataremos o nosso problema também permitindo cortes não exatos). 
Vejamos nas próximas seções, três métodos de resolução para problemas de corte guilhotinado bidimensional: Programação Dinâmica para problemas irrestritos e não estagiados, Abordagem em Grafo E/OU para problemas restritos e estagiados e um método proposto por Gilmore e Gomory, 1965 para problemas irrestritos em 2-estágios.

\subsection{Programação Dinâmica}

Herz (1972) e depois Christofides e Whitlock (1977) mostraram que, sem perda de generalidade, os cortes guilhotinados podem ser reduzidos a combinações lineares inteiras não-negativas das dimensões das peças (isto é, os padrões normais). Ou seja, podemos reduzir cortes verticais ao longo do comprimento $L$ ao conjunto

$$
X=\left\{x / x=\sum_{i=1}^{m} \alpha_{i} l_{i}, \quad 1 \leq x \leq L-l_{0}, \quad \alpha_{i} \geq 0 \text { e int eiro }\right\}
$$

onde $l_{0}=\min \left\{l_{i}, \quad i=1,2, \ldots, m\right\}$.

Similarmente, os cortes ao longo da largura $W$ podem ser reduzidos aos elementos do conjunto $Y$, definido como:

$$
Y=\left\{y / y=\sum_{i=1}^{m} \beta_{i} w_{i}, \quad 1 \leq y \leq W-w_{0}, \quad \beta_{i} \geq 0 \text { e int eiro }\right\}
$$

onde $w_{0}=\min \left\{w_{i}, \quad i=1,2, \ldots, m\right\}$.

Os conjuntos $X$ e $Y$ são chamados Conjuntos de Discretização.

Beasley (1985) apresentou fórmulas recursivas de programação dinâmica para encontrar a solução ótima de problemas de corte bidimensional guilhotinado e irrestrito, utilizando estes conjuntos $X$ e $Y$. Uma solução particular, somente com peças iguais, é chamada homogênea. A melhor solução homogênea para um retângulo $(x, y)$ é definida como:

$$
\left.H(x, y)=\max _{i=1, \ldots, m}\left\{v_{i}\left\lfloor x / l_{i}\right\rfloor y / w_{i}\right\rfloor\right\}
$$


Seja $F(x, y)$ o valor da melhor solução para um retângulo $(x, y)$ dado por:

$$
\begin{aligned}
& F(x, y)=\max \left\{H(x, y) ; F\left(x_{1}, y\right)+F\left(\left\lfloor x-x_{1}\right\rfloor_{x}, y\right), x_{1} \in X, x_{1} \leq x-1 ;\right. \\
& \left.F\left(x, y_{1}\right)+F\left(x,\left\lfloor y-y_{1}\right\rfloor_{y}\right), y_{1} \in Y, y_{1} \leq y-1\right\}, x \in X \cup\{L\}, y \in Y \cup\{W\}
\end{aligned}
$$

onde:

$$
\begin{aligned}
& \lfloor x\rfloor_{x}=\max \left\{0, x_{1} / x_{1} \leq x, x_{1} \in X\right\} \\
& \lfloor y\rfloor_{y}=\max \left\{0, y_{1} / y_{1} \leq y, y_{1} \in Y\right\}
\end{aligned}
$$

Se os conjuntos $X$ e $Y$ forem completamente gerados então o método produz a solução ótima. Entretanto, dependendo das dimensões da placa e das peças, estes conjuntos podem ser muito grandes e inviabilizar computacionalmente este método exato (observe que (2.1) requer uma capacidade de memória para $O(|X| \| Y \mid)$ números). Beasley apresentou uma heurística para limitar o tamanho destes conjuntos (que não iremos apresentar nesse trabalho).

\subsection{Abordagem por grafo E/OU}

Uma abordagem em grafo E/OU foi proposta por Morábito et al. (1992) para resolver problemas de corte guilhotinado bidimensional irrestrito e não estagiado. Essa abordagem foi estendida por Morábito e Arenales (1996) para resolver problemas restritos e estagiados, como veremos a seguir.

\subsubsection{Representação de padrões de cortes por Grafo E/OU}

Um grafo $\mathrm{G}=(\mathrm{V}, \varepsilon)$ consiste de um conjunto finito não-vazio $\mathrm{V}=\{1,2, \ldots, r\}$ e um conjunto $\varepsilon=\left\{e_{1}, e_{2}, \ldots, e_{s}\right\}$ cujos elementos são subconjuntos de $\mathrm{V}$ de tamanho 2 , isto é, $e_{u}=(i, j)$, onde $i, j \in \mathrm{V}$. Os elementos de $\mathrm{V}$ são chamados vértices (ou nós), e os elementos de $\varepsilon$ são chamados arestas (ou arcos), veja figura 2.3a. 
Uma maneira de generalizar um grafo é permitir arcos em $\varepsilon$ de diferentes tamanhos, por exemplo, um arco $e_{u}=(i, j, k), i, j, k \in \mathrm{V}$. Para essa generalização $\mathrm{G}=(\mathrm{V}, \varepsilon)$ é chamado um hipergrafo, veja figura $2.3 \mathrm{~b}$.

Outra maneira de generalizar um grafo é definir arcos como pares $e_{u}=\left(i, V_{u}\right)$ onde $i \in \mathrm{V}$ e $V_{u} \subset \mathrm{V}$, por exemplo, um arco $e_{u}=(i,\{j, k\})$ onde $i \in \mathrm{V}$ e $\{j, k\} \subset \mathrm{V}$.

Se $V_{u}$ tem cardinalidade maior que 1 então $e_{u}$ é chamado um arco E e G um grafo $E / O U$, veja figura $2.3 \mathrm{c}$. Note que um arco de um grafo define uma relação entre dois nós, um arco de um hipergrafo define uma relação entre um subconjunto de nós, e um arco de um grafo E/OU define uma relação entre um nó e um subconjunto de nós.

(a) Grafo: $\mathrm{G}=(\mathrm{V}, \varepsilon), e_{u}=(i, j), i, j \in \mathrm{V}$

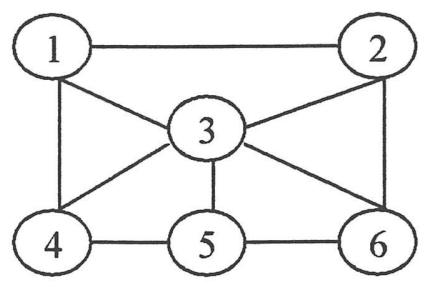

(b) Hipergrafo: $e_{u}=(i, j, k)$

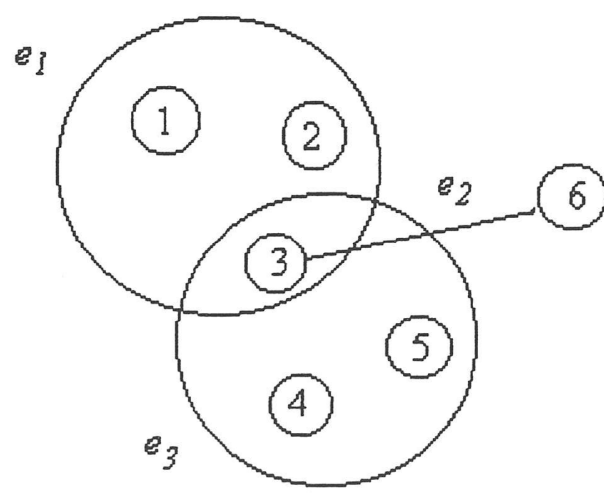

$e_{1}=(1,2,3)$

$e_{2}=(3,6)$ $e_{3}=(3,4,5)$

(c) Grafo E/OU: $e_{u}=(i,(j, k))$

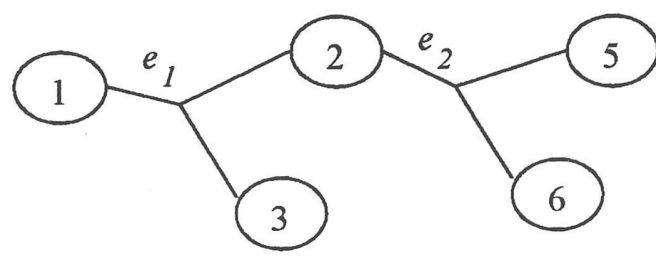

\section{4}

figura 2.3.: Representação de Grafo, Hipergrafo e Grafo E/OU. 
Um grafo E/OU particular pode ser definido para representar todos os possíveis padrões de corte guilhotinados bidimensional. O padrão de corte na figura 2.4 pode ser representado pelo caminho num grafo E/OU onde nós representam retângulos e arcos representam cortes.
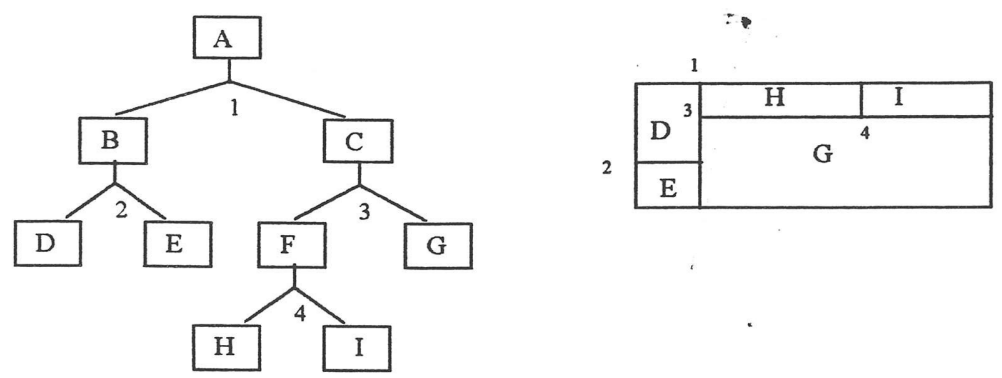

Figura 2.4: Seqüência de cortes e padrão de corte correspondente.

Diferentes opções de divisão de um nó são indicados por arcos-OU. Um arco especial, chamado 0 -corte, reproduz o retângulo e encerra o processo de cortagem.

Note que um nó $(l, w)$ tal que $l<\min \left\{l_{i}, i \in M\right\}$ ou $w<\min \left\{w_{i}, i \in M\right\}$ aceita somente um corte- 0 e tal nó representa a perda no padrão de corte.

\subsubsection{Padrão $k$-estagiado}

Para gerar padrões de corte $k$-estagiado, procedemos como segue:

Seja $N$ um nó do grafo E/OU e CORTE e ESTÁGIO funções de $N$ definidas como:

$\operatorname{CORTE}(N)= \begin{cases}\mathrm{v} & \text { se } N \text { for obtido por um corte vertical } \\ \mathrm{h} & \text { se } N \text { for obtido por um corte horizontal }\end{cases}$

$\operatorname{ESTÁGIO}(N)=$ o número de estágios já realizados até o nó $N$.

Sejam $N_{1}$ e $N_{2}$ um par de sucessores de $N$, obtidos de um corte guilhotinado. É claro que $\operatorname{CORTE}\left(N_{1}\right)=\operatorname{CORTE}\left(N_{2}\right)$ os quais foram definidos pela decisão de um corte vertical ou horizontal em $N$. A função ESTÁGIO é definida para os novos nós como: 


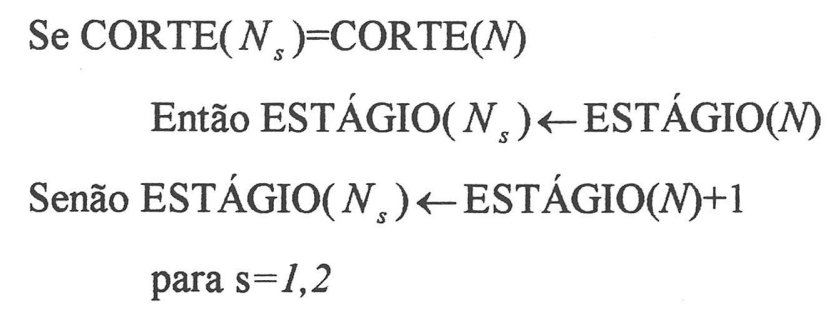

Assim, se $\operatorname{CORTE}(N)=\mathrm{v}$ e $\operatorname{ESTÁGIO}(N)=k$ (o número máximo de estágios é atingido) somente cortes verticais são aceitos em $N$. Analogamente, se $\operatorname{CORTE}(N)=$ h e $\operatorname{ESTÁGIO}(N)=k$, então somente cortes horizontais são aceitos em $N$.

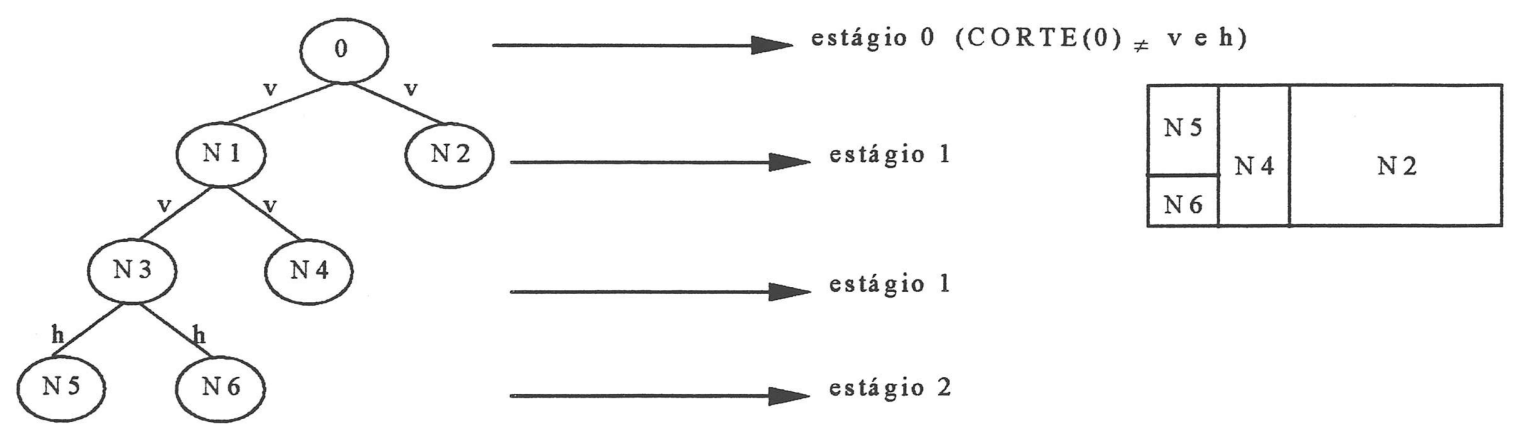

figura 2.5: Padrão 2-estágios

A figura 2.5 representa cortes iniciais verticais num primeiro estágio, e num segundo estágio um corte horizontal, e ao lado o padrão de corte correspondente.

\subsubsection{Padrão Restrito}

Neste caso, a decisão de obter a peça do tipo $i$ de um retângulo representado por $N$ não é independente da decisão de obter outra peça do tipo $i$ de outros nós no mesmo caminho que inclui $N$.

Seja $b_{i}$ o número máximo de peças do tipo $i$ que podem ser produzidas e $b_{i}(N)$ a quantidade máxima de peças do tipo $i$ que podem ser produzidas no retângulo do nó $N$. Se $a_{i}^{l}$ : número de peças do tipo $i$ produzidas em $N_{1}$. $a_{i}^{2}$ : número de peças do tipo $i$ produzidas em $N_{2}$. 


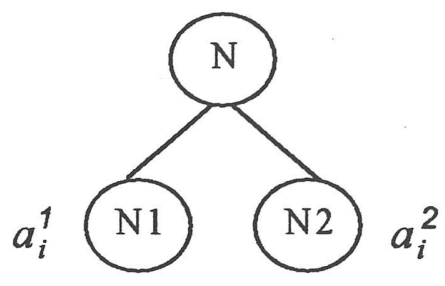

figura 2.6: Nó $N$ e sucessores $N_{1}$ e $N_{2}$

Então, para cada nó deve-se verificar: $a_{i}^{1}+a_{i}^{2} \leq b_{i}(N)$

Note que se $b_{i}$ for grande o suficiente, temos um problema irrestrito. Uma heurística utilizada por Morábito e Arenales (1996) para o problema restrito é dada por: Inicialmente consideramos o nó $N_{1}$ com o limite $b_{i}(N)$, isto é, $b_{i}\left(N_{1}\right)=b_{i}(N)$, $i=1,2, \ldots, m$, e determinamos um padrão de corte para o retângulo representado por $N_{1}$. Consideremos o nó $N_{2}$ com o limite $b_{i}\left(N_{2}\right)=b_{i}(N)-a_{i}^{1}, i=1,2, \ldots, m$, e assim sucessivamente, o mesmo procedimento é repetido para $N_{2}$ e $N_{1}$. A melhor solução entre eles é usada.

\subsubsection{Estratégia de busca}

Combina-se duas estratégias básicas:

- backtracking (BT): baseada em uma busca em profundidade: o nó mais recentemente gerado, é escolhido para ser ramificado.

- hill-climbing (HC): baseada em otimização local: depois de expandir o nó (isto é, gerar todos os seus sucessores), escolhe-se o melhor sucessor a ser expandido.

Seja LP um número inteiro positivo denotando o limite de profundidade para a estratégia BT.

\section{Algoritmo BT-HC}

Passo 1: Defina LP para cada sub-árvore E/OU a ser gerada. Seja RAIZ a lista de nós que podem ser ramificados que no começo contém somente o nó inicial, representando a placa $(L, W)$.

Passo 2: Enquanto RAIZ não é vazia, faça: 
Passo 3: Seja $s$ o primeiro nó em RAIZ. Gere uma sub-árvore E/OU a partir do nó $s$, usando a estratégia BT. Tire $s$ de RAIZ.

Passo 4: Escolha o caminho mais valioso a partir de $s$ e descarte os caminhos restantes (estratégia HC). Se existem nós no caminho cuja profundidade é LP e não é nó final, coloque-o em RAIZ.

Observações: No passo 3, a geração de sucessores da raiz $s$ leva em conta regras para evitar padrões de corte equivalentes, limitantes, e eventualmente heurísticas para reduzir o espaço de busca (veja Morábito e Arenales (1995)). No passo 4, cada caminho escolhido a partir de $s$ corresponde a uma seção (com profundidade no máximo igual a LP) do caminho completo do nó inicial aos nós finais. Observe que a estratégia HC, baseada na otimização local em cada seção não assegura encontrar o caminho mais valioso. $O$ algoritmo BT-HC não requer grande memória computacional pois armazena somente o melhor caminho.

A abordagem em Grafo E/OU parece ser efetiva resolvendo problemas de corte e empacotamento pois por um lado produz bons resultados computacionais e por outro lado permite que restrições práticas importantes sejam incluídas. Mais ainda, como a divisão pelos cortes guilhotinados sempre produz novos problemas com as mesmas características do anterior, a generalização para outras dimensões é simples. Esse método pode ser também usado para resolver o problema de empacotamento tridimensional (carregamento de contêineres) sujeito às restrições de estabilidade da carga (Morábito e Arenales, 1994).

\subsection{Problema de corte bidimensional guilhotinado e irrestrito em 2-estágios}

\subsubsection{Introdução}

Considere a placa de dimensões $(L, W)$ e $m$ peças demandadas de dimensões $\left(l_{i}, w_{i}\right)$ com o valor de utilidade $v_{i}$. Os cortes são restritos a 2-estágios. 
$\mathrm{Na}$ seção anterior apresentamos uma abordagem heurística baseada na busca em grafo E/OU. Nesta seção apresentamos um modelo matemático e propomos um método exato de resolução.

Para resolver o problema de corte bidimensional guilhotinado irrestrito em 2estágios precisamos num primeiro passo decidir qual padrão de corte deverá ser utilizado em cada faixa $\left(L, w_{j}\right)$ e num segundo passo, saber quantas vezes essa faixa irá se repetir na placa $(L, W)$.

Logo, para determinar um padrão de corte 2-estágios precisamos responder às seguintes questões:

1. Como descrever padrões para as faixas $\left(L, w_{j}\right)$ ?

2. Quantas vezes cada padrão para a faixa $\left(L, w_{j}\right)$ deve ser repetido ?

Temos então dois casos do problema de corte bidimensional guilhotinado em 2estágios a estudar: o caso irrestrito e o restrito (onde há limitação no número de peças por padrão de corte). Para o caso irrestrito, não temos problemas em relação à segunda questão acima, pois não temos limites no número de peças a serem produzidas, apenas precisamos descobrir quais os melhores padrões de corte para as faixas $\left(L, w_{j}\right)$ e repetilos quantas vezes forem necessário para preencher a placa $(L, W)$. Enquanto que para o caso restrito, a restrição de limitação no número de peças a serem cortadas é relevante, não podemos exceder o número permitido de peças na placa, não violando assim uma restrição do problema. Estudaremos nas próximas seções o caso irrestrito e no próximo capítulo o caso restrito (objetivo desta dissertação).

\subsubsection{Modelo Matemático}

A seguir apresentamos um modelo matemático para o problema de corte bidimensional guilhotinado irrestrito em 2-estágios. 
O k-ésimo padrão unidimensional para a faixa $\left(L, w_{j}\right)$, denotado por "padrão$(k, j)$ ", é determinado pelo vetor $\left(\alpha_{k j}^{1}, \alpha_{k j}^{2}, \ldots, \alpha_{k j}^{m}\right)$ de componentes inteiras e nãonegativas, satisfazendo:

$$
\sum_{i=1}^{m} \alpha_{k j}^{i} l_{i} \leq L, \quad k=1,2, \ldots, K_{j}
$$

e $\alpha_{k j}^{i}=0$ se $w_{i}>w_{j}$, onde $K_{j}$ é o número máximo de padrões de corte para a faixa $\left(L, w_{j}\right)$ utilizáveis no padrão bidimensional: $K_{j}=\left\lfloor\frac{W}{w_{j}}\right\rfloor$. Por simplicidade de notação, admitimos $m$ faixas $\left(L, w_{j}\right), j=1,2, \ldots, m$. (A rigor, evita-se duplicações de faixas, isto é, se $w_{r}=w_{s}$ utilizamos apenas a faixa $\left.\left(L, w_{r}\right)\right)$.

Ou equivalentemente,

$$
\sum_{i \in W_{j}} \alpha_{k j}^{i} l_{i} \leq L \quad k=1, \ldots, K_{j}
$$

onde $W_{j}=\left\{i / w_{i} \leq w_{j}\right\}$.

Agora, seja $\beta_{k j}$ o número de vezes que o padrão- $(k, j)$ é repetido dentro da placa $(L, W)$. Então

$$
\sum_{j=1}^{m} w_{j} \sum_{k=1}^{K_{j}} \beta_{k j} \leq W
$$

Note que : $\sum_{k=1}^{K_{j}} \beta_{k j}=$ número de vezes que a faixa $\left(L, w_{j}\right)$ surge no padrão de corte 2estágios.

Portanto, o modelo matemático para o problema de corte bidimensional 2-estágios e irrestrito pode ser escrito como: 


$$
\max \sum_{i=1}^{m} \sum_{j=1}^{m} \sum_{k=1}^{K_{j}} \alpha_{k j}^{i} \beta_{k j} v_{i}
$$

sujeito a:

$$
\begin{aligned}
& \sum_{i=1}^{m} \alpha_{k j}^{i} l_{i} \leq L \quad \begin{array}{l}
j=1, \ldots, m \\
k=1, \ldots, K_{j}
\end{array} \\
& \sum_{j=1}^{m} w_{j} \sum_{k=1}^{K_{j}} \beta_{k j} \leq W \\
& \alpha_{k j}^{i} \geq 0, \quad \beta_{k j} \geq 0 \quad \text { inteiros }
\end{aligned}
$$

\subsubsection{Método de Resolução}

O modelo proposto por Gilmore e Gomory (1965) consiste em rescrever o modelo (2.1)-(2.4) como segue:

Apenas trocando de posição o somatório em $i$, temos:

$$
\begin{array}{ll}
\max & \sum_{j=1}^{m} \sum_{k=1}^{K_{j}}\left(\sum_{i=1}^{m} \alpha_{k j}^{i} v_{i}\right) \beta_{k j} \\
\text { s.a.: } & \sum_{i=1}^{m} \alpha_{k j}^{i} l_{i} \leq L \quad j=1, \ldots, m \quad k=1, \ldots, K_{j} \\
& \sum_{j=1}^{m} w_{j} \sum_{k=1}^{K_{j}} \beta_{k j} \leq W \\
& \alpha_{k j}^{i} \geq 0, \beta_{k j} \geq 0 \quad \text { e inteiros }
\end{array}
$$

Seja: $\quad V_{k j}=\left(\sum_{i=1}^{m} \alpha_{k j}^{i} v_{i}\right)$, isto é, $V_{k j}=$ valor da faixa $w_{j}$.

Logo, o modelo (2.5) é equivalente a: 


$$
\begin{array}{ll}
\max & \sum_{j=1}^{m} \sum_{k=1}^{K_{j}} V_{k j} \beta_{k j} \\
\text { s.a.: } & \sum_{i=1}^{m} \alpha_{k j}^{i} l_{i} \leq L \quad j=1, \ldots, m \quad k=1, \ldots, K_{j} \\
& V_{k j}=\sum_{i=1}^{m} \alpha_{k j}^{i} v_{i} \\
& \sum_{j=1}^{m} w_{j} \sum_{k=1}^{K_{j}} \beta_{k j} \leq W \\
& \alpha_{k j}^{i} \geq 0, \beta_{k j} \geq 0 \quad \text { e inteiros }
\end{array}
$$

Observe que o problema (2.6) pode ser decomposto em 2 níveis: primeiro determinamos valores de $\alpha_{k j}^{i}$ que atribuam os maiores valores para $V_{k j}$ e, em seguida determinamos $\beta_{k j}$. Por exemplo, se $V_{11}>V_{k 1}$, para $k=2,3, \ldots, K_{j}$ (isto é, o padrão 1 é o mais valioso na faixa $w_{1}$ ), então, na otimalidade temos que $\beta_{k 1}=0$, para $k=2,3, \ldots, K_{j}$, ou seja, não utilizaremos nenhuma faixa correspondente aos padrões $2,3, \ldots, K_{j}$, usaremos apenas a faixa que corresponde ao padrão- $(1,1)$, isto é, podemos rescrever o modelo (2.6) através dos dois problemas seguintes:

Considere os seguintes $m$ problemas (na verdade, tantos quanto forem as faixas):

$$
\begin{gathered}
V_{j}=\max \sum_{i=1}^{m} \alpha_{j}^{i} v_{i} \\
\text { s.a.: } \sum_{\substack{i=1 \\
\alpha_{j}^{i} \geq 0}}^{m} \alpha_{j}^{i} l_{i} \leq L \quad, j=1,2, \ldots, m
\end{gathered}
$$

Observe que o índice $k$ foi abandonado, pois apenas o padrão mais valioso será considerado.

Assim, escolhemos o padrão mais valioso para cada faixa $w_{j}$.

Finalmente teremos agora que decidir quantas vezes essas faixas serão repetidas na placa $(L, W)$, isto é, resolver o segundo problema: 


$$
\begin{array}{ll}
\max & \sum_{j=1}^{m} V_{j} \beta_{j} \\
\text { s.a.: } & \sum_{j=1}^{m} w_{j} \beta_{j} \leq W \\
& \beta_{j} \geq 0 \text { e inteiros, } j=1,2, \ldots, m
\end{array}
$$

Note que para (2.7) teremos que resolver no máximo $m$ problemas da mochila, e (2.8) é resolvido com apenas mais um problema da mochila. Esta decomposição foi proposta por Gilmore e Gomory (1965) e consiste num método eficiente de resolução.

Vejamos no próximo capítulo o caso restrito, onde as restrições de limitação no número de peças por padrão de corte são adicionadas ao modelo irrestrito. 


\section{PARTE II : Problema de Corte Bidimensional Guilhotinado Restrito em 2-Estágios}

\section{CAPÍTULO 3}

\section{Formulação Matemática e Um Método de Resolução}

\subsection{Introdução}

No capítulo anterior apresentamos um modelo matemático e um método exato de resolução para o problema de corte bidimensional guilhotinado irrestrito em 2-estágios. Neste capítulo abordaremos o caso restrito, ou seja, o problema de corte bidimensional guilhotinado restrito em 2-estágios.

Consideremos os mesmos dados do problema do capítulo anterior, isto é, considere a placa de dimensões $(L, W)$ e $m$ peças demandadas de dimensões $\left(l_{i}, w_{i}\right)$ com o valor de utilidade $v_{i}, i=1, \ldots, m$ e limitadas no padrão por $b_{i}, i=1, \ldots, m$. Lembremos que $b_{i}$ é o número máximo de peças do tipo $i$ que podemos ter na placa $(L, W)$. Os cortes são restritos a 2-estágios.

O objetivo é determinar o padrão de corte ótimo tal que os valores de utilidade das peças alocadas na placa sejam maximizadas, não violando as restrições de limitação no 
número de peças alocadas e a limitação no número de estágios (no nosso caso, 2-estágios). O modelo matemático do problema é um modelo não-linear, dificultando portanto sua resolução.

A proposta de resolução baseia-se na relaxação lagrangeana e no método do subgradiente. As restrições complicadas (não-lineares) são relaxadas obtendo-se subproblemas irrestritos, os quais podem ser resolvidos pelo método proposto por Gilmore e Gomory, 1965 no capítulo anterior. E os valores dos multiplicadores de lagrange serão obtidos pelo método do subgradiente, como veremos mais adiante.

Na próxima seção apresentamos o modelo matemático do problema.

\subsection{Modelagem Matemática}

A abordagem de resolução do problema restrito é semelhante à abordagem do problema irrestrito, isto é, aqui também temos que responder às seguintes questões:

1. Como descrever padrões para as faixas $\left(L, w_{j}\right)$ ?

2. Quantas vezes cada padrão para a faixa $\left(L, w_{j}\right)$ deve ser repetido ?

Para o caso restrito, diferentes padrões de corte para uma faixa $\left(L, w_{j}\right)$ podem ser usados, por exemplo:

Dados do problema:

\begin{tabular}{|c|c|c|c|c|c|}
\hline & tipo 1 & tipo 2 & tipo 3 & tipo 4 & tipo 5 \\
\hline comprimento $\left(\boldsymbol{l}_{\boldsymbol{i}}\right)$ & 34 & 27 & 47 & 25 & 34 \\
\hline largura $\left(\boldsymbol{w}_{\boldsymbol{i}}\right)$ & 19 & 22 & 23 & 34 & 40 \\
\hline limitação $\left(\boldsymbol{b}_{\boldsymbol{i}}\right)$ & 10 & 5 & 1 & 8 & 4 \\
\hline valor $\left(\boldsymbol{v}_{\boldsymbol{i}}\right)$ & 0.06460 & 0.05640 & 0.10810 & 0.08500 & 0.13600 \\
\hline
\end{tabular}


O retângulo abaixo representa a placa a ser cortada:

$L$

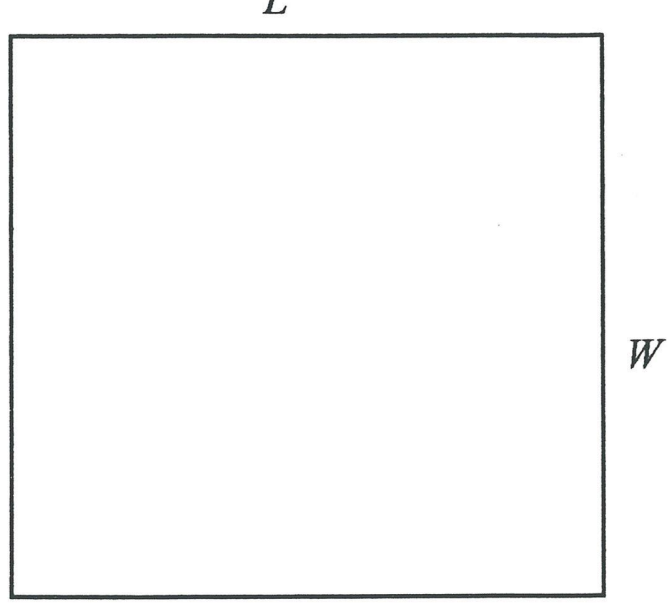

onde $L=100$ e $W=100$.

Peças demandadas:
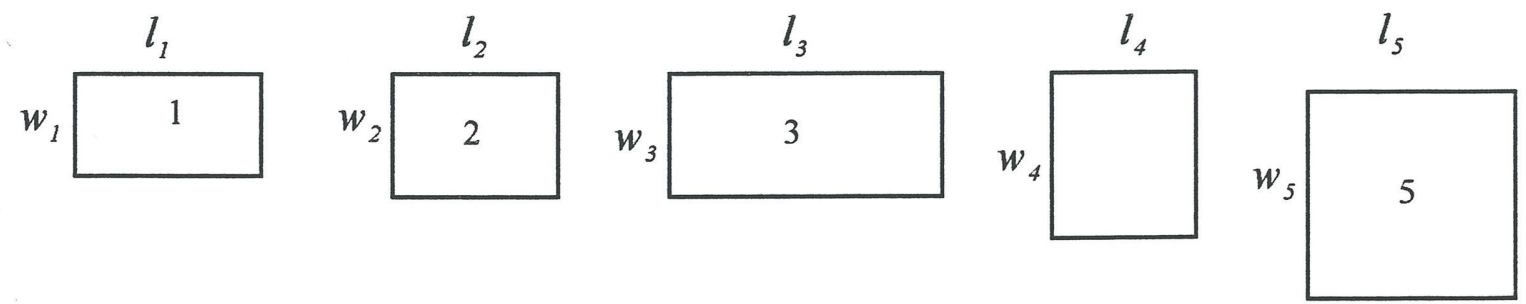

Representação de alguns padrões de corte, com seus respectivos valores:

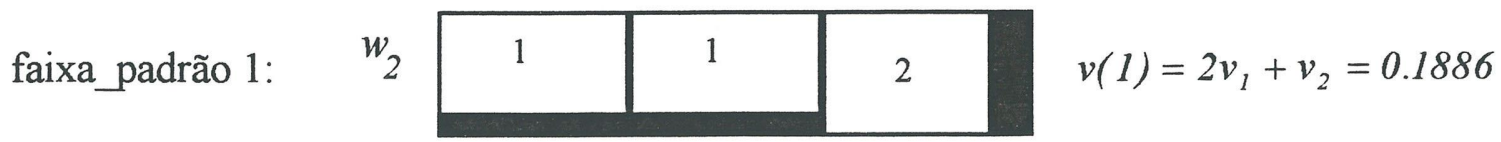

faixa_padrão 2 :

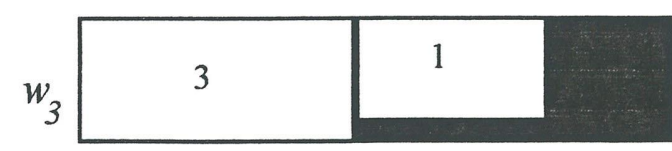

$v(2)=v_{1}+v_{3}=0.1727$

faixa_padrão 3: $\quad w_{4}$\begin{tabular}{|l|l|l|l|l|}
\hline & 4 & 4 & 4 & 4 \\
\hline
\end{tabular}

$v(3)=4 v_{4}=0.1700$

faixa_padrão 4: $\quad w_{5}$\begin{tabular}{|l|l|l|l|}
\hline 4 & 4 & 3 \\
\hline
\end{tabular}

$v(4)=2 v_{4}+v_{3}=0.2781$ 
Um padrão de corte utilizando a faixa_padrão 4 (a mais valiosa) e uma faixa_padrão 1:

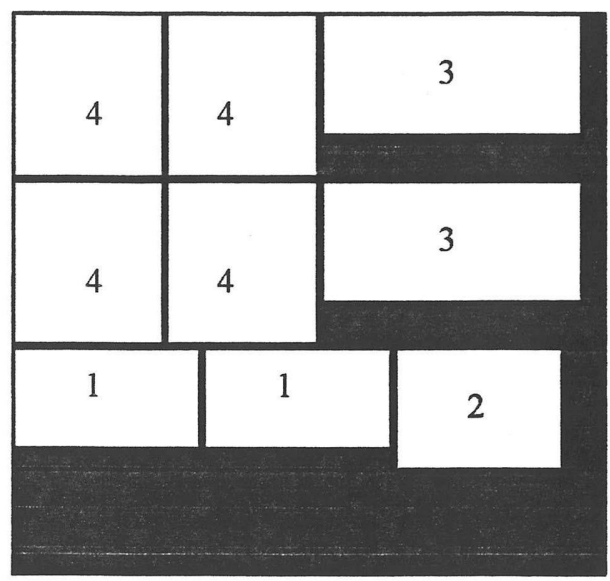

$V=0.7448$

produz um padrão infactível, pois ultrapassa o limite no número de peças do tipo 3.

Agora, o padrão obtido pelas faixas_padrões 1, 2 e 3 :

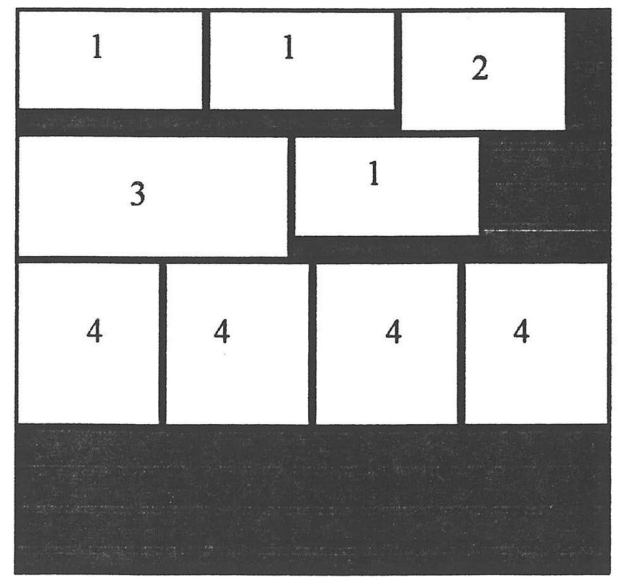

$V=0.5313$

embora resultando em um valor menor, produz um padrão factível, pois as restrições sobre o número de peças para cada tipo não são violadas.

Observe que o número máximo de faixas_padrões utilizáveis para a faixa de largura $w_{1}=19$ é $K_{1}=\left\lfloor\frac{W}{w_{1}}\right\rfloor=\left\lfloor\frac{100}{19}\right\rfloor=5$, isto é, para formar um padrão bidimensional, não 
utilizamos mais que 3 faixas de largura $w_{1}=19$. Fazendo a mesma analogia para a faixa de largura $w_{2}=22$, temos que $K_{2}=4$, e assim por diante, obtemos $K_{3}=4, K_{4}=3$ e $K_{5}=2$.

Para o caso irrestrito, Gilmore e Gomory associa somente o melhor padrão de corte para cada faixa, isto é, o padrão mais valioso.

As mesmas questões podem ser feitas para $\left(l_{j}, W\right)$, isto é, quando o primeiro estágio é um corte vertical.

A seguir apresentamos um modelo matemático para o problema de corte bidimensional guilhotinado restrito em 2-estágios.

O modelo é semelhante ao apresentado no capítulo anterior, para o caso restrito apenas incluímos as seguintes restrições:

O número de peças do tipo $i$, denotado por $a_{i}$, é:

$$
a_{i}=\sum_{j=1}^{m} \sum_{k=1}^{K_{j}} \alpha_{k j}^{i} \beta_{k j}, \quad i=1,2, \ldots, m
$$

Como o problema é restrito, então:

$$
a_{i}=\sum_{j=1}^{m} \sum_{k=1}^{K_{j}} \alpha_{k j}^{i} \beta_{k j} \leq b_{i} \quad i=1,2, \ldots, m
$$

Observe que estas restrições são não-lineares.

Temos então o seguinte modelo matemático: 


$$
\max \sum_{i=1}^{m} \sum_{j=1}^{m} \sum_{k=1}^{K_{j}} \alpha_{k j}^{i} \beta_{k j} v_{i}
$$

sujeito a:

$$
\begin{aligned}
& \sum_{i=1}^{m} \alpha_{k j}^{i} l_{i} \leq L \quad j=1, \ldots, m \\
& k=1, \ldots, K_{j} \\
& \sum_{j=1}^{m} w_{j} \sum_{k=1}^{K_{j}} \beta_{k j} \leq W \\
& \sum_{j=1}^{m} \sum_{k=1}^{K_{j}} \alpha_{k j}^{i} \beta_{k j} \leq b_{i} \quad i=1, \ldots, m \\
& \alpha_{k j}^{i} \geq 0, \beta_{k j} \geq 0 \quad \text { inteiros }
\end{aligned}
$$

onde a função objetivo (3.1) maximiza os valores de utilidade das peças, as desigualdades (3.2) e (3.3) definem as restrições físicas do problema, as desigualdades (3.4) definem a limitação no número de peças e as restrições (3.5) garantem a não-negatividade e a integralidade das variáveis.

Observe que o modelo apresentado no capítulo 2, seção 2.4 é um caso particular do modelo do problema de corte bidimensional guilhotinado restrito em 2-estágios.

Na próxima seção veremos como utilizamos a relaxação lagrangeana e o método do subgradiente para resolver o modelo (3.1)-(3.5).

\subsection{Relaxação Lagrangeana e Método do Subgradiente}

A relaxação lagrangeana é hoje uma técnica bastante eficiente para gerar limites superiores (ou inferiores) para problemas de otimização. Situa-se bem em problemas onde há um grupo de restrições complicadas e outro grupo de restrições simples.

Considere o seguinte programa inteiro: 


$$
\begin{aligned}
\mathrm{z}_{\mathrm{P}}=\max & f(x) \\
\text { sujeito } a: & G^{i}(x) \leq b^{i} \quad i=1,2, \ldots, m \\
& x \in \Omega
\end{aligned}
$$

onde $\Omega=\left\{x \in Z_{+}^{n} / A x \leq b\right\}$.

Definimos a relaxação lagrangeana do problema $(\mathrm{P})$ com respeito ao conjunto de restrições complicadas $G^{i}(x) \leq b^{i}$, introduzindo um vetor multiplicador de lagrange $(\lambda \geq 0)$ que é anexado a esse conjunto de restrições e adicionado à função objetivo, resultando:

$$
\begin{gathered}
\mathrm{z}_{\mathrm{PR}}(\lambda)=\max _{\text {sujeito } a:} \quad f(x)+\sum_{i=1}^{m} \lambda_{i}\left(b_{i}-G^{i}(x)\right) \\
\end{gathered}
$$

que é chamado "problema lagrangeano" de (P) com respeito a $G^{i}(x) \leq b^{i}$.

Observe que $(\operatorname{PR}(\lambda))$ não contém as restrições complicadas.

Proposição: $z_{P R}(\lambda) \geq f(x)$ para todo $\lambda \geq 0$ e $x$ factível em $(P)$.

Como conseqüência da proposição acima, $z_{P R}(\lambda) \geq z_{P}$ para todo $\lambda \geq 0$. Logo, $(\operatorname{PR}(\lambda))$ nos fornece um limitante superior na solução ótima do problema original (P) para qualquer $\lambda \geq 0$.

Em particular, estamos interessados em encontrar os valores para os multiplicadores de Lagrange que fornecem o menor limitante superior, isto é, o limite superior que está tão próximo quanto possível da solução ótima de $(\mathrm{P})$. Isso envolve encontrar multiplicadores de lagrange que correspondam a:

$$
z_{D L}=\min _{\lambda \geq 0}\left\{\begin{array}{ll}
\max & f(x)+\sum_{i=1}^{m} \lambda_{i}\left(b_{i}-G^{i}(x)\right) \\
\text { sujeito } a: & x \in \Omega
\end{array}\right\}
$$


que é chamado "problema dual lagrangeano".

Aplicaremos a relaxação lagrangeana ao nosso problema, para relaxar as restrições não-lineares (as restrições complicadas) do modelo de corte bidimensional guilhotinado restrito em 2-estágios.

Relaxando-se portanto as restrições não-lineares (3.4), reduzimos o problema a uma seqüência de problemas irrestritos (os quais já sabemos como resolver eficientemente).

Escolhendo-se então o conjunto de restrições (3.4) a serem relaxadas, a função lagrangeana é dada por:

$$
\begin{aligned}
L(\alpha, \beta, \lambda) & =\sum_{i=1}^{m} \sum_{j=1}^{m} \sum_{k=1}^{K_{j}} \alpha_{k j}^{i} \beta_{k j} v_{i}+\sum_{i=1}^{m} \lambda_{i}\left(b_{i}-\sum_{j=1}^{m} \sum_{k=1}^{K_{j}} \alpha_{k j}^{i} \beta_{k j}\right) \\
& =\sum_{i=1}^{m} \sum_{j=1}^{m} \sum_{k=1}^{K_{j}}\left(v_{i}-\lambda_{i}\right) \alpha_{k j}^{i} \beta_{k j}+\sum_{i=1}^{m} \lambda_{i} b_{i}, \lambda \geq 0 .
\end{aligned}
$$

Note que agora o valor das peças também depende de $\lambda_{i}$.

Então o problema lagrangeano é:

$$
\begin{array}{ll}
h(\lambda)=\max \quad & \sum_{i=1}^{m} \sum_{j=1}^{m} \sum_{k=1}^{K_{j}}\left(v_{i}-\lambda_{i}\right) \alpha_{k j}^{i} \beta_{k j}+\sum_{i=1}^{m} \lambda_{i} b_{i} \\
\text { sujeito } a: \quad & \sum_{i=1}^{m} \alpha_{k j}^{i} l_{i} \leq L \quad j=1, \ldots, m \quad k=1, \ldots, K_{j} \\
& \sum_{j=1}^{m} w_{j} \sum_{k=1}^{K_{j}} \beta_{k j} \leq W \\
& \alpha_{k j}^{i} \geq 0, \quad \beta_{k j} \geq 0 \quad e \text { int eiros }
\end{array}
$$

Observe que para cada $\lambda$, o problema lagrangeano acima produz subproblemas irrestritos que podem ser resolvidos pelo método descrito no capítulo 2 , seção 2.4 .

Para cada $\lambda$ também, o problema lagrangeano nos fornece um limitante superior da solução ótimo da problema restrito, e, gostaríamos de encontrar o menor limitante superior, mais ainda, gostaríamos de obter o multiplicador de lagrange que nos fornecesse 
um limitante superior tão próximo quanto possível da solução ótima do problema original, como mostra a figura 4.1 .

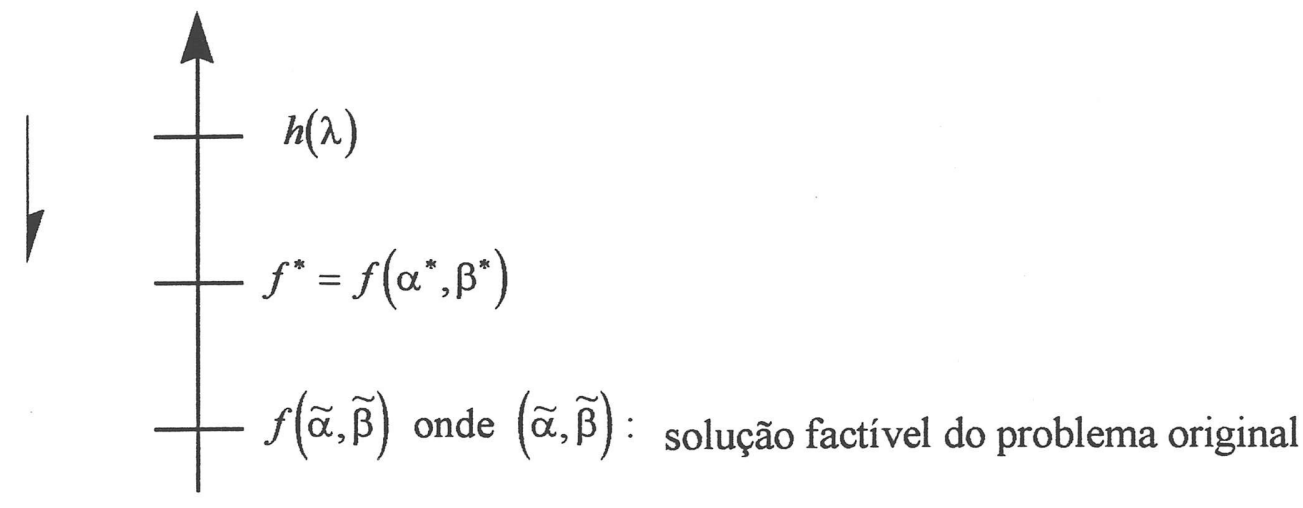

figura 3.1

onde $h(\lambda)$ é a solução obtida resolvendo o problema lagrangeano para um dado vetor multiplicador de lagrange e $f\left(\alpha^{*}, \beta^{*}\right)$ é a solução ótima do problema original.

Logo estamos interessados em resolver o seguinte problema:

$$
\min _{\lambda \geq 0} h(\lambda)
$$

onde

$$
\begin{array}{ll}
h(\lambda)=\max & \sum_{i=1}^{m} \sum_{j=1}^{m} \sum_{k=1}^{K_{j}}\left(v_{i}-\lambda_{i}\right) \alpha_{k j}^{i} \beta_{k j}+\sum_{i=1}^{m} \lambda_{i} b_{i} \\
\text { sujeito } a: \quad & \sum_{i=1}^{m} \alpha_{k j}^{i} l_{i} \leq L \quad j=1, \ldots, m \quad k=1, \ldots, K_{j} \\
& \sum_{j=1}^{m} w_{j} \sum_{k=1}^{K_{j}} \beta_{k j} \leq W \\
& \alpha_{k j}^{i} \geq 0, \quad \beta_{k j} \geq 0 \quad e \text { int eiros }
\end{array}
$$

denominado problema dual lagrangeano.

$\mathrm{E}$, para encontrarmos o vetor multiplicador de lagrange que nos fornece o menor limitante superior, utilizamos o método do subgradiente, ou seja: 
A nossa proposta de resolução consiste em resolver o problema lagrangeano para um $\lambda$ inicial fornecido pelo usuário, obtendo uma certa solução. Se as condições de otimalidade forem satisfeitas (veja observação 1 abaixo) para essa solução então estamos na solução ótima do problema original. Caso contrário devemos atualizar o vetor multiplicador de lagrange aplicando o método do subgradiente (veja Apêndice) e reinicializar o processo. Até que algum critério de parada seja satisfeito (veja observação 2 abaixo).

Observação 1: As condições de otimalidade são:

$\Rightarrow$ a solução obtida após a resolução do problema lagrangeano satisfaz as restrições relaxadas e;

$\Rightarrow$ os valores das funções objetivos do problema original e do problema lagrangeano coincidem.

Observação 2: Os critérios de parada mais comumente usados para o método do subgradiente são:

$\Rightarrow$ em alguma iteração $t$, encontrarmos o subgradiente nulo;

$\Rightarrow$ se o passo for muito pequeno não tendo assim mais muitas modificações nas soluções;

$\Rightarrow$ se um certo número máximo de iterações for atingido;

$\Rightarrow$ se os limitantes inferior e superior forem iguais ou com valores muito próximos.

\subsection{Algoritmo do Problema de Corte Bidimensional Guilhotinado Restrito em 2-Estágios}

Para cada exemplo resolvemos o algoritmo descrito abaixo duas vezes. Numa primeira vez, resolvemos o problema para faixas horizontais, e numa segunda vez, giramos as peças (veja passo 6) e obtemos então faixas verticais. 
Passo 1: Para $i=1$ até $m$ faça: $\quad\left\{\begin{array}{l}\bar{l}_{i} \leftarrow l_{i} \\ \bar{w}_{i} \leftarrow w_{i}\end{array}\right.$

\{início do algoritmo\}

Passo 2: Para posição_peças $=1$ até 2 faça:

\{início para posição_peças\}

Passo 3 : Determine uma solução inicial factível e seja $Z_{L B}^{\text {melhor }}$ o valor da função objetivo do problema original calculado nesta solução encontrada (esse procedimento será abordado no Capítulo 4).

Passo 4: Escolha $\lambda^{0} \geq 0$ (vetor multiplicador de lagrange), $\max =$ número máximo de iterações, $t=0$ (iteração atual), PARE=FALSO, $Z_{U B}^{\text {melhor }}=\sum_{i=1}^{m} v_{i} b_{i}$ (limitante superior inicial).

Passo 5: Enquanto PARE=Falso e $t \leq \max$ faça:

\{início enquanto

5.1.: Resolva o problema relaxado (bidimensional irrestrito)

$\operatorname{PR}\left(\lambda^{t}\right)$, pelo método descrito na seção 2.4 e obtenha $\left(\alpha^{t}, \beta^{t}\right)$.

5.2.: Calcule o limitante superior, isto é, o valor da função objetivo de $\operatorname{PR}\left(\lambda^{t}\right)$, que denominaremos $Z_{U B}$.

5.3.: $\left\{\right.$ guarde o menor valor de $Z_{U B}$ \}

Se $Z_{U B}<Z_{U B}^{\text {melhor }}$, então $Z_{U B}^{\text {melhor }}=Z_{U B}$.

5.4.: $\{$ Calcule os subgradientes\}

Calcule $a^{t}=b-\alpha^{t} \beta^{t}$.

5.5.: Se $a^{t}=0$ então PARE=Verdade, ou seja, a solução atual é ótima.

5.6.: Se $a^{t}>0$ então calcule o limitante inferior, isto é, o valor da função objetivo do problema original denominando-o $Z_{L B}$.

Senão, isto é, se $a^{t}<0$ então utilize uma heurística lagrangeana para factibilizar a solução obtida (veja Capítulo 5), e calcule $Z_{L B}$.

5.7.: $\left\{\right.$ guarde o maior valor de $Z_{L B}$ \} 
Se $Z_{L B}>Z_{L B}^{\text {melhor }}$ então $Z_{L B}^{\text {melhor }}=Z_{L B}$.

5.8.: Se $Z_{U B}^{\text {melhor }}-Z_{L B}^{\text {melhor }}<\varepsilon$ então PARE=Verdade

Senão aplique o método do subgradiente:

$$
\begin{aligned}
& \lambda_{i}^{t+1}=\max \left\{0, \lambda_{i}^{t}+\theta_{t} a^{t}\right\}, i=1,2, \ldots, m, \text { onde } \theta_{\mathrm{t}} \text { é o passo. } \\
& t=t+1 .
\end{aligned}
$$

fim do enquanto

Passo 6 : Para $i=1$ até $m$ faça $\quad\left\{\begin{array}{l}l_{i} \leftarrow \bar{w}_{i} \\ w_{i} \leftarrow \bar{l}_{i}\end{array}\right.$

\{fim do para posição_peças\}

\{fim do algoritmo

Vejamos no próximo capítulo três heurísticas para a obtenção de uma solução factível inicial (passo 3 do algoritmo acima descrito). 


\section{CAPÍTULO 4}

\section{Heurísticas para Obtenção de Uma Solução Factível}

\section{Inicial}

\subsection{Introdução}

Durante a implementação do algoritmo proposto no capítulo anterior, observamos que em alguns casos o Método do Subgradiente não forneceu uma solução factível, logo, para obtermos um padrão de corte para o nosso problema calculamos soluções factíveis iniciais através de heurísticas. Essas heurísticas fornecem limitantes inferiores para o problema restrito, e o maior desses limitantes é utilizado no cálculo do subgradiente (basta observar que o passo utiliza os limitantes inferiores e superiores, veja apêndice). Veremos três heurísticas utilizadas para a obtenção de uma solução factível inicial: Heurística Gulosa por Peça, Heurística Gulosa por Faixa e Heurística Gulosa Por Substituição. Na primeira, como o próprio nome sugere alocamos primeiramente as peças mais valiosas (segundo uma certa ordenação), na segunda heurística apresentada alocamos primeiramente as faixas mais valiosas e a terceira é uma pequena modificação da heurística gulosa por faixa.

Ao final deste capítulo apresentamos comparações dos resultados obtidos pelas heurísticas desenvolvidas. 


\subsection{Heurística Gulosa por Peça (G/P)}

A idéia básica de G/P consiste em produzir as faixas tomando-se como referência as peças mais valiosas.

Seja $a_{i}=$ número de peças do tipo $i$ já produzidas. Inicialmente $a_{i}=0$. Considere também o conjunto $M=\left\{\right.$ i tal que $\left.b_{i}-a_{i}>0\right\}$, o conjunto das peças que ainda podem ser produzidas. Inicialmente $M=\{1,2, \ldots, m\}$. Consideramos a peça mais valiosa, aquela de maior valor para $p_{i}=v_{i} /\left(l_{i}{ }^{*} w_{i}\right), i \in M$. Suponha por simplicidade de notação que $p_{1} \chi_{2} \geq . . p_{m}$. As menores largura e comprimento das peças em produção são, respectivamente, $w_{0}=\min \left\{w_{i}, i \in M\right\}, l_{0}=\min \left\{l_{i}, i \in M\right\}$. As variáveis $L_{a u x}$ e $W_{a u x}$ representam o comprimento restante na faixa em construção e a largura restante na placa. Inicialmente, $L_{a u x}=L$ e $W_{a u x}=W$. A variável $k$ indica a faixa atual, inicialmente $k=1$.

\{inicio da heurística $G / P\}$

Enquanto $W_{\text {aux }} \geq w_{0}$ faça:

\{inicio do enquanto 1$\}$

Defina a faixa $k:\left(L, w_{j}\right)$ tal que: $p_{j}=\max \left\{p_{i}, i \in M\right\}$.

Para $i=j$ a $m$, faça:

Se $w_{i} \leq w_{j}$ e $i \in M$, então

$L_{a u x}=L$

Enquanto $L_{a u x} y_{0}$ faça:

\{inicio do enquanto 2$\}$

$\alpha_{i k} \leftarrow \min \left\{b_{i}-a_{i},\left\lfloor L_{a u x} l_{i} /\right\} ; a_{i x} \leftarrow \alpha_{i k}+a_{i} ; L_{a u x} \leftarrow L_{a u x}-l_{i} \alpha_{i k}\right.$

Se $a_{i}=b_{i}$ então $M \leftarrow M-\{i\}$ e atualize $l_{0}$

\{fim do enquanto 2$\}$

\{fim do para i\}

$W_{a u x} \leftarrow W_{a u x}-w_{k}$. e atualize $w_{0} ; k \leftarrow k+1$

\{fim do enquanto 1$\}$

$\{$ fim da heurística\} 
Esta heurística produz uma solução factível e, portanto, um limitante inferior. Entretanto, como os resultados foram muito pobres, consideramos uma tolerância $\delta$ para a construção das faixas, isto é, ao invés da faixa $\left(L, w_{k}\right)$, consideramos a faixa $\left(L, w_{k}+\delta\right)$. (Utilizamos na implementação $\delta=0.1 \mathrm{~W}$ ).

Utilizando o mesmo exemplo dado no capítulo anterior, seção 3.2, G/P resulta em:

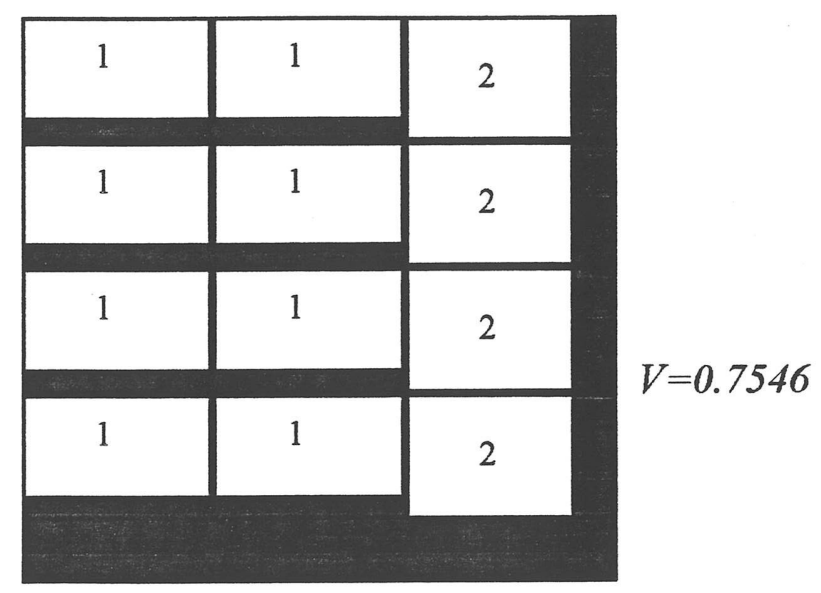

figura 4.1: Padrão de corte obtido por G/P.

\subsection{Heurística Gulosa por Faixa (G/F)}

Este método consiste em considerar o modelo (3.1) - (3.5), fixando-se as variáveis $\alpha_{k j}^{i}$ (isto é, fixando-se faixas) e então determinar os valores de $\beta_{k j}$. Veremos nas próximas seções como essas faixas são escolhidas e alocadas.

\subsubsection{Modelo Matemático}

Seja $r$ o número de peças com diferentes larguras, e $W_{j}=\left\{i / w_{i} \leq w_{j}\right\}$.

O modelo que temos que resolver é: 


$$
\begin{aligned}
& \max \sum_{j=1}^{m} V_{j} \beta_{j} \\
& \text { s.a.: } \sum_{j=1}^{m} w_{j} \beta_{j} \leq W \\
& \qquad \sum_{j=1}^{m} \alpha_{i j} \beta_{j} \leq b_{i}, i=1, \ldots, m \\
& \quad \beta_{j} \geq 0 \text { e inteiros } j=1, \ldots, m
\end{aligned}
$$

onde os valores de $V_{j}$ e $\alpha_{i j}$ são obtidos resolvendo-se para $j=1, \ldots, r$ :

$$
\begin{aligned}
& V_{j}=\max \sum_{i \in W_{j}} v_{i} \alpha_{i j} \\
& \text { s. } a .: \sum_{i \in W_{j}} \alpha_{i j} l_{i} \leq L \\
& \quad 0 \leq \alpha_{i j} \leq b_{i} \text { e inteiros, } i=1, \ldots, m
\end{aligned}
$$

Este método sugere que temos que resolver $r$ problemas da mochila (4.2) e um programa linear inteiro (4.1).

\subsubsection{Funcionamento de $G / F$}

A heurística G/F consiste em resolver o modelo (4.2) para $j=1, \ldots, r$ obtendo assim $r$ faixas factíveis, e então obter uma solução gulosa para o modelo (4.1) determinado dentre as $r$ faixas qual será alocada na placa. Repete-se este procedimento até que a largura da placa não seja mais suficiente para alocar nenhuma faixa. Para resolver o modelo (4.2), utilizamos o procedimento da mochila restrita, isto é:

Seja $F_{i}(x)$ o máximo valor obtido ao combinar os comprimentos $l_{1}, l_{2}, \ldots, l_{i}, i=1, \ldots, m$ ao longo do comprimento $x, x=0,1, \ldots, L$. Ou seja:

$$
\begin{aligned}
& F_{i}(x)=\max \sum_{k=1}^{i} v_{k} a_{k} \\
& \text { sujeito a : } \sum_{k=1}^{i} l_{k} a_{k} \leq x \\
& \quad 0 \leq a_{k} \leq b_{k} \text { e inteiros, } k=1, \ldots, i
\end{aligned}
$$


Seja $l_{o}=\min \left\{l_{i}, i=1, \ldots, m\right\}$ definido como o menor comprimento entre as peças. O comprimento $x$ deve ser preenchido pelos comprimentos $l_{1}, l_{2}, \ldots, l_{m}$ até restar, no máximo, o comprimento $l_{0}-1$ de $L$. Note que $F_{i}(x)=0$ para $x=0,1, \ldots, l_{0}-1$ e para $x=l_{0}, l_{0}+1, \ldots, L$, este valor pode ser obtido com

$$
\left.F_{i}(x)=\max \left\{v_{i} a_{i}+F_{i-1}\left(x-l_{i} a_{i}\right) / 0 \leq a_{i} \leq \min \left\{b_{i}, \mid x / l_{i}\right\rfloor\right\}, i=1, \ldots, m\right\}
$$

e $F_{0}(y)=0$ para qualquer $y$.

Note que $F_{m}(L)$ corresponde à solução ótima do problema.

Após resolver as $r$ mochilas restritas (obtendo $V_{j}, j=1, \ldots, r$ ) temos que, com $\alpha_{i j}$ fixo, resolver o modelo (4.1), mas temos uma certa dificuldade, pois o modelo continua complicado (problema inteiro com $m+1$ restrições). Portanto para sua resolução, abandonamos as restrições de limitação e as restrições de integralidade da variável $\beta_{j}$, $j=1, \ldots, r$ resultando assim em um problema de programação linear onde a melhor solução por unidade de comprimento é: $\frac{V_{k}}{w_{k}}=\max \left\{\frac{V_{j}}{w_{j}}, j=1, \ldots, r\right\}$

Vejamos agora os principais passos de G/F no diagrama abaixo: 


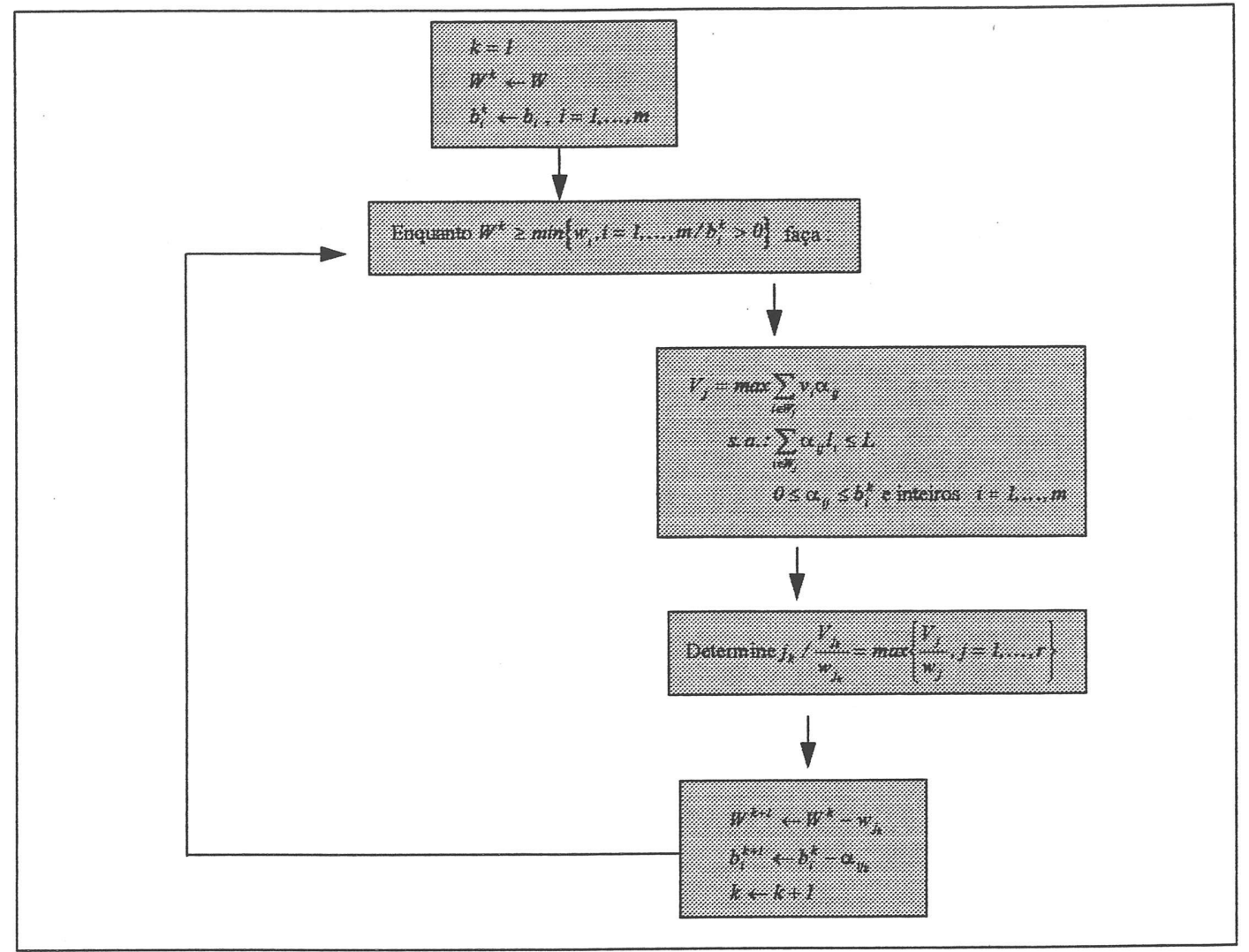

figura 4.2: Diagrama do funcionamento de $\mathrm{G} / \mathrm{F}$.

Novamente utilizando o exemplo dado no capítulo anterior, seção 3.2 , a heurística gulosa por faixa resulta em:

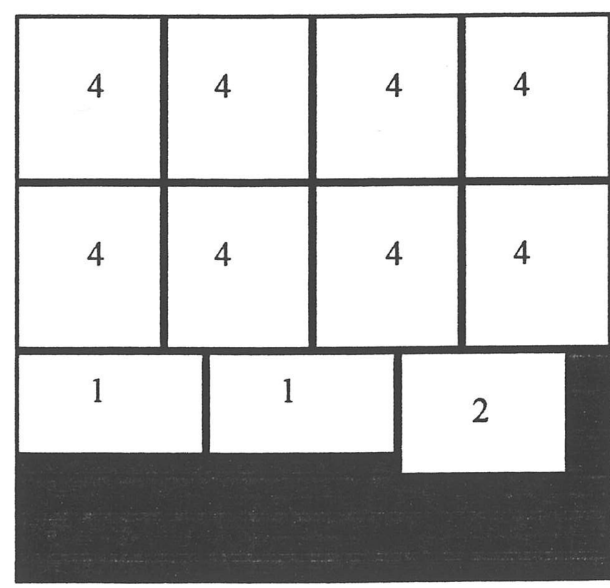

$V=0.8686$

figura 4.3: Padrão de corte obtido por G/F. 


\subsection{Heurística Gulosa de Substituição (G/S)}

Da mesma maneira que a heurística gulosa por faixa, temos que resolver $r$ problemas da mochila (4.2) e um programa linear inteiro (4.1).

A diferença entre essas duas heurísticas está na resolução do modelo linear inteiro (4.1). Na heurística gulosa por substituição fazemos um caso particular de surrogate em (4.1), isto é, construindo uma equação representante (somando-se as $m+1$ restrições) obtemos:

$$
\begin{aligned}
& \max \sum_{j=1}^{m} V_{j} \beta_{j} \\
& \text { s.a.: } \sum_{j=1}^{m}\left(w_{j}+\left(\sum_{i=1}^{m} \alpha_{i j}\right)\right) \beta_{j} \leq W+\sum_{i=1}^{m} b_{i} \\
& \quad \beta_{j} \geq 0 \text { e inteiros }, j=1, \ldots, m .
\end{aligned}
$$

Podemos tratar o modelo acima como um problema da mochila, onde o valor é dado por $F_{j}(L)$ e os comprimentos dados por $w_{j}+\sum_{i=1}^{m} \alpha_{i j}$. Logo o maior valor relaxando as restrições de integralidade e agindo de uma maneira "gulosa" será:

$$
\frac{V_{k}}{w_{k}+\sum_{i=1}^{m} \alpha_{i k}}=\max \left\{\frac{V_{j}}{w_{j}+\sum_{i=1}^{m} \alpha_{i j}}, j=1, \ldots, r\right\}
$$

Utilizando novamente exemplo do capítulo 3, G/S resulta em:

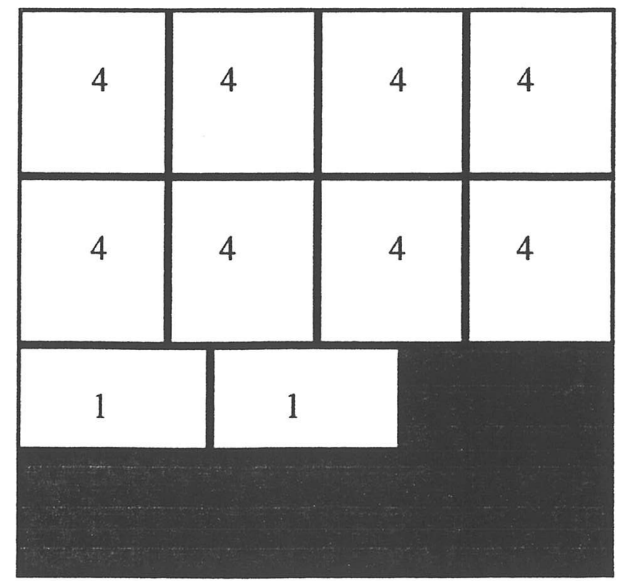

figura 4.4.: Padrão de corte obtido pela $\mathrm{G} / \mathrm{S}$.

onde $V=0.8092$. 


\subsection{Heurística em Grafo E/OU}

Essa heurística consiste em dividir o retângulo original $(L, W)$ em $(L, p)$ e $(L, W-p)$, e para cada um desses retângulos aplicar uma heurística, obtendo suas soluções. Repetese esse processo para cada $p \in \wp=\left\{p=\sum_{i=1}^{m} \alpha_{i} l_{i}<L, \alpha_{i} \geq 0\right.$, inteiros $\}$ (para maiores detalhes veja Christofides e Whitlock, 1977). Cada vez que o processo é repetido guardamos a melhor solução, isto é, aquela que fornece maior soma dos valores de utilidade das peças alocadas nos retângulos. Vejamos os passos principais dessa heurística:

1. A placa $(L, W)$ é dividida em : $(L, p)$ e $(L, W-p)$

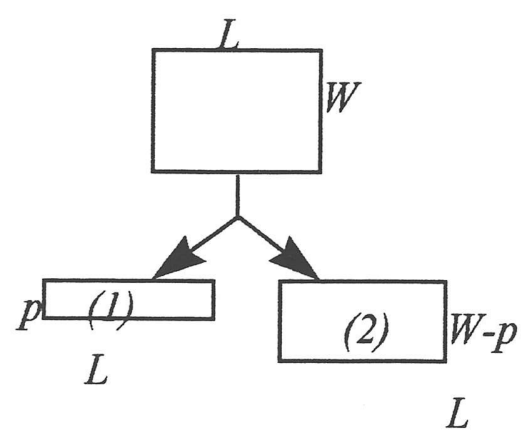

figura 4.5: Placa $(L, W)$ dividida em $(L, p)$ e $(L, W-p)$.

2. 2.1. Uma heurística é aplicada em $(L, p)$, obtendo uma solução tal que $a_{i}^{1} \leq b_{i}, i=1, \ldots, m$ (onde $a_{i}^{1}=$ número de peças tipo $i$ no retângulo 1 )

2.2. A mesma heurística é aplicada em $(L, W-p)$, obtendo: $a_{i}^{2} \leq b_{i}-a_{i}^{1}, i=1, \ldots, m$.

2.3. A solução $a_{i}=a_{i}^{l}+a_{i}^{2}$ é factível para a placa $(L, W)$.

Esta heurística também pode ser aplicada dividindo a placa $(L, W)$ em $(q, W)$ e $(L-$ $q, W)$.

Para todos os exemplos da heurística em grafo E/OU utilizamos a G/S como a heurística utilizada nos passos 2.1 e 2.2 dos passos principais acima. 
O algoritmo proposto por Hifi et al (1997) difere da heurística em grafo E/OU pois ao dividir a placa em dois retângulos (no ponto $p$ ) temos que decidir para cada retângulo restante quais faixas serão alocadas. Como podemos ver na figura 4.6 se alocarmos faixas horizontais em $(L, p)$ e faixas verticais em $(L, W-p)$ obteremos cortes guilhotinados 3estágios, os quais não estamos interessados, logo, para o nosso objetivo devemos alocar apenas faixas horizontais ou faixas verticais como podemos observar também na figura 4.6.

Utilizando o algoritmo geral de Hifi et al, podemos ter:

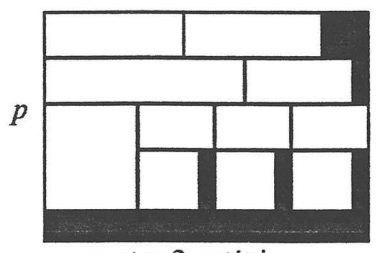

cortes 3-estágios

Enquanto que para o nosso problema podemos apenas obter cortes dos tipos:

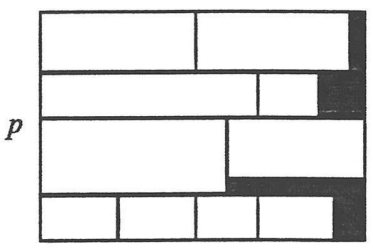

cortes 2-estágios (cortes iniciais horizontais)

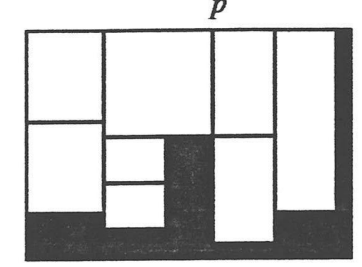

cortes 2-estágios (cortes iniciais verticais)

figura 4.6: Padrões de corte obtidos pelo algoritmo geral de Hifi et al e pela heurística em grafo $\mathrm{E} / \mathrm{OU}$.

Novamente utilizando o exemplo dado no capítulo anterior, seção 3.2, a heurística em grafo E/OU resulta em:

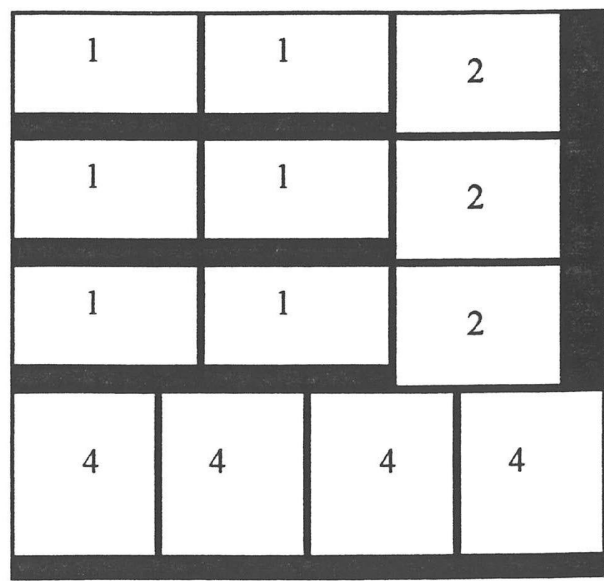

$V=0.9058$

figura 4.7.: Padrão de corte obtido pela heurística em Grafo E/OU. 


\subsection{Comparação entre $\mathbf{G} / \mathbf{P}, \mathrm{G} / \mathrm{F}, \mathrm{G} / \mathrm{S}$}

Nessa seção apresentamos alguns resultados do método do subgradiente a partir de cada uma das heurísticas apresentadas nesse capítulo.

Para cada exemplo rodamos o algoritmo descrito no capítulo 3 três vezes, isto é, cada heurística (G/P, G/F e G/S) é utilizada tanto na obtenção da solução inicial quanto na heurística lagrangeana (que estudaremos no próximo capítulo).

Os valores que se encontram abaixo de cada padrão de corte representam os limitantes superiores e inferiores. Os limitantes superiores são obtidos pelo método do subgradiente e os limitantes inferiores são obtidos pela soma dos valores de utilidade das peças alocadas na placa. Nestes exemplos, as placas têm dimensões $(100,100)$ e $m=10$ (número de peças) e os dados (comprimentos, larguras, limitações e valores de utilidades das peças) dos problemas são fornecidos abaixo de cada exemplo.

Comparações com a heurística em Grafo E/OU serão feitas no próximo capítulo.

\section{Simulação 1:}

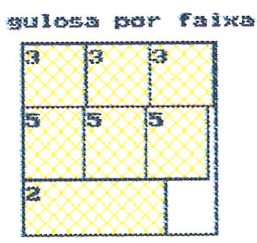

0.9578139

0.9061000

Disdos do Probiema :

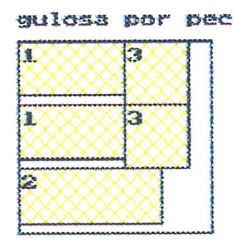

0.9801000

0.7804000

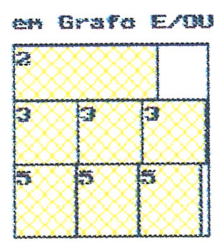

0.9801000

0.8061000

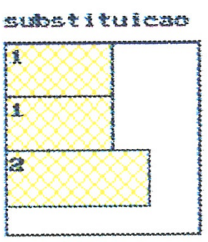

0.9502000 0.5226000 

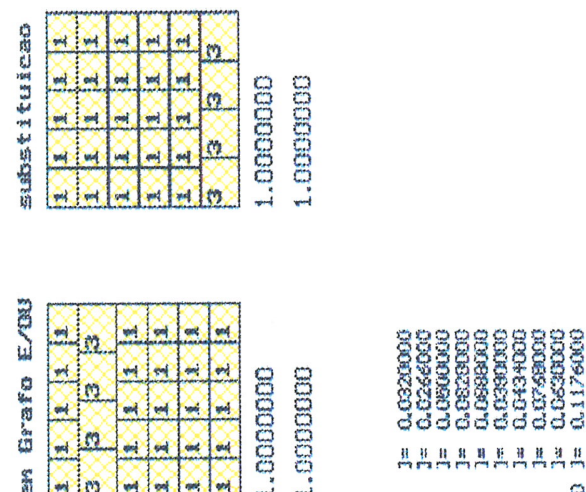

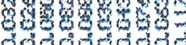

411 11 :

ШNल心

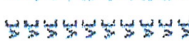

in

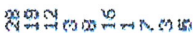

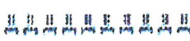

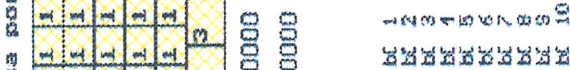

世-山-

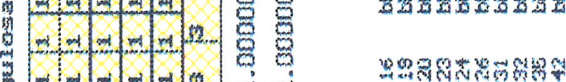

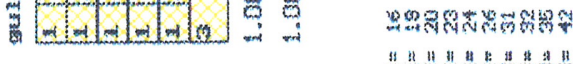

momming

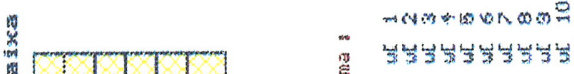

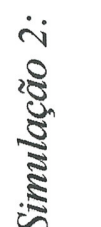

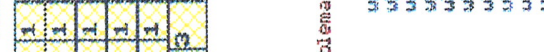

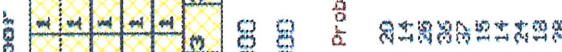

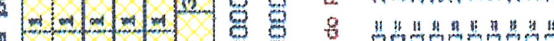

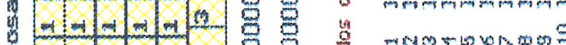

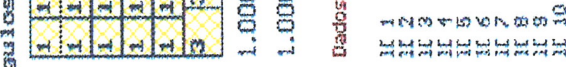
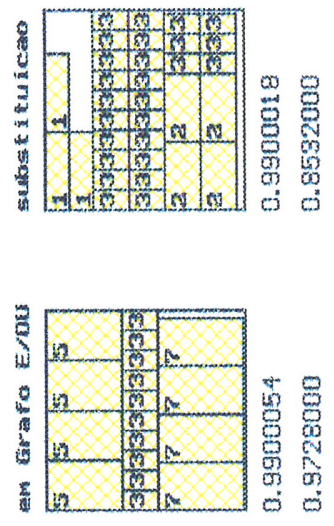

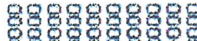

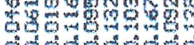

is a : : : :

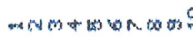

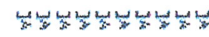

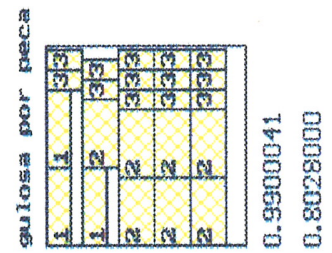

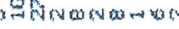

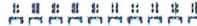

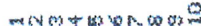

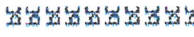

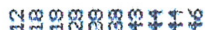

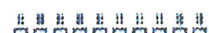

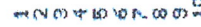

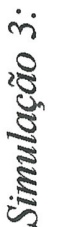

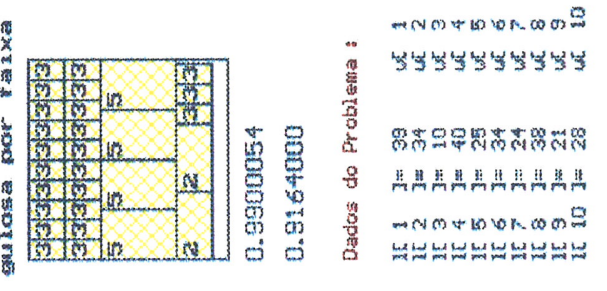




\section{Simulação 4:}

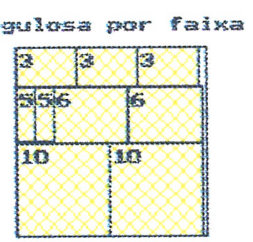

3.9795520

0.3738000

Dados do Problems:

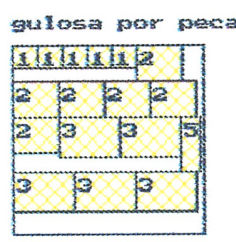

0.9832000

0.7166000

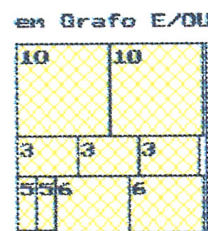

0.9832000

0.9739000

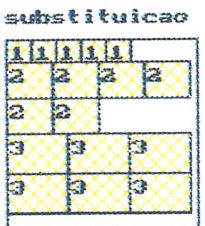

0.9832000

0.754800 ณ

\section{Simulação 5:}

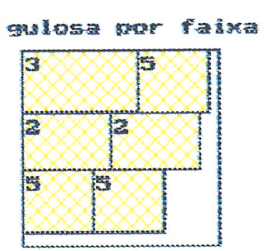

0.8966022

0.7855000

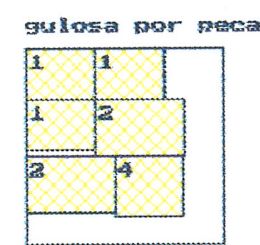

0.8367296

0.6394000

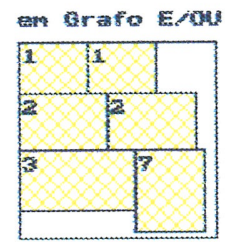

0.9016663

0.7729030

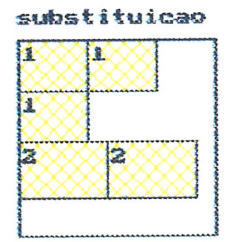

0.9016663

0.5340000

Dados do Froblema:
if. $\frac{1}{2} \quad \begin{aligned} & 1=35 \\ & j=\frac{35}{45}\end{aligned}$
w $\begin{array}{lll}1 & j=25 \\ 2 & 3=28\end{array}$

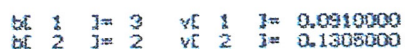
it $3 \quad 3=59$ w[ 3 क $3=31$

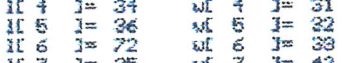

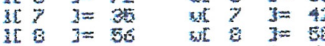

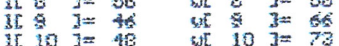

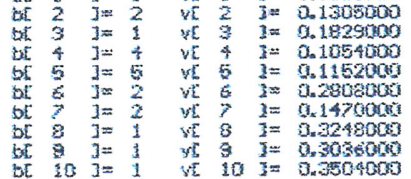




\section{Simulação 6:}
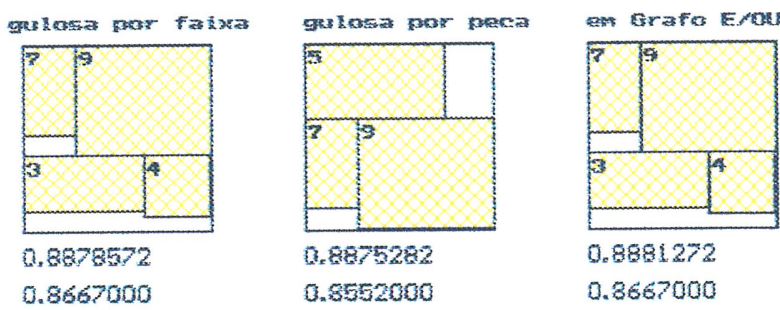

0.8875282

0.8881272

0.8667000

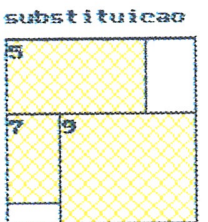

0.8881 .272

0.8552000

Dactas do frobiena:

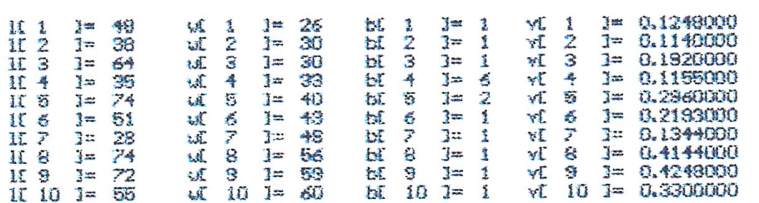




\section{CAPÍTULO 5}

\section{Factibilização da Solução do Subgradiente}

\subsection{Introdução}

No capítulo anterior, desenvolvemos heurísticas para a obtenção de soluções factíveis iniciais, e a partir destas soluções, o objetivo passa a ser atingir soluções de melhor qualidade. Com este intuito, neste capítulo construímos mais uma heurística utilizada quando o Método do Subgradiente não encontra soluções viáveis. Geralmente usamos essa heurística, denominada heurística lagrangeana, quando a cada $n$ iterações consecutivas não há melhora na solução (no nosso caso quando não aumenta o limitante inferior). No método implementado utilizamos $n=10$.

\subsection{Heurística Lagrangeana}

Quando após o cálculo do problema relaxado (irrestrito) for determinada uma solução infactível para o problema original (3.1)-(3.5), isto é, quando uma ou mais restrições de limitação no número de peças for violada, retiramos a faixa (ou quantas forem necessárias) que contém as peças excedentes, e com o retângulo que restou, atualizamos $W$ e $b_{i}, i=1, \ldots, m$ e aplicamos $\mathrm{G} / \mathrm{F}$ (estudada no capítulo anterior). 
Vejamos no diagrama abaixo os passos principais dessa heurística lagrangeana.

Sejam:

$w_{p}=$ largura da faixa_perda ocorrida na placa após a resolução do problema irrestrito.

$w_{r}=$ largura da(s) faixa(s) retirada(s).

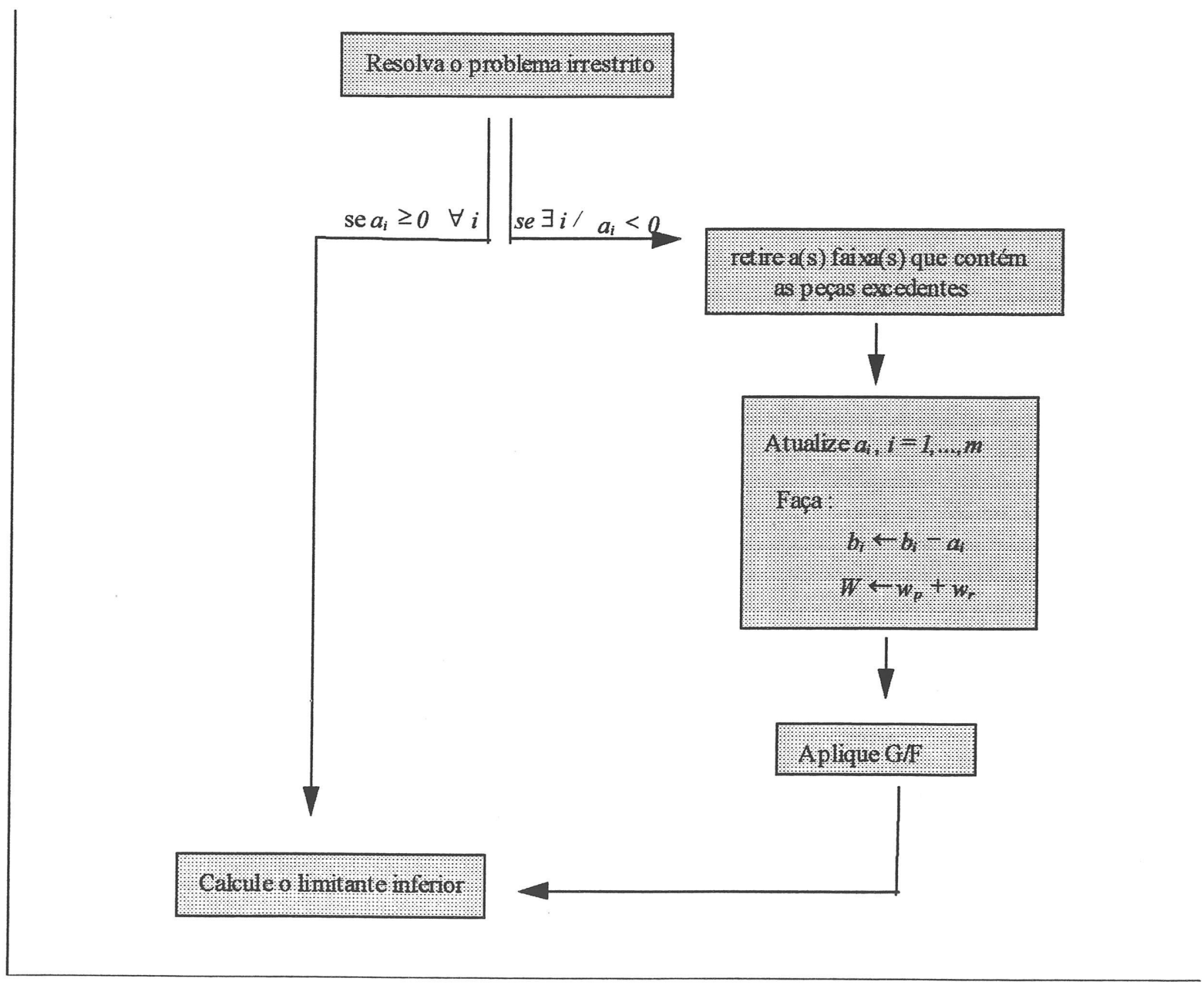

figura 5.1: Diagrama do funcionamento da heurística lagrangeana.

E assim factibilizamos uma solução proveniente do problema irrestrito (Gilmore e Gomory, 1965) obtendo então um padrão de corte viável para o problema restrito. Observe que esta é a heurística utilizada no passo 5.6 do algoritmo descrito no capítulo 3 . 


\subsection{Comparações Entre as Heurísticas em grafo $\mathrm{E} / \mathrm{OU}$ e a lagrangeana.}

Mostraremos agora alguns exemplos comparando resultados obtidos pela heurística em grafo E/OU (estudada no capítulo 4) e pela heurística lagrangeana (estudada neste capítulo) que chamaremos de subgradiente. Também mostraremos os resultados das heurísticas $\mathrm{G} / \mathrm{P}, \mathrm{G} / \mathrm{F}$ e $\mathrm{G} / \mathrm{S}$, onde a melhor solução dentre essas três heurísticas será utilizada como solução inicial para o método do subgradiente.

Abaixo apresentamos os dados dos exemplos (comprimentos, larguras, valores de utilidade e limitações de cada peça demandada) e seus respectivos padrões de corte. Abaixo de cada padrão de corte apresentamos os limitantes inferiores e superiores. Cada exemplo é calculado duas vezes, numa primeira vez construindo faixas horizontais e outra produzindo apenas faixas verticais. Em todos os exemplos as placas a serem cortadas têm dimensões $(100,100)$ e $m=10$ (número de peças). Vejamos agora alguns exemplos:

\section{Simulação 1:}

horizontal:

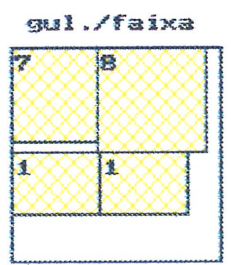

4.1140000

0.6786000

vertical:

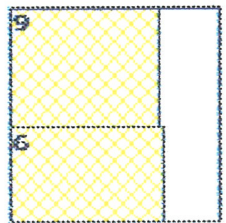

4.1140000

0.7188000

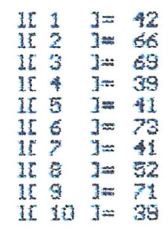

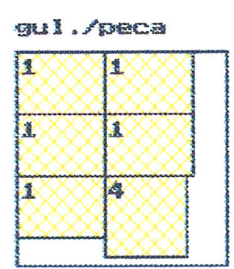

4.1140000

0.75720000

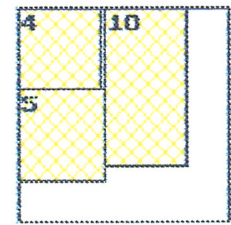

4.3140000

0.6131000

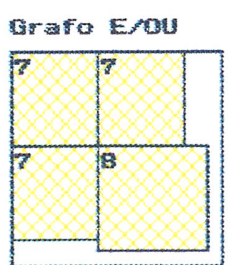

4.1140000

0.7960000

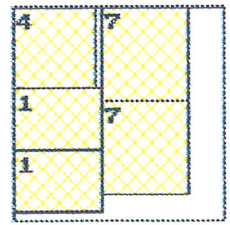

4.1140000

0.7526000

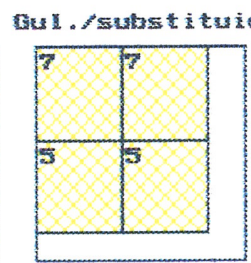

4.1140000

0.7134000

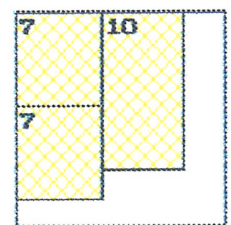

4.1140000

0.6494000

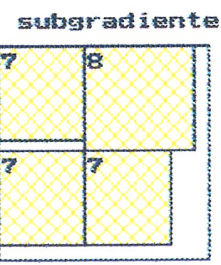

0.8270021

0.7960000

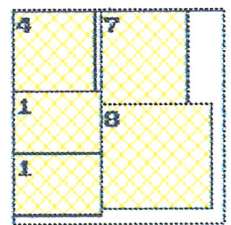

0.8293016

0.8270000 


\section{Simulação 2:}

horizontal:

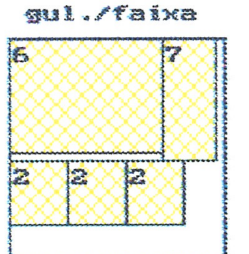

3.2433000

0.7441000

vertical:

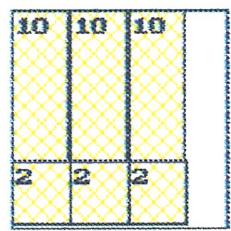

3.2433000

0.7731000

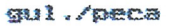

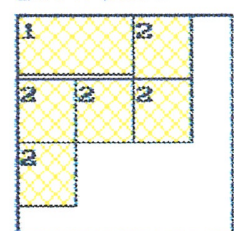

3.2433000

0.5973000

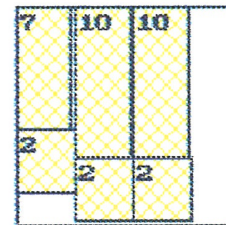

3.2433000

ก. 7337000

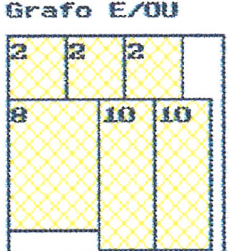

3.2433600

0.8457000

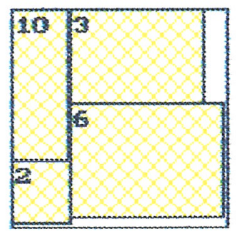

3.2433000

0.8935000

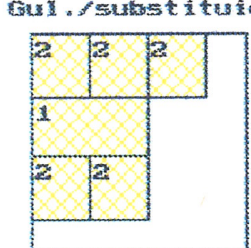

3.2433000

0.5373000

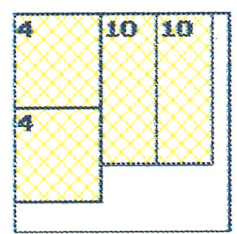

3.2433000

0.7028000

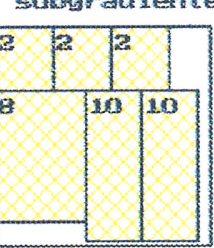

0.8605460

0.8457000

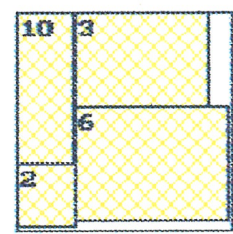

0.8935000

0.8935000

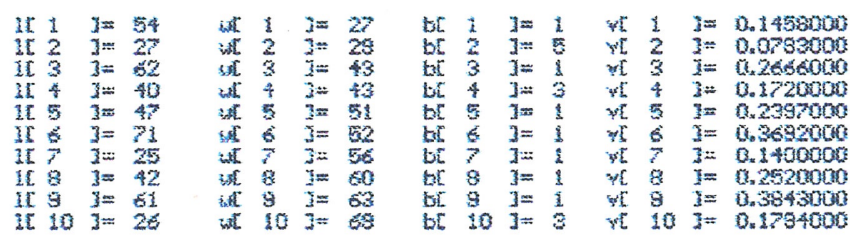

\section{Simulação 3:}

horizontal:

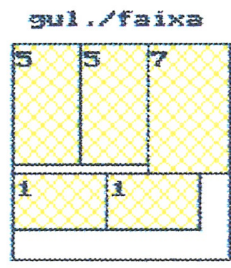

3.4009000

0.7950000

vertical:

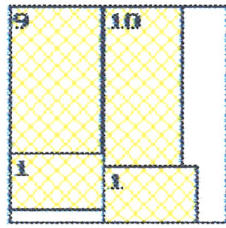

3.4009000

0.7756000

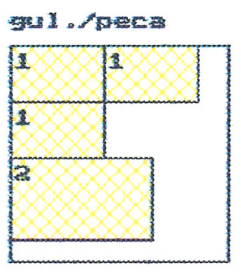

3.4009000

0.5824000

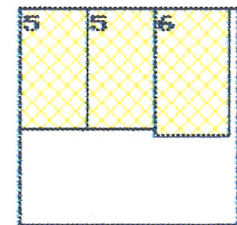

34009000

0.5478000

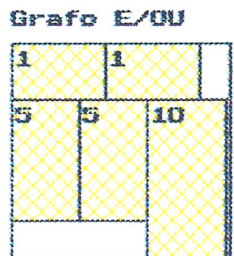

3.4ถดงอออ

0.8372000

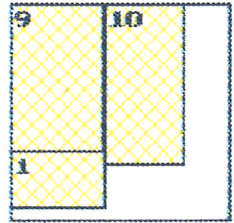

3.4009000

0.6638000

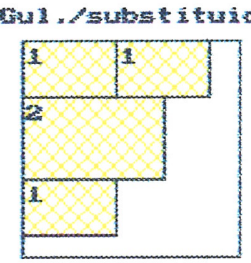

3.4009000

0.5824000

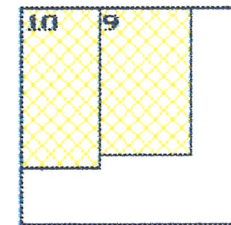

3.4009000

0.5520000

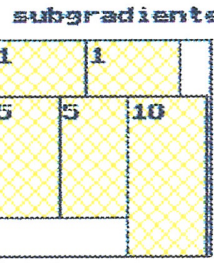

B.8372000

0.5972000

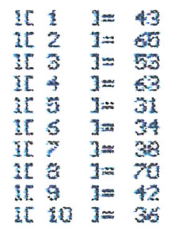

wit $1 \frac{1}{2} y=26$

be $1 \quad y=3$

wi $\quad I=0.1118000$

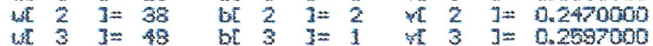

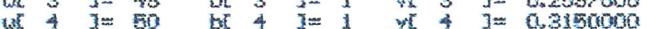

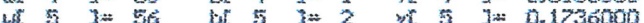

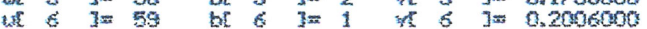

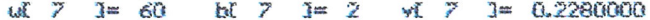

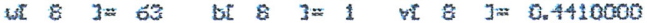

we 9$]=68$ be $9 \mathrm{j}=1$, $9 \mathrm{~g}=0.2006000$

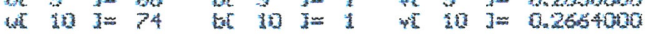

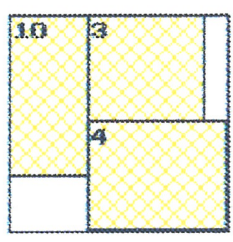

0.9067097

0.8411000 
Simulação 4:

horizontal:

gus 0 of

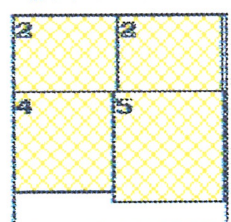

3.9607000

0.8441000

vertical:

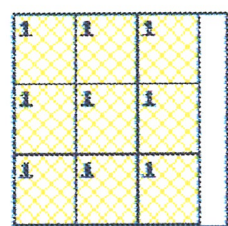

3.9607000

0.8613000

$15 \frac{1}{3}=29$

if $\frac{1}{3} \quad 3=\frac{49}{3=0}$

if $3=4$

II. $6 \quad 3=68$

III? $3=58$

II. 9 is $3=74$

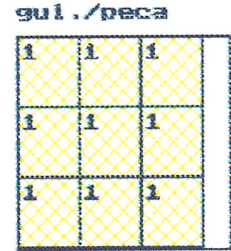

3.9607000

$0.86 \div 3000$

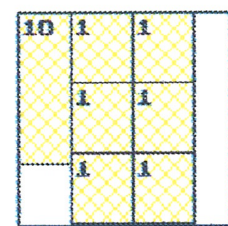

3.9607000

0.7517000

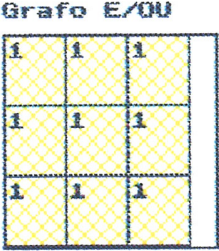

3.9607000

0.8613000

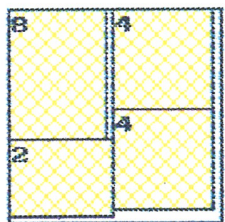

3.3607000

0.3985000

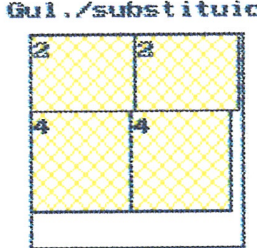

3.9607000

0.7346000

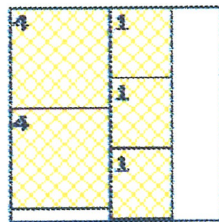

3.9607000

0.7289000

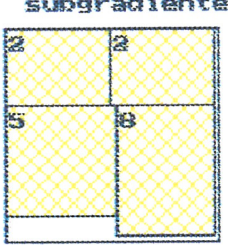

0.9267395

0.9038000

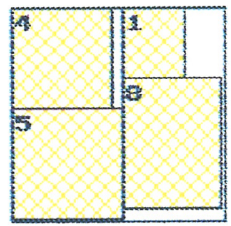

$0.92673 \div 9$

0.8676000

Simulação 5:

horizomial:

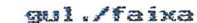

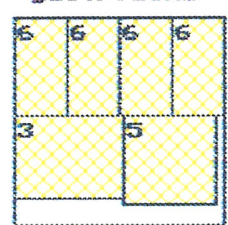

3. 41.420000

0.8672000

vertical:

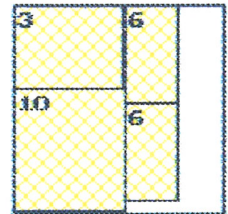

3.4142000

0.7557000 gul 1 seces

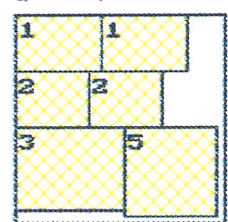

3. 41.42000

0.8076000

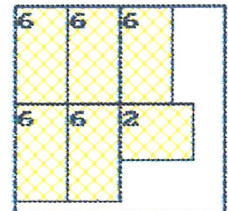

3.4142000

0.6820000
Grafo Erou

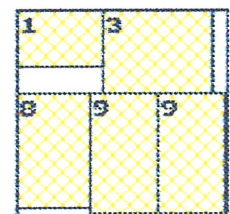

3.41.42000

0.8824000

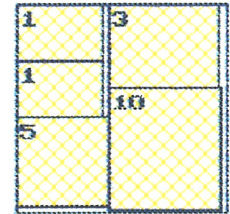

3.4142000

0.9313000

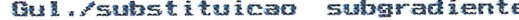

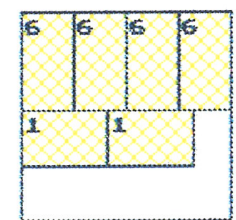

3. 4142000

0.6914000

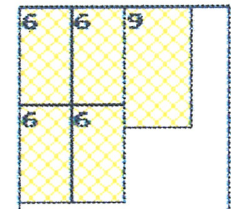

3.4142000

0.6556000

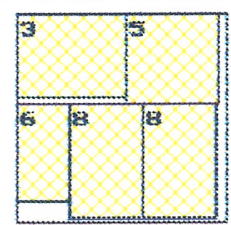

0.9348567

0.8997000

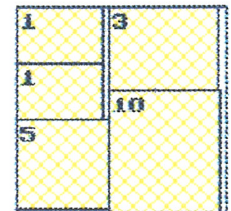

0.9367516

0.9913000

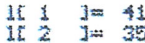

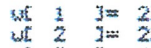
紫 $\frac{1}{2} \quad \begin{aligned} & 3=2 \\ & y\end{aligned}$

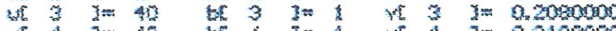

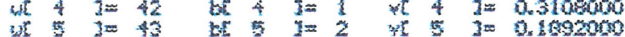

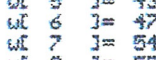

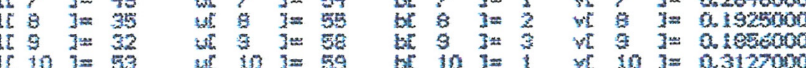

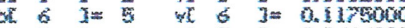
$7=1$
7

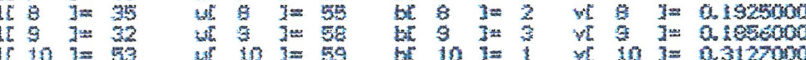


Simulação 6:

horizontal:

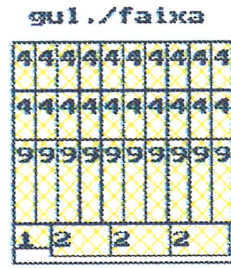

4.5415000

0.9602000

vertical:

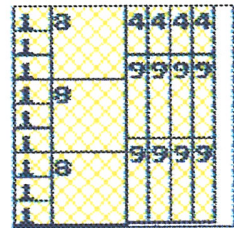

4.5415000

0.8969000

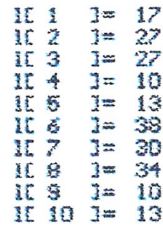

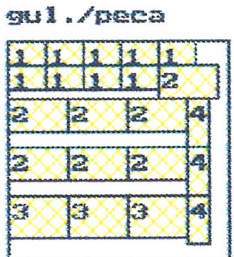

4.5415000

0.6717000

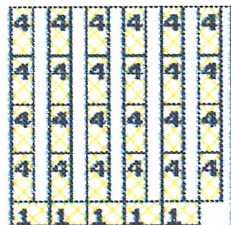

4.5415000

0.6215000
Grafo E/CU

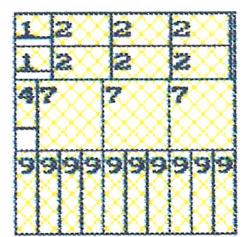

4.5415000

0.9704000

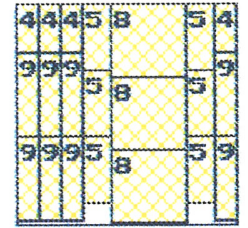

4.5415000

0.3626000

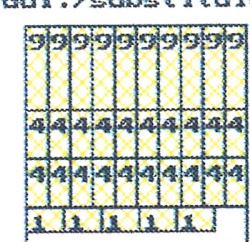

4.5415000

0.9135000

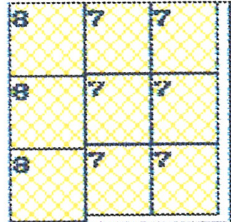

4.5415000

0.9226000

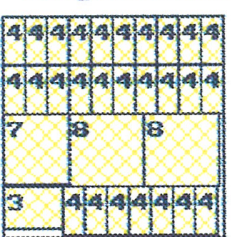

0.9803829

0.9657000

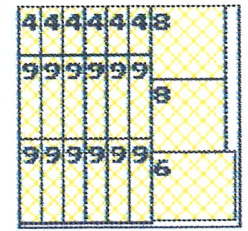

0.9728442

0.9302000

Simulação 7 :

horizontal:

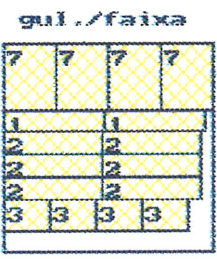

3.2882000

0.3582000

yertical:

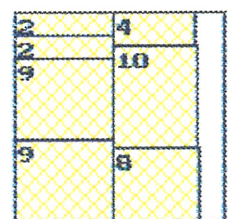

3.2882000

0.8719000

II 1 I $]=48$

II $2=j=\frac{17}{2}$

11 $4 \quad j=22$

12. $\quad y=2$

$156 y=41$

II $8 j=41$

if $10 \mathrm{j}=40$

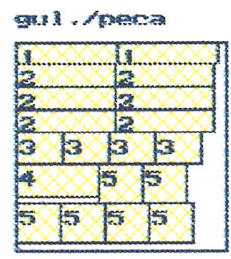

3.2882000

0.8400000

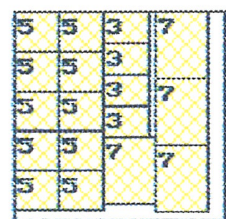

3.2882000

0.8510000

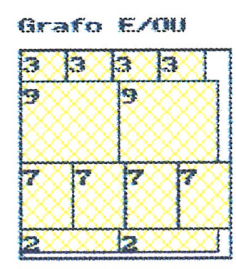

3.2882000

0.9220000

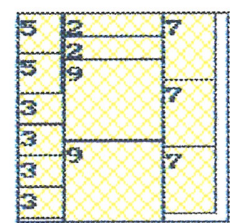

3.2882000

0.9218000

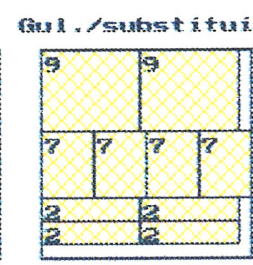

3.2882080

0.8534000

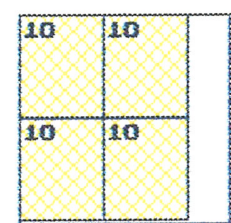

3.2882000

0.7840000

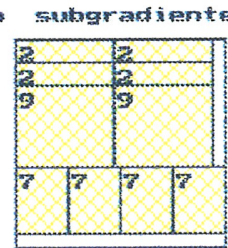

0.9677872

0.8934000

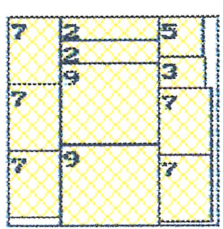

0.9552626

0.3429000

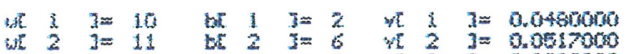

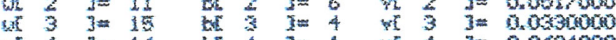

w5 $43=16$ be $\quad \begin{aligned} & 3=1 \\ & 5\end{aligned}$

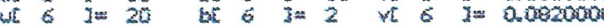

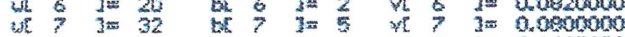

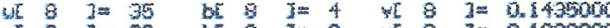

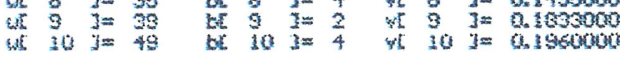




\section{PARTE III : Conclusões}

\section{CAPÍTULO 6}

\section{Resultados dos Testes Computacionais}

\subsection{Introdução}

Neste capítulo são apresentados os resultados computacionais do método proposto no capítulo 3. A implementação deste método foi escrita em PASCAL, Turbo Pascal 7.0 e os exemplos foram rodados num microcomputador PC-486-DX2, 66Mhz com 8 Mbytes de Ram.

No método do subgradiente utilizamos o passo $\theta_{t}=\pi\left(\frac{Z_{U B}-Z_{L B}}{\left\|a^{t}\right\|^{2}}\right)$ onde $0<\pi<2$. Exemplos foram gerados aleatoriamente com placas de dimensões $(100,100)$ e 10 peças $(m=10)$, os quais são divididos em duas classes (segundo Morábito, R., 1992), exemplos grandes e pequenos: 
(i) Exemplos pequenos: os valores $l_{i}, w_{i}, i=1,2, \ldots, m$, foram sorteados (e em seguida arredondados) de uma distribuição uniforme nos intervalos $[0.25 \mathrm{~L}, 0.75 \mathrm{~L}],[0.25 \mathrm{~W}, 0.75 \mathrm{~W}]$ respectivamente.

(ii) Exemplos grandes: os valores $l_{i}, w_{i}, i=1,2, \ldots, m$, foram sorteados (e em seguida arredondados) de uma distribuição uniforme nos intervalos $[0.10 \mathrm{~L}, 0.50 \mathrm{~L}],[0.10 \mathrm{~W}, 0.50 \mathrm{~W}]$ respectivamente.

Dividimos também os exemplos para valores de utilidade $v_{i}, i=1,2, \ldots, m$ definidos por $v_{i}=\frac{l_{i}^{*} w_{i}}{L^{*} W}, i=1,2, \ldots m$, (nesse caso o valor da função objetivo é no máximo 1) e $v_{i}$, $i=1,2, \ldots, m$ gerados aleatoriamente (nesse caso a função objetivo pode atingir qualquer valor).

Em todos os exemplos, as limitações são dadas por valores aleatórios entre 1 e $b_{i}=\frac{L^{*} W}{l_{i} * w_{i}}+1, i=1, \ldots, m$ (também em seguida arredondados.

Em todos os exemplos utilizamos o número máximo de iterações permitidas igual a 100 e utilizamos a heurística lagrangeana a cada 10 iterações sem melhora no limitante inferior.

Utilizaremos como medida de qualidade de uma solução obtida pelo algoritmo a razão:

$$
\Delta=\frac{z_{U B}-z_{L B}}{z_{L B}}
$$

que fornece a porcentagem da solução obtida necessária para atingir o limitante superior. (Observamos que podemos ter uma solução de baixa qualidade devido a um limitante superior pobre, apesar da solução obtida ser muito boa). 
A análise dos resultados fornecidos pelo algoritmo é baseado na qualidade das soluções considerando-se os seguintes casos:

1. cada heurística é utilizada tanto na obtenção da solução inicial, quanto na heurística lagrangeana;

2. melhor solução entre as heurísticas é utilizada como solução inicial e a heurística gulosa por faixa é utilizada na heurística lagrangeana.

Para analisarmos a qualidade das soluções quando o subgradiente é calculado a partir de cada uma das heurísticas, procedemos da mesma maneira que a feita no capítulo 4.

Após esses cálculos, aplicamos a heurística em Grafo E/OU que nos fornece um limitante inferior, e com o maior dos limitantes superiores dentre os obtidos acima, calculamos também a qualidade da solução obtida pela heurística em grafo E/OU.

\subsection{Resultados a partir de cada heurística}

Vejamos a seguir a qualidade das soluções obtidas, para 40 exemplos. Resultados de 20 exemplos pequenos e 20 exemplos grandes, ambos com valores de utilidade obtidos pela área das peças são colocados nos gráficos abaixo, onde utilizamos a seguinte notação:

$\mathrm{G} / \mathrm{P}=$ heurística gulosa por peça.

$\mathrm{G} / \mathrm{F}=$ heurística gulosa por faixa.

$\mathrm{G} / \mathrm{S}=$ heurística gulosa por substituição.

Em Grafo E/OU=heurística em grafo E/OU. 


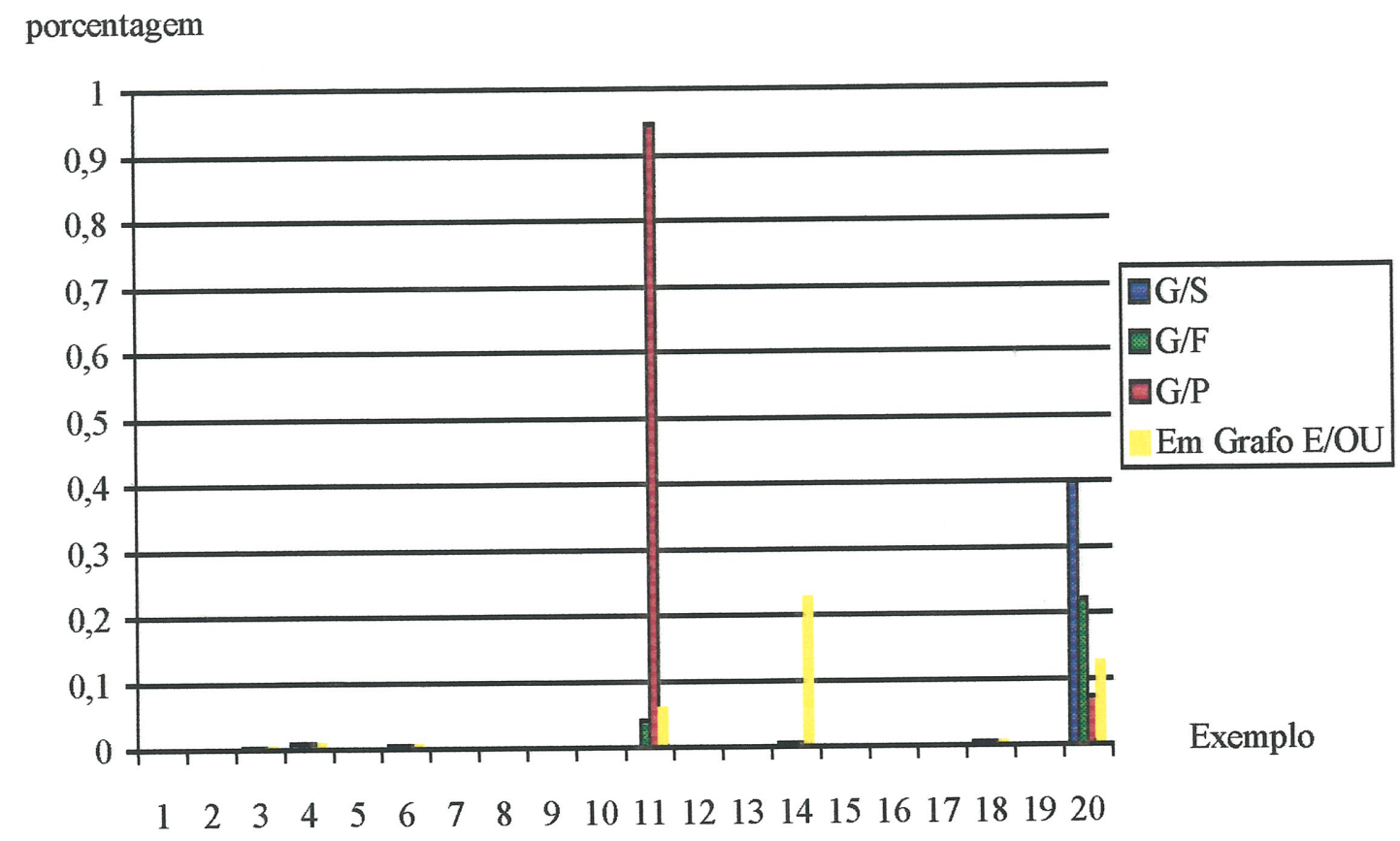

gráfico 6.1 - Exemplos pequenos.

Observe que no exemplo 1, (assim como para os exemplos 2,5,7,8,9,10,12,13,15,16,17 e 19) todas as soluções foram ótimas $(\Delta=0)$, enquanto que no exemplo $11 \mathrm{G} / \mathrm{P}$ foi de baixa qualidade $(\Delta=0.95)$ indicando que o limitante inferior é quase a metade do limitante superior. 


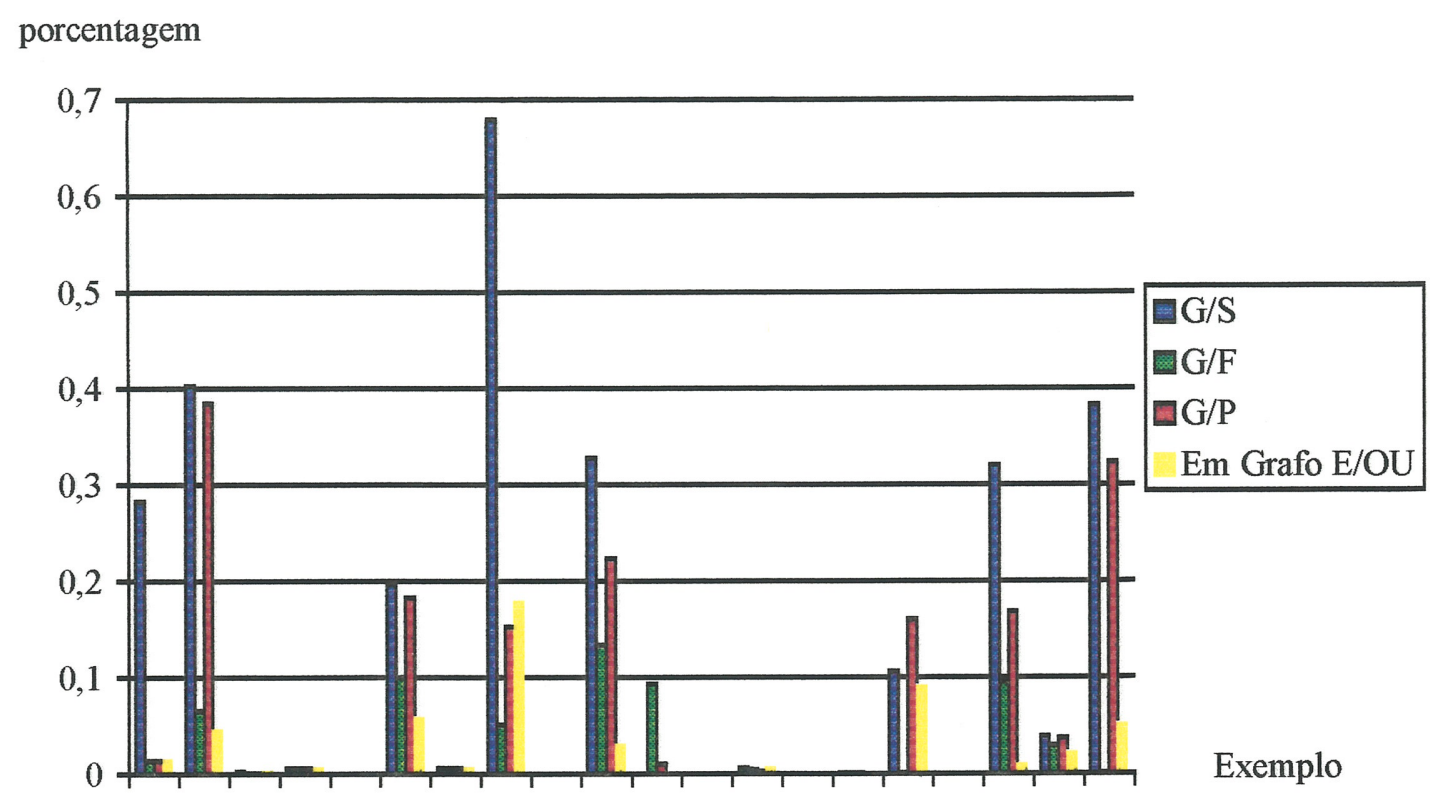

$\begin{array}{llllllllllllllllllll}1 & 2 & 3 & 4 & 5 & 6 & 7 & 8 & 9 & 10 & 11 & 12 & 13 & 14 & 15 & 16 & 17 & 18 & 19 & 20\end{array}$

gráfico 6.2. - Exemplos grandes.

Podemos observar que para exemplos pequenos há uma grande quantidade de soluções ótimas e quase-ótimas, enquanto que para exemplos grandes as heurísticas gulosa por substituição e gulosa por peça tiveram maior dificuldade em encontrar boas soluções.

Agora analisaremos a qualidade das soluções quando tomamos como solução inicial factível a melhor solução obtida entre G/P, G/F e G/S e no lagrangeano utilizamos G/F. Para isto, foram gerados aleatoriamente 1600 exemplos. Alguns exemplos publicados na literatura também são utilizados. Forneceremos as médias dos limitantes inferiores e superiores e o número de soluções ótimas a cada 100 exemplos.

Nos exemplos que apresentaremos nas próximas seções teremos tabelas representando os resultados computacionais, onde : 
- A coluna $\boldsymbol{m}$ representa o número de tipos de peças demandadas.

- A coluna solução apresenta a média dos limitantes superiores e inferiores.

- A coluna \# sol. ótimas fornece a quantidade de soluções ótimas encontradas pelo algoritmo proposto dentre 100 exemplos.

Os gráficos abaixo das tabelas representam respectivamente para $m=5,10,20$ e 30 a qualidade das soluções para cada heurística utilizada, isto é, representa a quantidade de soluções obtidas por cada heurística abaixo de $\Delta(\Delta=0 \%, 0.5 \%, 1 \%, 1.5 \%, 2 \%, 3 \%, 4 \%, 5 \%$, $6 \%, 7 \%, 8 \%, 9 \%, 10 \%, 20 \%, 30 \%$ e $50 \%$ ). O eixo $x$ representa as porcentagens acima descritas e o eixo $y$ representa a quantidade de soluções.

Para todos exemplos, tanto pequenos como grandes e com valores de utilidade sendo a área ou gerados aleatórios, observaremos que quanto maior o número de tipos de peças demandadas $(m)$ maior o aproveitamento da placa (maior o limitante inferior), pois temos mais opções de construir faixas mais valiosas.

\subsection{Resultados a partir da melhor heurística}

\subsubsection{Exemplos Pequenos}

\section{Valores de utilidade dados pela área}

A tabela 6.1 abaixo apresenta os resultados de 400 exemplos pequenos (100 para cada $m$ ). Os valores de utilidade das peças demandadas foram obtidos pela área, ou seja, $v_{i}=\frac{l_{i}^{*} w_{i}}{L^{*} W}, i=1, \ldots, m$

\begin{tabular}{|c|c|c|c|}
\hline $\boldsymbol{m}$ & \multicolumn{2}{|c|}{ solução } & \# sol. \\
& lim. superiores & lim. inferiores & Ótimas \\
\hline $\mathbf{5}$ & 0.8103881 & 0.787233 & 53 \\
\hline $\mathbf{1 0}$ & 0.9036385 & 0.891274 & 52 \\
\hline $\mathbf{2 0}$ & 0.9544924 & 0.945803 & 58 \\
\hline $\mathbf{3 0}$ & 0.9736553 & 0.968858 & 52 \\
\hline
\end{tabular}

tabela 6.1 


\section{Qualidade das soluções}

$m=5$ :

Número de Exemplos

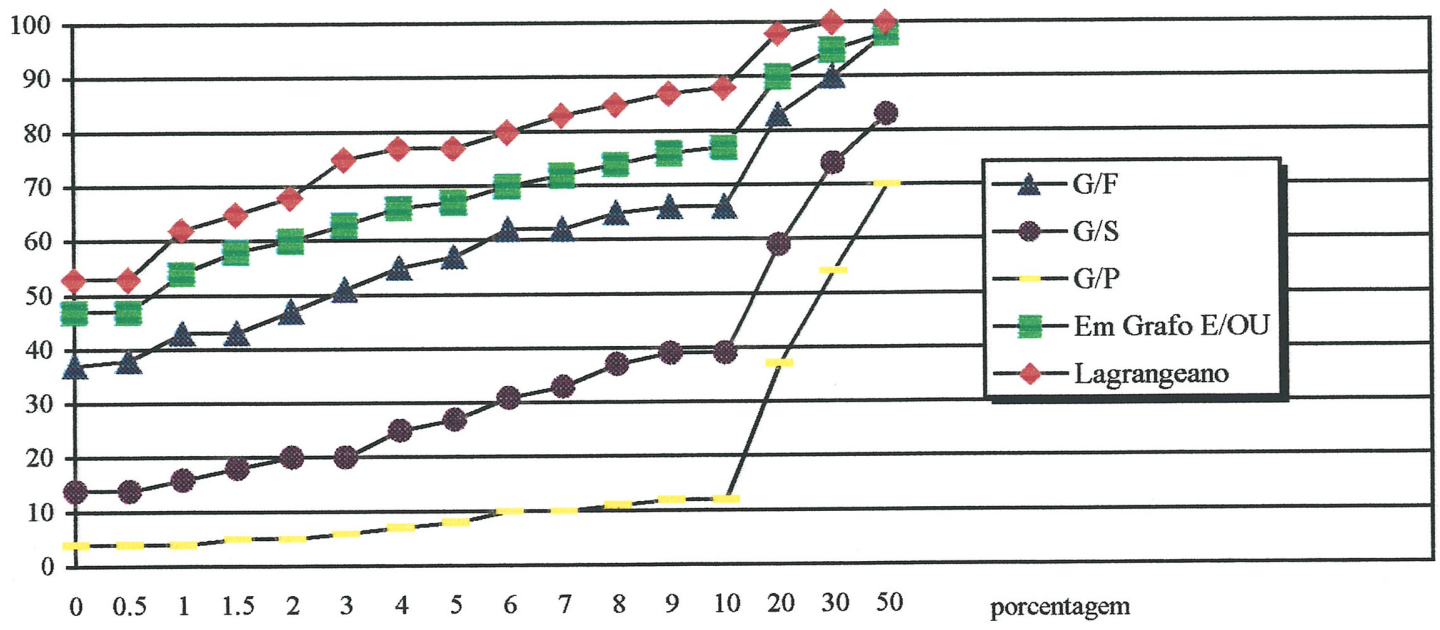

gráfico 6.3 .

$m=10$

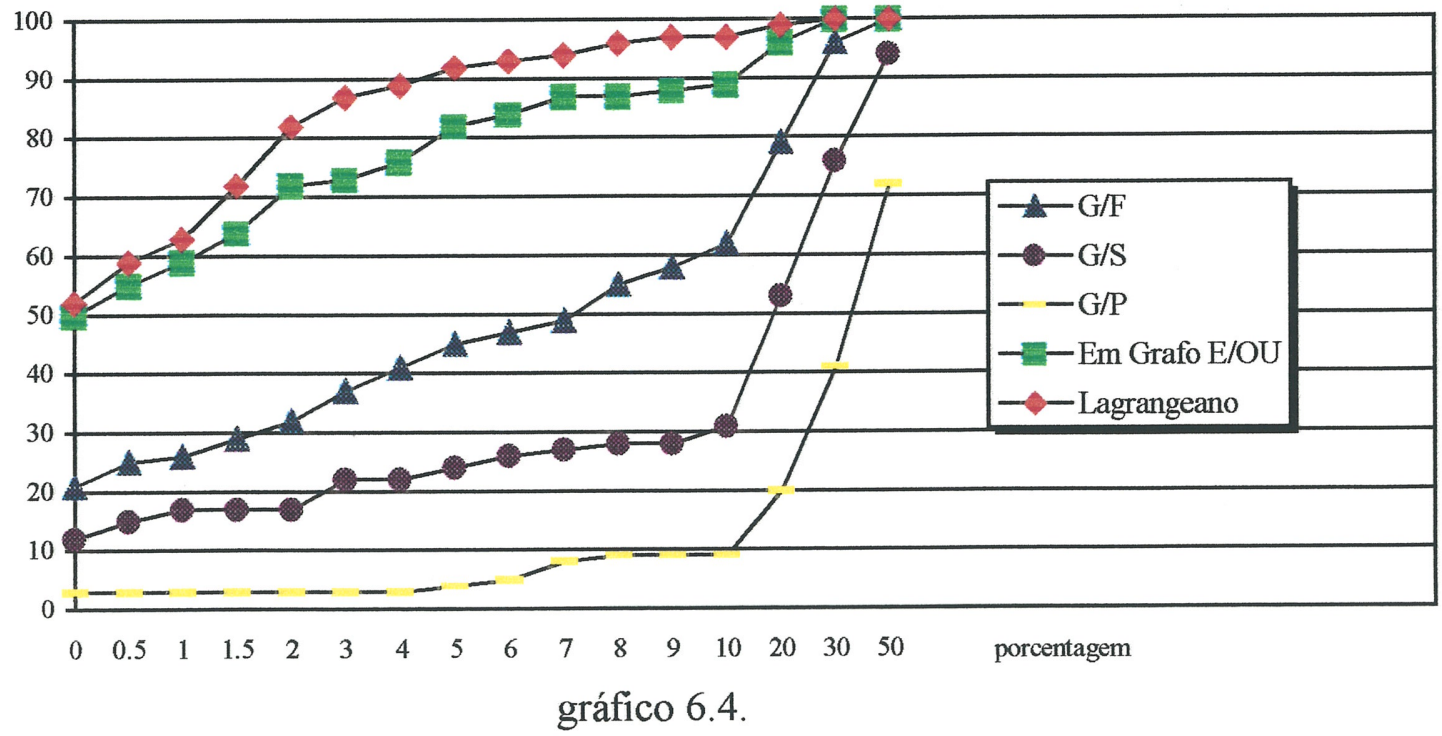


$m=20$

Número de Exemplos

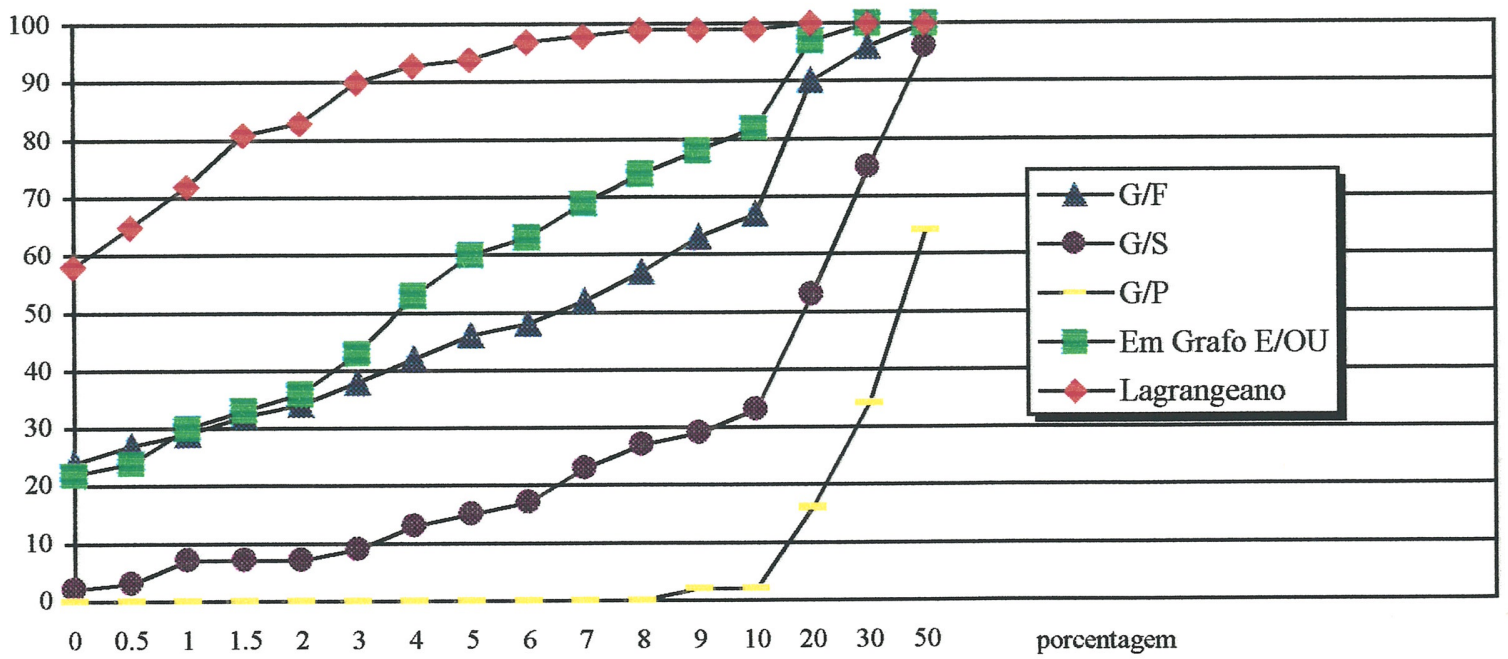

gráfico 6.5 .

$m=30$

Número

de Exemplos

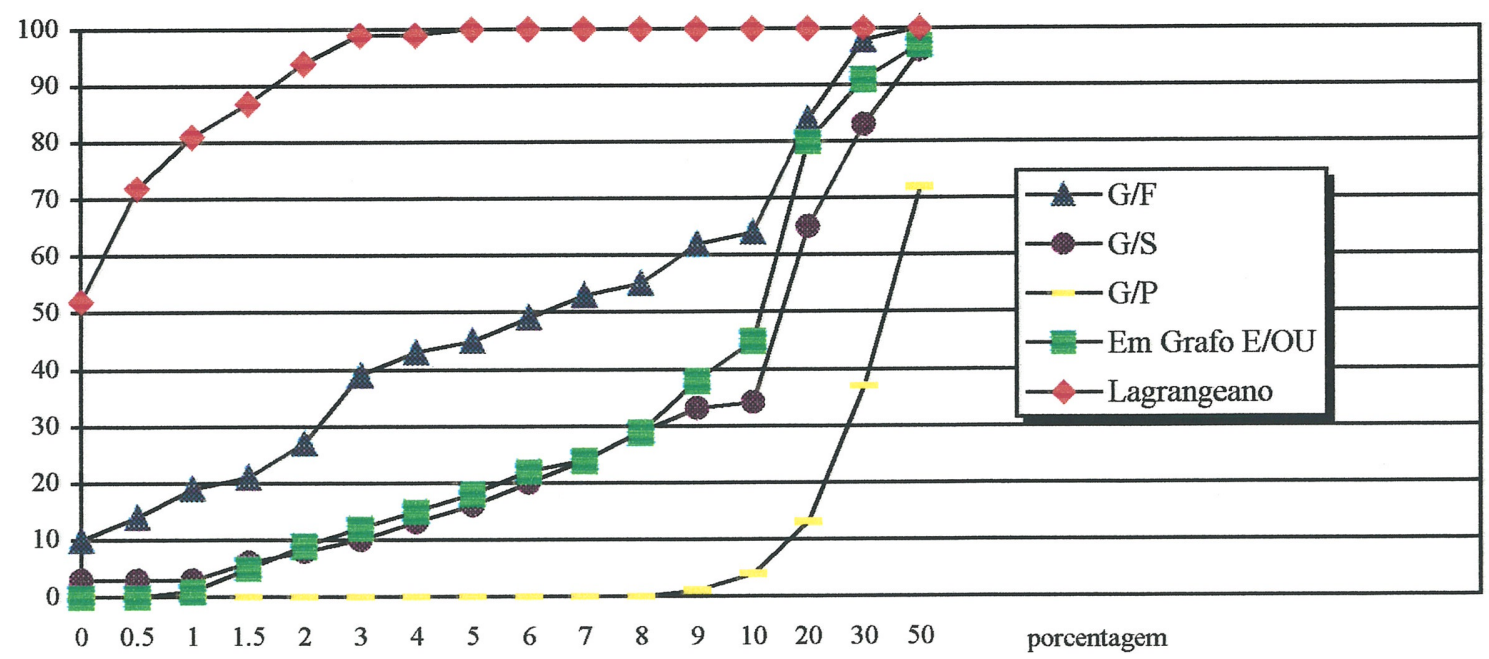

gráfico 6.6. 


\section{Valores de utilidade gerados aleatoriamente}

A tabela 6.2 representa 400 exemplos pequenos com valores de utilidade gerados aleatoriamente de 1 a 20.

\begin{tabular}{|c|c|c|c|}
\hline $\boldsymbol{M}$ & \multicolumn{2}{|c|}{ solução } & \# sol. \\
& lim. superiores & lim. inferiores & ótimas \\
\hline $\mathbf{5}$ & 54.51196 & 51.54999 & 46 \\
\hline $\mathbf{1 0}$ & 79.31772 & 76.75000 & 44 \\
\hline $\mathbf{2 0}$ & 100.91689 & 96.66000 & 31 \\
\hline $\mathbf{3 0}$ & 117.63618 & 113.07999 & 25 \\
\hline
\end{tabular}

tabela 6.2

\section{Qualidade das soluções}

$m=5$

Número de Exemplos

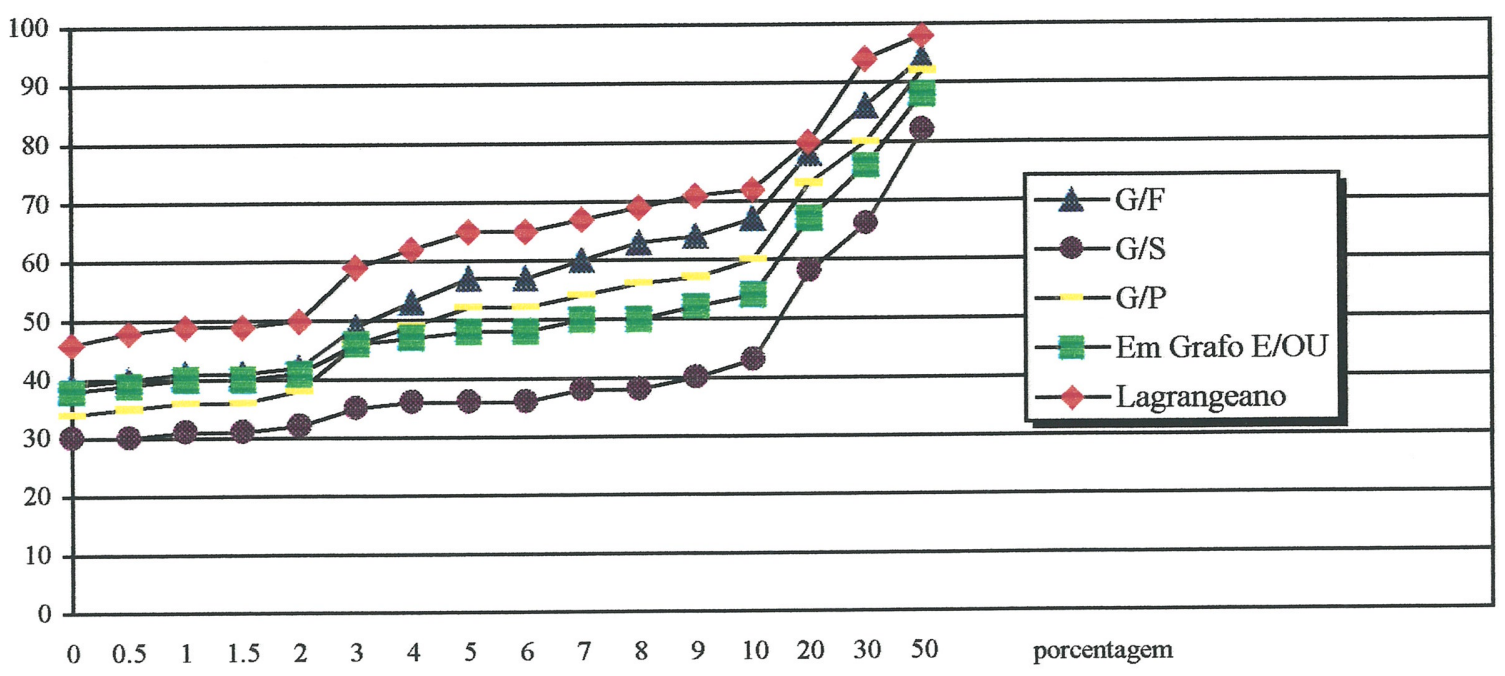

gráfico 6.7 . 
$m=10$

Número

de Exemplos

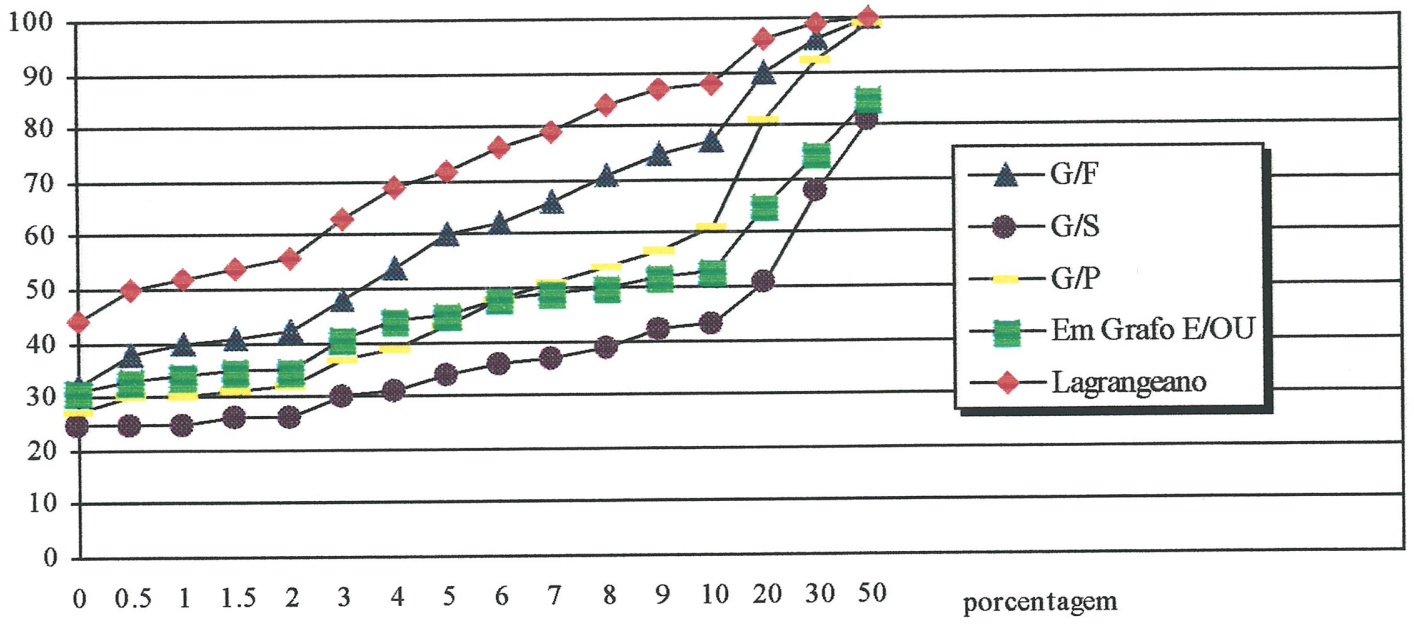

gráfico 6.8.

$m=20$

Número

de Exemplos

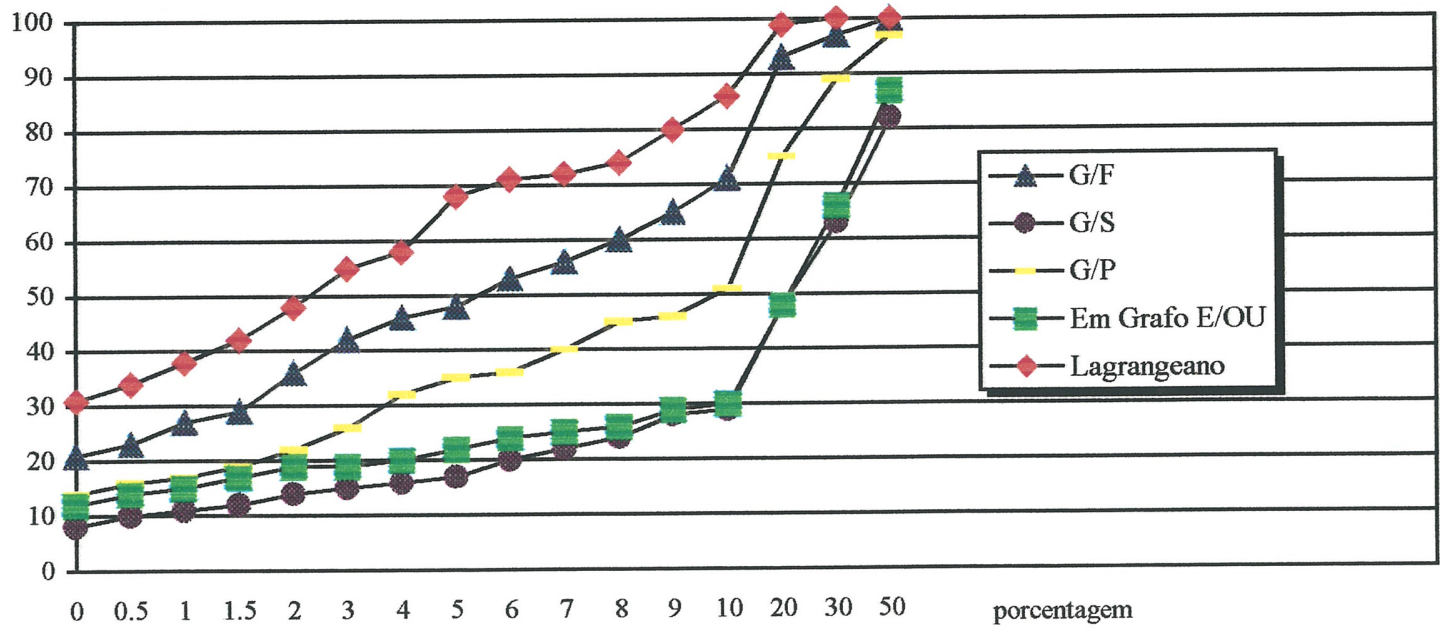

gráfico 6.9. 
$m=30$

Número

de Exemplos

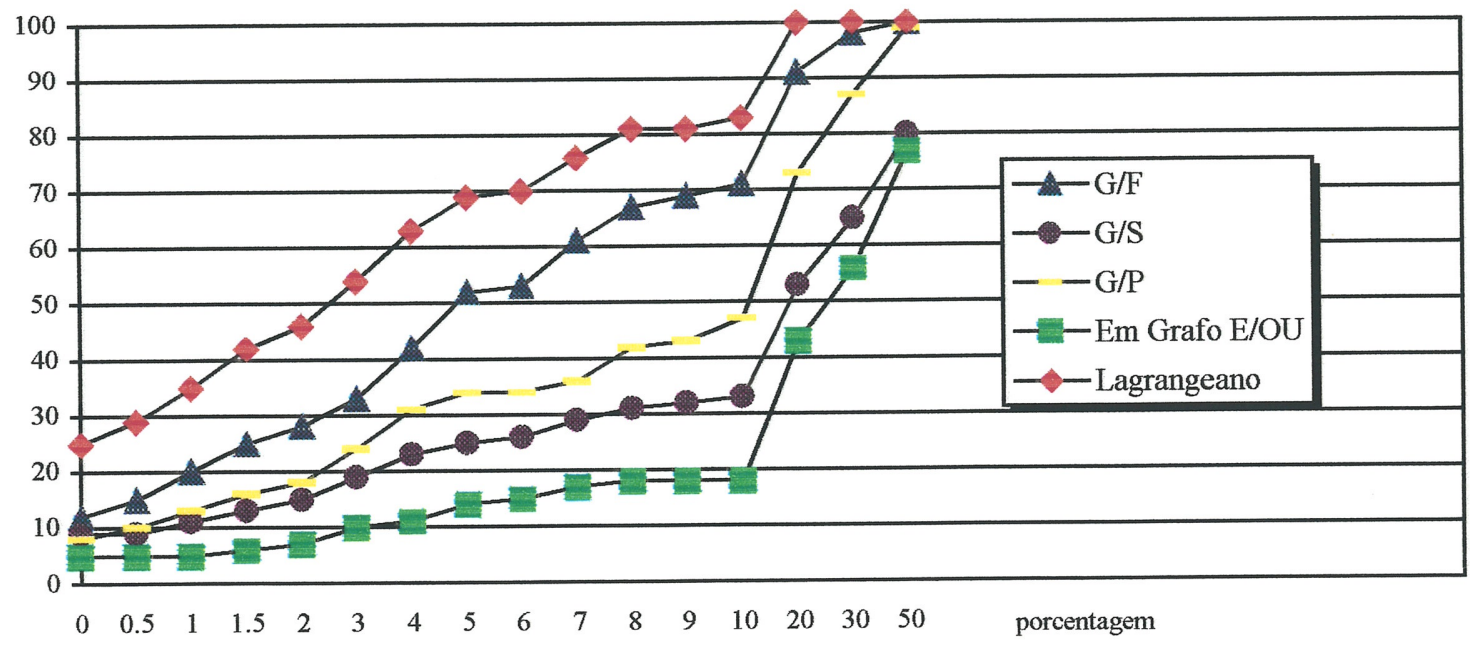

gráfico 6.10 .

\subsubsection{Exemplos Grandes}

\section{Valores de utilidade dados pela área}

A tabela 6.3 abaixo apresenta os resultados de 400 exemplos grandes, onde os valores de utilidade das peças demandadas foram obtidos pela área, ou seja, $v_{i}=\frac{l_{i}^{*} w_{i}}{L^{*} W}, i=1, \ldots, m$.

\begin{tabular}{|c|c|c|c|}
\hline $\boldsymbol{m}$ & \multicolumn{2}{|c|}{ solução } & \# sol. \\
& lim. superiores & lim. inferiores & ótimas \\
\hline $\mathbf{5}$ & 0.929941 & 0.905590 & 27 \\
\hline $\mathbf{1 0}$ & 0.974255 & 0.963597 & 35 \\
\hline $\mathbf{2 0}$ & 0.991311 & 0.983019 & 35 \\
\hline $\mathbf{3 0}$ & 0.996541 & 0.990899 & 41 \\
\hline
\end{tabular}

tabela 6.3 


\section{Qualidade das soluções}

$m=5$

Número de Exemplos

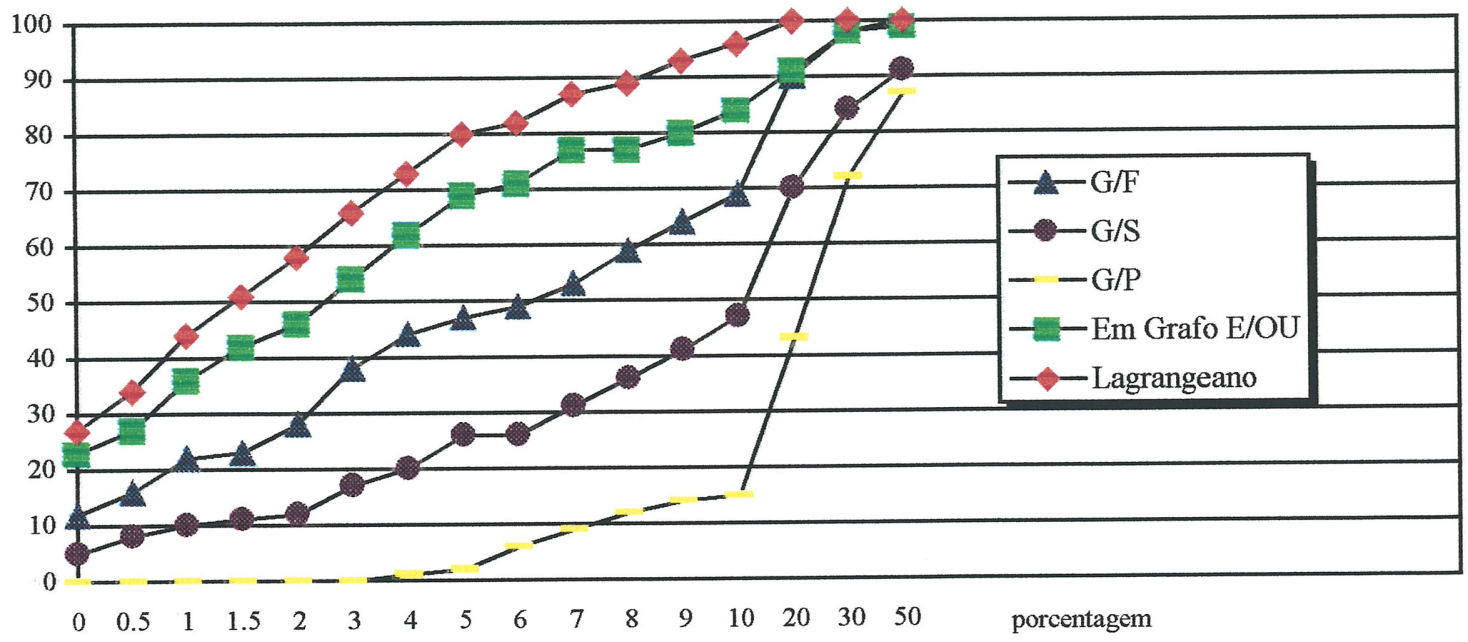

gráfico 6.11.

$$
m=10
$$

Número de Exemplos

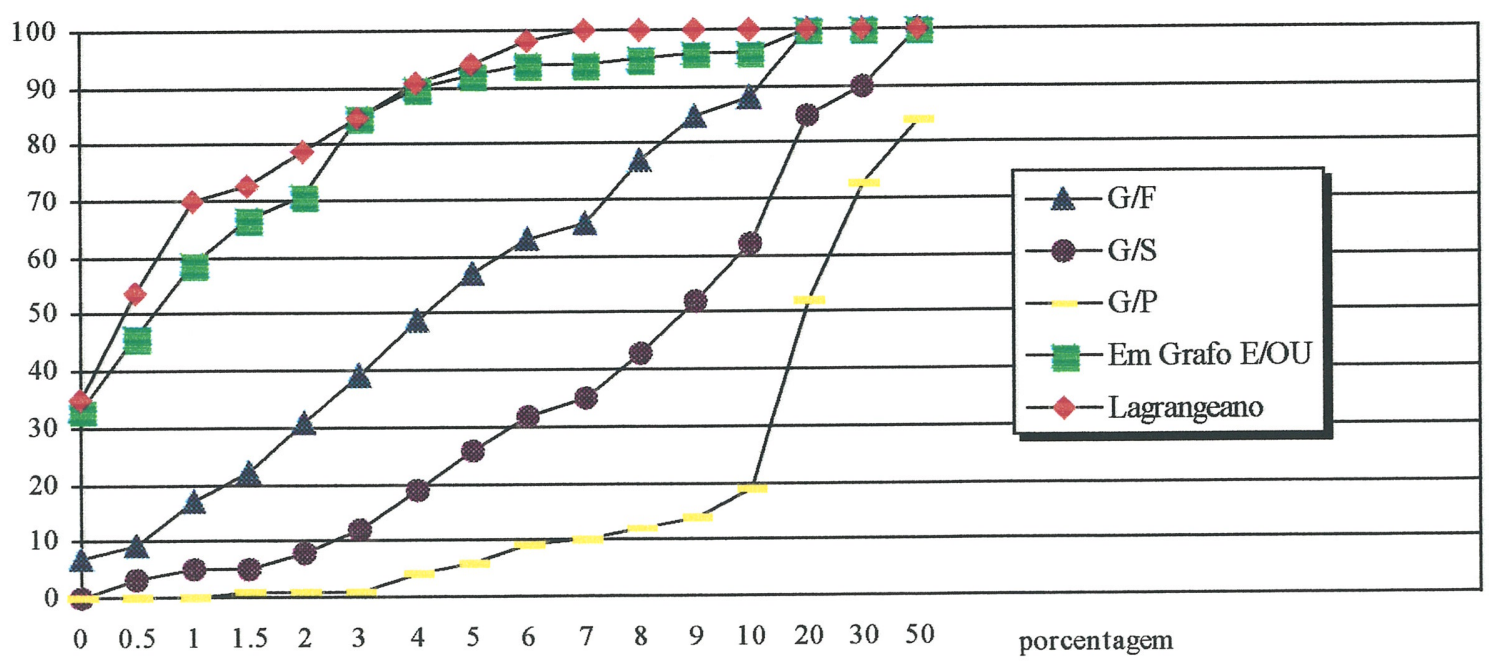

gráfico 6.12 
$m=20$

Número de Exemplos

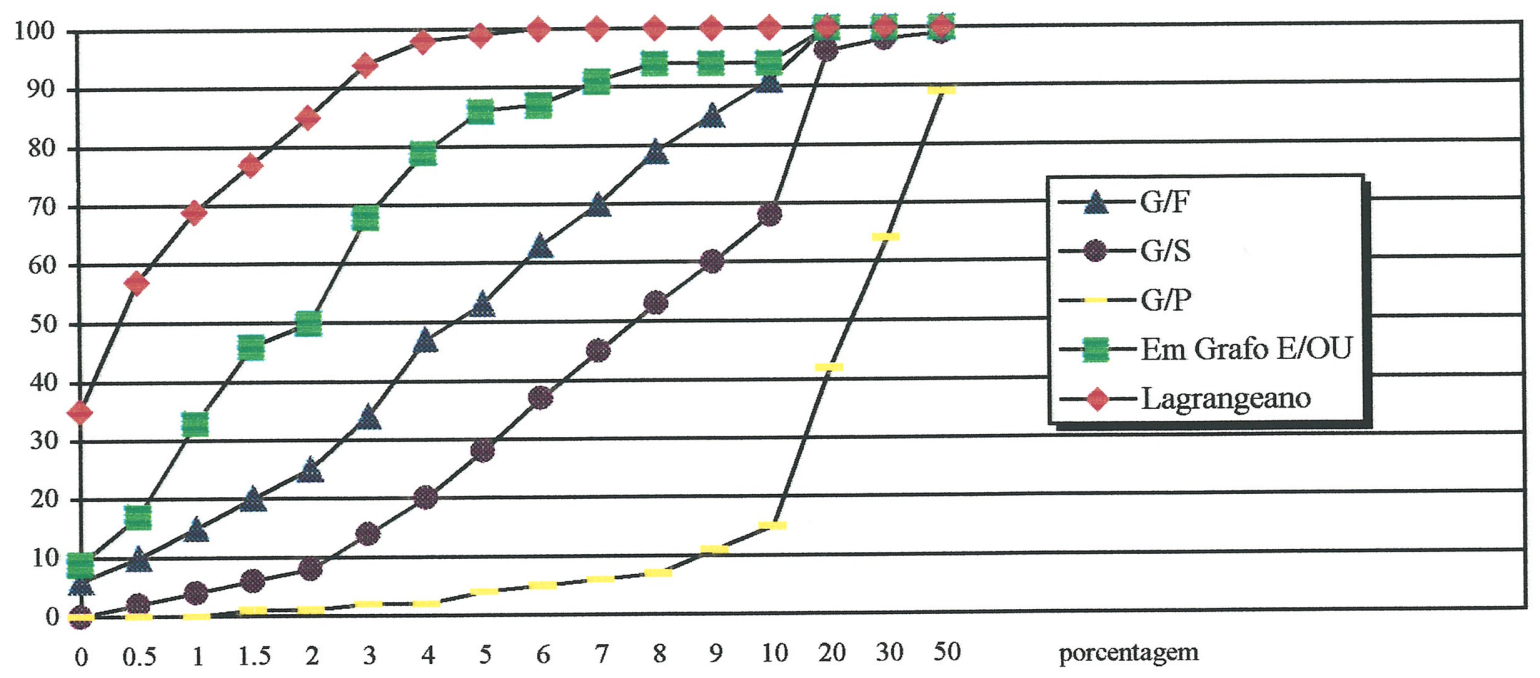

gráfico 6.13 .

$m=30$

Número

de Exemplos

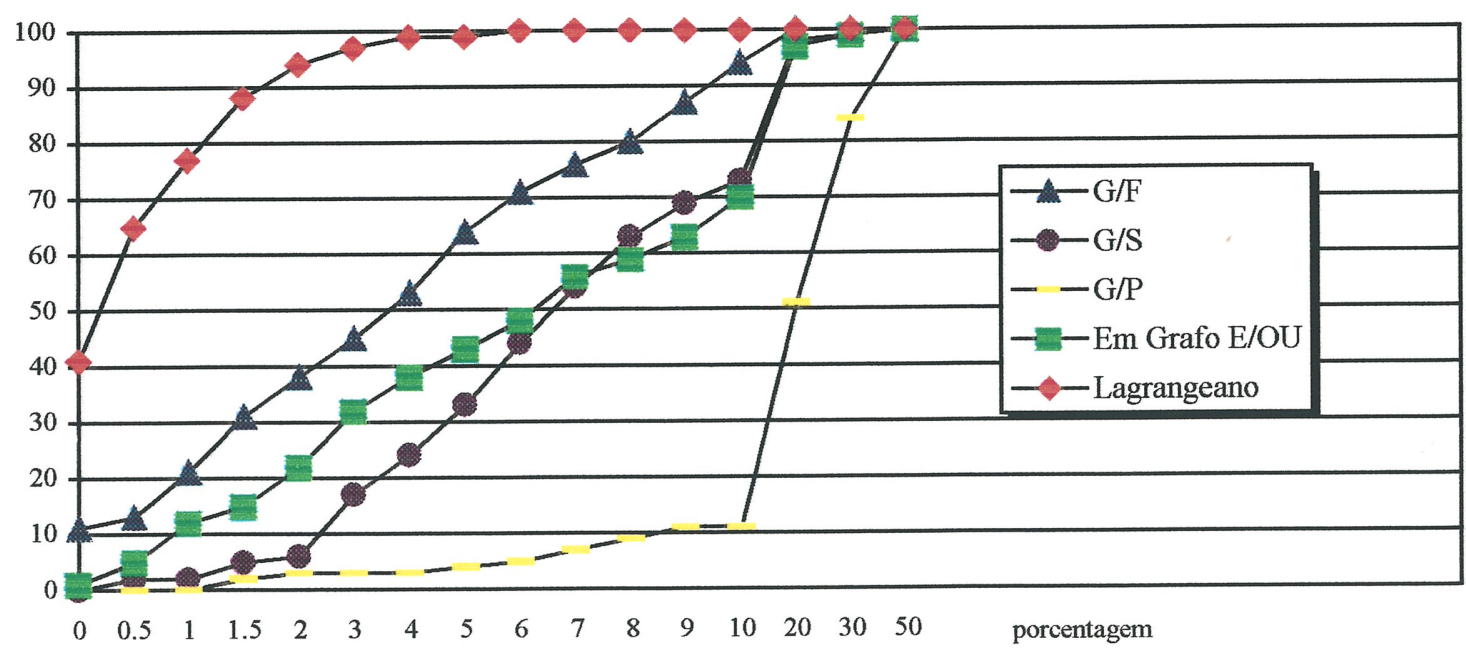

gráfico 6.14. 


\section{Valores de utilidade gerados aleatoriamente}

A tabela 6.4 abaixo apresenta os resultados de 400 exemplos grandes, onde os valores de utilidade das peças demandadas foram gerados aleatoriamente de 1 a 20 .

\begin{tabular}{|c|c|c|c|}
\hline $\boldsymbol{m}$ & \multicolumn{2}{|c|}{ solução } & \# sol. \\
& lim. superiores & lim. inferiores & ótimas \\
\hline $\mathbf{5}$ & 272.62964 & 259.39999 & 10 \\
\hline $\mathbf{1 0}$ & 361.61020 & 347.02000 & 6 \\
\hline $\mathbf{2 0}$ & 549.97135 & 531.59000 & 3 \\
\hline $\mathbf{3 0}$ & 575.90219 & 556.5900 & 11 \\
\hline
\end{tabular}

tabela 6.4

\section{Qualidade das soluções}

$m=5$

Número de Exemplos

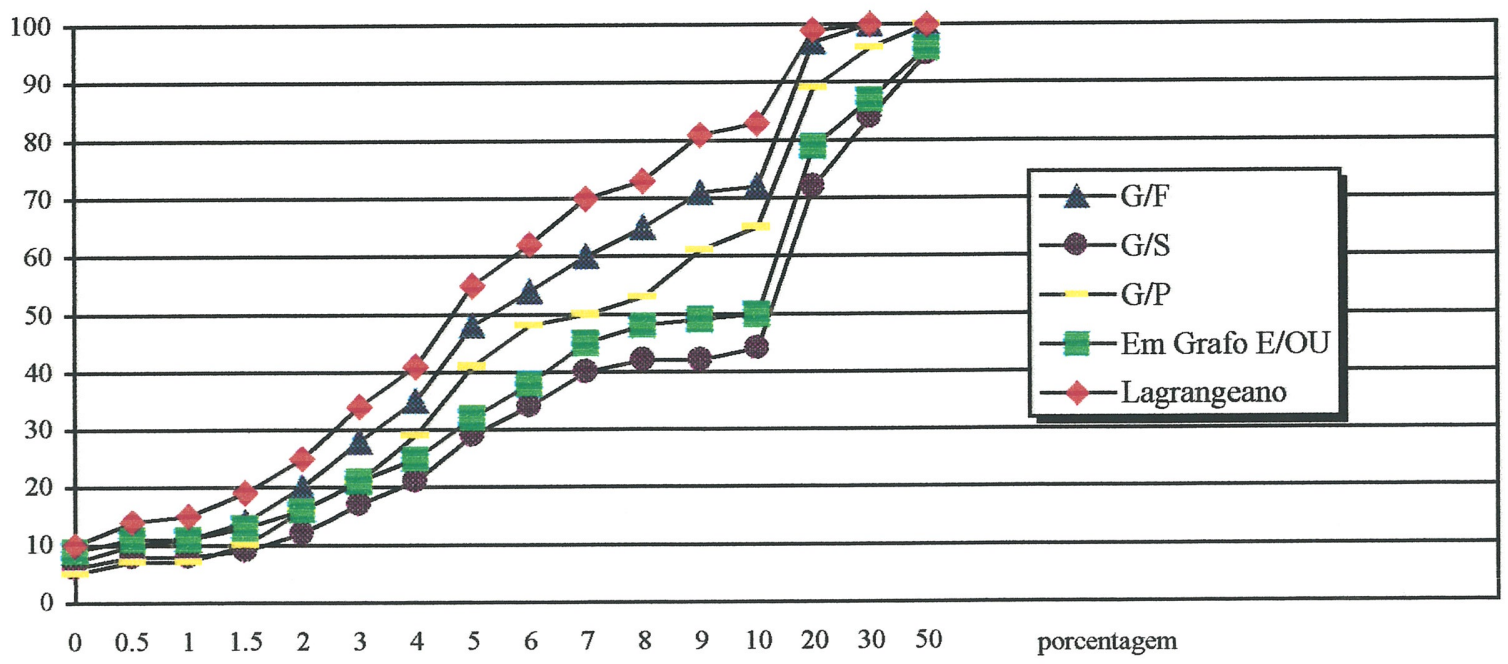

gráfico 6.15 
$m=10$

Número de Exemplos

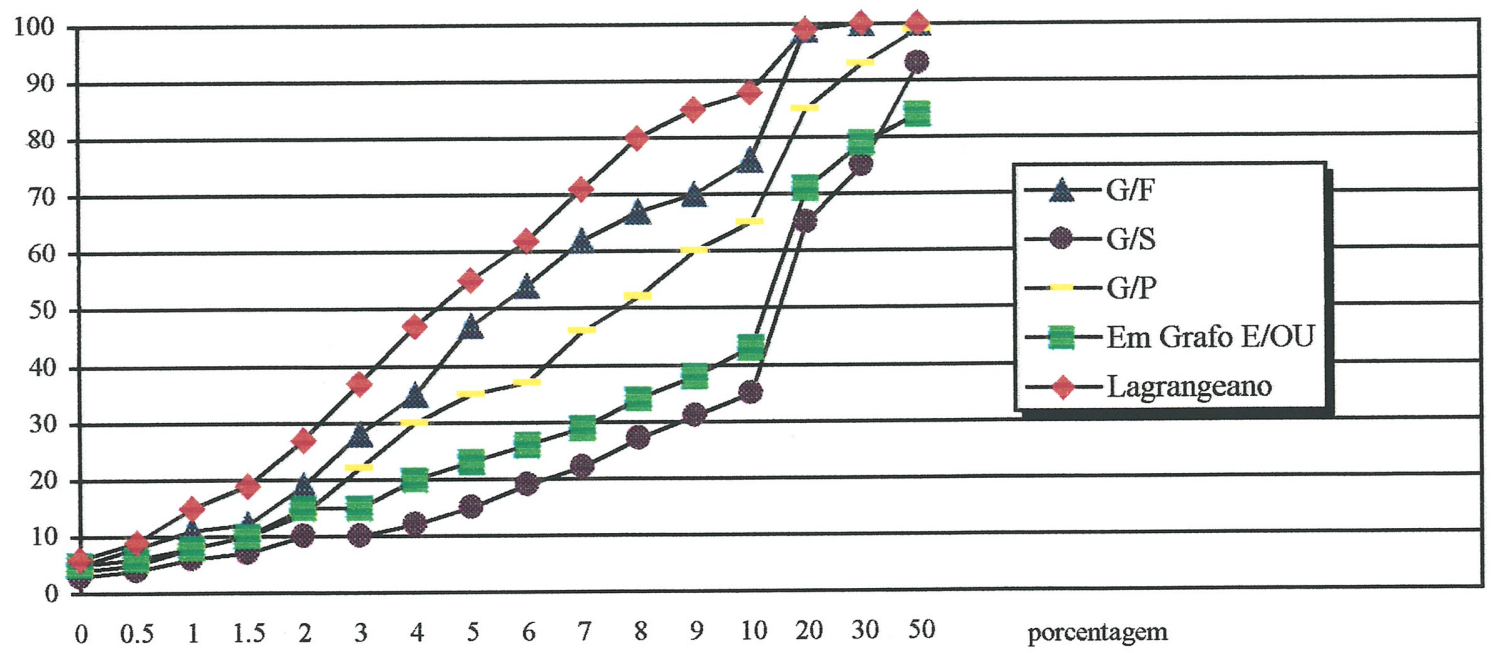

gráfico 6.16 .

$m=20$

Número de Exemplos

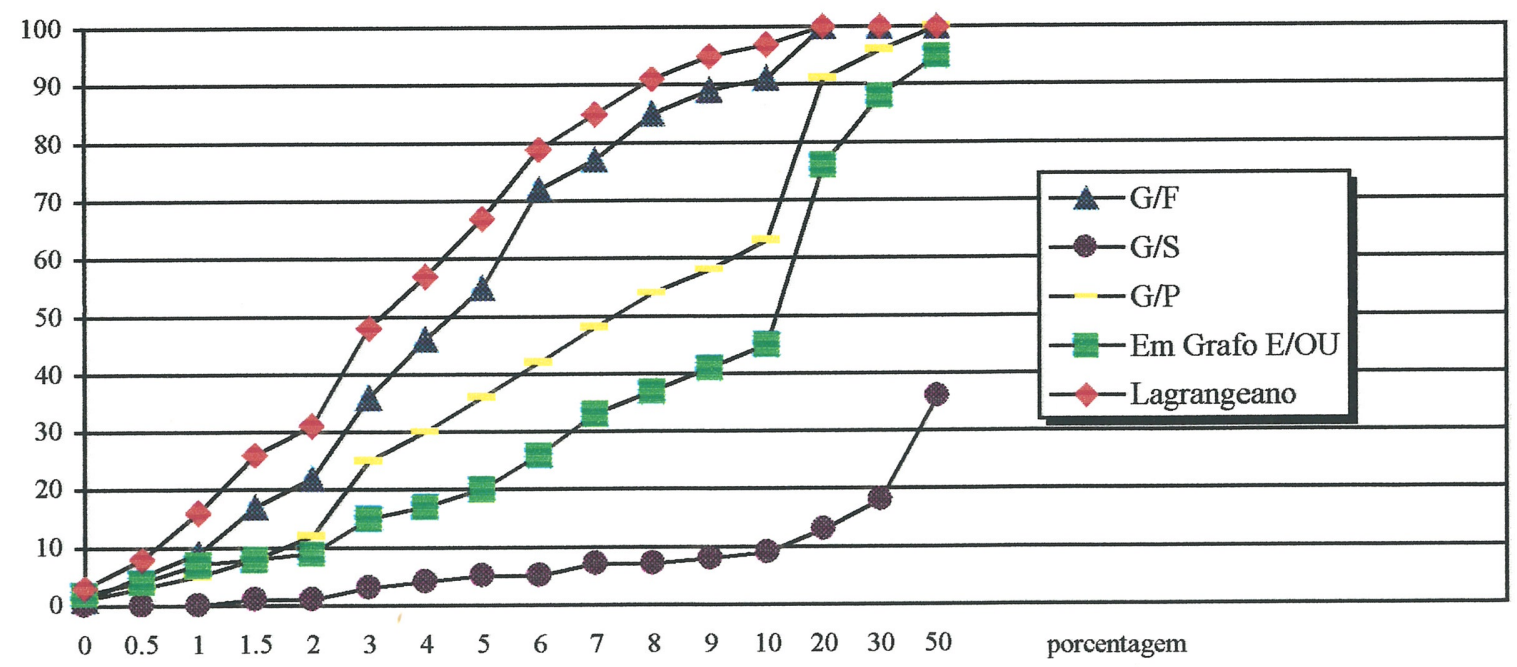

gráfico 6.17 
$m=30$

Número de Exemplos

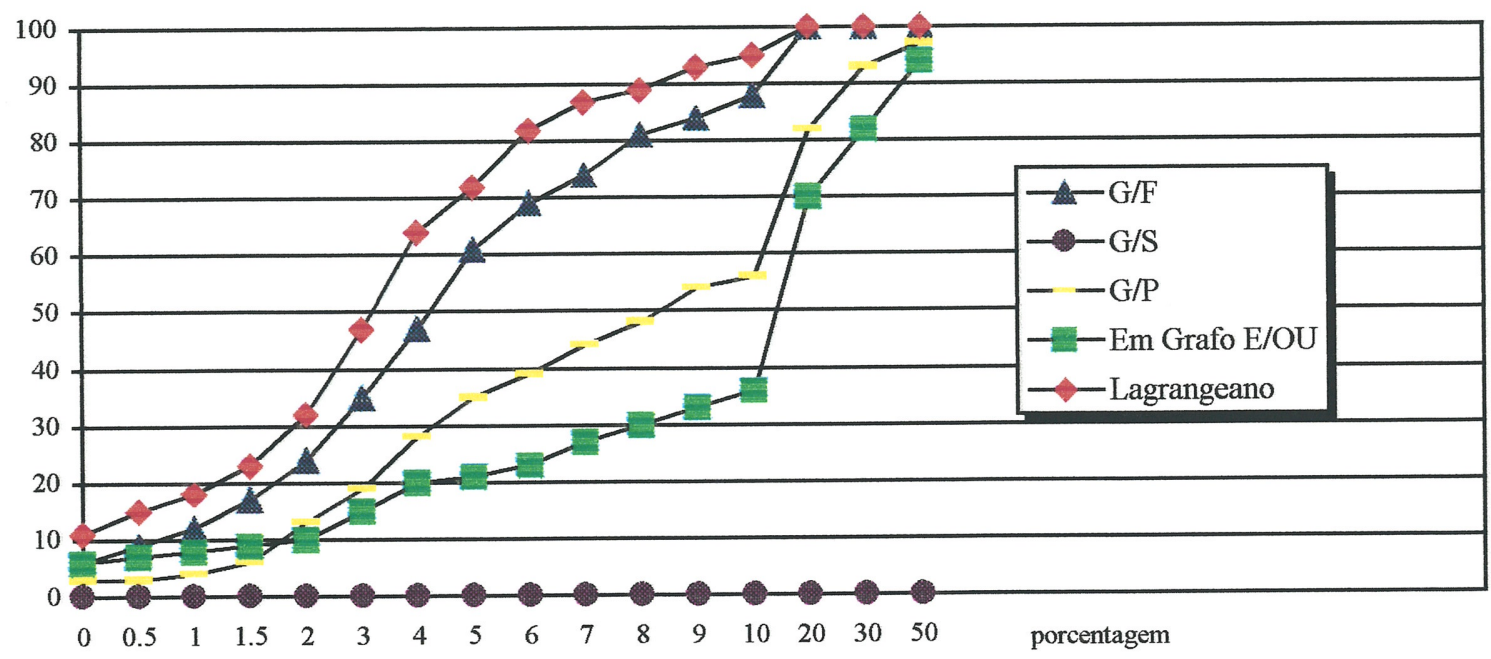

gráfico 6.18.

\section{Observações sobre os exemplos:}

Algumas observações podem ser feitas com os resultados obtidos pelas tabelas de soluções e pelos gráficos que mostram as qualidades das soluções obtidas.

- o aproveitamento percentual da placa melhorou com o aumento do número de tipos de peças demandadas, o que é esperado, pois o arranjo de poucas peças demandadas na placa resulta menores possibilidades de construção de faixas mais valiosas.

- melhores soluções foram obtidas para exemplos grandes do que para os exemplos pequenos (veja tabelas de soluções). Isto também seria esperado pois com peças $\left(l_{i}, w_{i}\right)$, $i=1, \ldots, m$ menores em relação a placa $(L, W)$, aumentam as chances de ocupar melhor a área desta placa. Apesar da quantidade de soluções ótimas ser maior para exemplos pequẹnos que grandes. 
- Observamos que mais de $90 \%$ de exemplos pequenos (quando os valores de utilidade são dados pela área) resolvidos pela heurística lagrangeana estão a menos de $5 \%$ da solução ótima, sendo que para pelo menos $50 \%$ dos exemplos pequenos foram obtidas as soluções ótimas.

- Notamos que quando os valores de utilidade são gerados aleatoriamente a quantidade de soluções para as quais podemos afirmar otimalidade $\left(z_{U B}=z_{L B}\right)$ diminui. Talvez apenas a qualidade do limitante superior seja pior e não de fato o número de soluções ótimas.

- Observamos que o lagrangeano parte da melhor solução entre G/P e G/F, logo seu resultado só poderia ser pior que a heurística em grafo $\mathrm{E} / \mathrm{OU}$, embora não observado. Notamos também que geralmente a heurística gulosa por peça forneceu os piores resultados (veja os gráficos).

- Para os exemplos com valores de utilidade sendo a área os gráficos tiveram o mesmo comportamento independente de $m$, a única mudança é que para exemplos pequenos a heurística em grafo E/OU obteve melhores resultados que a heurística gulosa por faixa e o contrário ocorreu para exemplos grandes (exceto para $m=30$ ).

- Para os exemplos com valores de utilidade gerados aleatoriamente a heurística em grafo E/OU obteve resultados ruins, às vezes até piores que a heurística gulosa por peça. Os gráficos tanto para exemplos pequenos como grandes tiveram o mesmo comportamento independente de $m$. 


\subsection{Exemplos da Literatura}

Retiramos da literatura alguns exemplos sendo que parte deles têm os valores de utilidade das peças iguais à área e outros aleatoriamente gerados. Em todos os exemplos abaixo utilizamos o número máximo de iterações permitidas igual a 100.

Todos os exemplos retirados da literatura têm soluções ótimas conhecidas obtidas aplicando algoritmos exatos desenvolvidos por Hifi et al, 1996. As solúções ótimas são de problemas de corte bidimensionais guilhotinados e restritos. Observe que não há restrições no número de estágios.

Notação utilizada nas tabelas abaixo:

sol-lagrangeano : limitantes superiores e inferiores obtidos pelo algoritmo proposto nesta dissertação (apresentado no capítulo 3) para o problema de corte bidimensional guilhotinado restrito em 2-estágios.

sol-ótima : solução ótima obtida por algoritmos exatos desenvolvidos por Hifi, 1996 para problemas de corte bidimensional guilhotinado e restrito (não necessariamente 2estágios).

sol-Hifi : solução obtida pelo algoritmo geral proposto por Hifi et al, 1997 (como em sol-ótima, o problema não necessariamente é tratado como 2-estágios).

\%: porcentagem de utilização da placa.

\subsubsection{Valores de utilidade dados pela área}

Para o conjunto de problemas onde os valores de utilidade das peças são designados pela área, consideramos 5 problemas : OF1 e OF2 foram retirados de Oliveira e Ferreira, 1990, $W$ é um exemplo usado por Wang, 1983 e $H$ representa exemplos gerados por Hifi et al, 1997. 


\section{1: $\mathrm{OF1}$}

$L=70, W=40$ e $m=10$.

\begin{tabular}{|l|l|l|l|l|l|l|l|l|l|l|}
\hline Peça & 1 & 2 & 3 & 4 & 5 & 6 & 7 & 8 & 9 & 10 \\
\hline$l_{i}$ & 29 & 9 & 55 & 31 & 11 & 23 & 29 & 16 & 9 & 22 \\
\hline$w_{i}$ & 5 & 39 & 9 & 15 & 16 & 21 & 14 & 19 & 36 & 4 \\
\hline$b_{i}$ & 1 & 4 & 1 & 1 & 2 & 3 & 4 & 3 & 2 & 2 \\
\hline
\end{tabular}

\begin{tabular}{|c|l|c|c|c|}
\hline OF1 & \multicolumn{1}{|c|}{$\begin{array}{c}\text { sol-lagrangeano } \\
\text { (2-estágios) }\end{array}$} & $\begin{array}{c}\text { sol-ótima } \\
\text { (multiestágio) }\end{array}$ & $\begin{array}{c}\text { sol-Hifi } \\
\text { (multiestágio) }\end{array}$ & $\%$ \\
\hline & $\begin{array}{l}\text { lim.sup. } 2713.00 \\
\text { lim. inf. } 2713.00\end{array}$ & 2737.00 & 2713.00 & 0.9689 \\
\hline
\end{tabular}

\section{2: $\mathrm{OF} 2$}

$L=70, W=40$ e $m=10$

\begin{tabular}{|l|l|l|l|l|l|l|l|l|l|l|}
\hline Peça & 1 & 2 & 3 & 4 & 5 & 6 & 7 & 8 & 9 & 10 \\
\hline$l_{i}$ & 22 & 40 & 13 & 23 & 29 & 16 & 47 & 19 & 13 & 36 \\
\hline$w_{i}$ & 18 & 10 & 27 & 18 & 8 & 4 & 9 & 19 & 16 & 16 \\
\hline $\boldsymbol{b}_{i}$ & 2 & 1 & 3 & 2 & 4 & 1 & 1 & 4 & 2 & 4 \\
\hline
\end{tabular}

\begin{tabular}{|c|l|c|c|c|}
\hline OF2 & \multicolumn{1}{|c|}{$\begin{array}{c}\text { sol-lagrangeano } \\
\text { (2-estágios) }\end{array}$} & $\begin{array}{c}\text { sol-ótima } \\
\text { (multiestágio) }\end{array}$ & $\begin{array}{c}\text { sol-Hifi } \\
\text { (multiestágio) }\end{array}$ & $\%$ \\
\hline & $\begin{array}{l}\text { lim.sup. } 2619.37 \\
\text { lim. inf. } 2515.00\end{array}$ & 2690.00 & 2586.00 & 0.8982 \\
\hline
\end{tabular}




\section{3: $W$}

$L=70, W=40$ e $m=20$

\begin{tabular}{|l|l|l|l|l|l|l|l|l|l|l|l|l|l|l|l|l|l|l|l|l|}
\hline Peça & 1 & 2 & 3 & 4 & 5 & 6 & 7 & 8 & 9 & 10 & 11 & 12 & 13 & 14 & 15 & 16 & 17 & 18 & 19 & 20 \\
\hline$l_{i}$ & 17 & 24 & 24 & 25 & 27 & 11 & 12 & 32 & 14 & 34 & 35 & 36 & 37 & 38 & 18 & 39 & 41 & 21 & 43 & 23 \\
\hline$w_{i}$ & 9 & 15 & 15 & 16 & 17 & 19 & 21 & 22 & 23 & 24 & 25 & 26 & 27 & 28 & 29 & 29 & 30 & 31 & 31 & 33 \\
\hline$b_{i}$ & 1 & 1 & 2 & 4 & 2 & 4 & 3 & 3 & 4 & 4 & 3 & 4 & 3 & 4 & 3 & 4 & 2 & 3 & 4 & 4 \\
\hline
\end{tabular}

\begin{tabular}{|c|l|c|c|c|}
\hline W & \multicolumn{1}{|c|}{$\begin{array}{c}\text { sol-lagrangeano } \\
\text { (2-estágios) }\end{array}$} & $\begin{array}{c}\text { sol-ótima } \\
\text { (multiestágio) }\end{array}$ & $\begin{array}{c}\text { sol-Hifi } \\
\text { (multiestágio) }\end{array}$ & $\%$ \\
\hline & $\begin{array}{l}\text { lim.sup. } 2656.11 \\
\text { lim. inf. } 2623.00\end{array}$ & 2721.00 & 2721.00 & 0.9367 \\
\hline
\end{tabular}

\section{4: $H$}

$L=150, W=175$ e $m=35$

\begin{tabular}{|l|l|l|l|}
\hline Peça & $l_{i}$ & $w_{i}$ & $b_{i}$ \\
\hline 1 & 78 & 44 & 2 \\
\hline 2 & 64 & 70 & 2 \\
\hline 3 & 52 & 70 & 3 \\
\hline 4 & 79 & 100 & 1 \\
\hline 5 & 66 & 60 & 1 \\
\hline 6 & 81 & 39 & 2 \\
\hline 7 & 91 & 94 & 1 \\
\hline 8 & 66 & 56 & 4 \\
\hline 9 & 91 & 50 & 2 \\
\hline 10 & 96 & 68 & 1 \\
\hline 11 & 40 & 112 & 3 \\
\hline 12 & 76 & 106 & 1 \\
\hline 13 & 63 & 35 & 8 \\
\hline 14 & 86 & 60 & 2 \\
\hline 15 & 93 & 84 & 1 \\
\hline
\end{tabular}




\begin{tabular}{|c|c|c|c|}
\hline 16 & 95 & 92 & 1 \\
\hline 17 & 70 & 57 & 1 \\
\hline \begin{tabular}{|l|}
18 \\
\end{tabular} & 66 & 71 & 1 \\
\hline 19 & 84 & 78 & 1 \\
\hline 20 & 51 & 67 & 4 \\
\hline 21 & 34 & 89 & 2 \\
\hline 22 & 77 & 87 & 2 \\
\hline 23 & 44 & 66 & 4 \\
\hline 24 & 76 & 76 & 2 \\
\hline 25 & 50 & 45 & 1 \\
\hline 26 & 36 & 66 & 4 \\
\hline 27 & 38 & 66 & 4 \\
\hline 28 & 75 & 39 & 6 \\
\hline 29 & 77 & 103 & 1 \\
\hline 30 & 50 & 45 & 8 \\
\hline 31 & 80 & 107 & 1 \\
\hline 32 & 61 & 54 & 5 \\
\hline 33 & 31 & 95 & 2 \\
\hline 34 & 39 & 67 & 5 \\
\hline 35 & 63 & 102 & 1 \\
\hline
\end{tabular}

\begin{tabular}{|c|l|c|c|c|}
\hline $\mathbf{H}$ & \multicolumn{1}{|c|}{$\begin{array}{c}\text { sol-lagrangeano } \\
\text { (2-estágios) }\end{array}$} & $\begin{array}{c}\text { sol-ótima } \\
\text { (multiestágio) }\end{array}$ & $\begin{array}{c}\text { sol-Hifi } \\
\text { (multiestágio) }\end{array}$ & $\%$ \\
\hline & $\begin{array}{l}\text { lim. sup. } 26100.00 \\
\text { lim. inf. } 26100.00\end{array}$ & 26100.00 & 25806.00 & 0.9942 \\
\hline
\end{tabular}




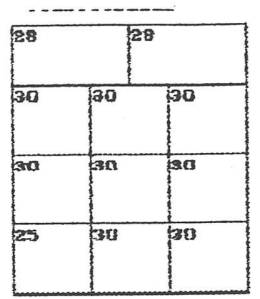

figura 6.1. - padrão de corte obtido pelo lagrangeano para o problema $H$.

\subsubsection{Valores de utilidade gerados aleatoriamente}

Finalmente para os valores de utilidade gerados aleatoriamente apresentamos 6 exemplos. Os dois primeiros exemplos, CHW1 e CHW2 foram retiradas de Christofides e Whitlock, 1977, TH1 e TH2 são dois exemplos considerados no trabalho de Tschoke e Holthofer, 1996 e Hifi et al, 1997 geraram 2 exemplos, CW1 e CW2.

\section{5: $C H W 1$}

$m=10, L=40, W=70$

\begin{tabular}{|l|l|l|l|l|l|l|l|l|l|l|}
\hline Peça & 1 & 2 & 3 & 4 & 5 & 6 & 7 & 8 & 9 & 10 \\
\hline $\boldsymbol{v}_{\boldsymbol{i}}$ & 216 & 315 & 140 & 143 & 94 & 90 & 110 & 582 & 210 & 403 \\
\hline $\boldsymbol{l}_{\boldsymbol{i}}$ & 9 & 9 & 10 & 11 & 12 & 13 & 14 & 21 & 30 & 31 \\
\hline $\boldsymbol{w}_{\boldsymbol{i}}$ & 24 & 35 & 14 & 13 & 8 & 7 & 8 & 22 & 7 & 13 \\
\hline $\boldsymbol{B}_{\boldsymbol{i}}$ & 3 & 3 & 1 & 3 & 3 & 3 & 3 & 1 & 2 & 1 \\
\hline
\end{tabular}

\begin{tabular}{|l|l|c|c|}
\hline CHW1 & \multicolumn{1}{|c|}{$\begin{array}{c}\text { sol-lagrangeano } \\
\text { (2-estágios) }\end{array}$} & $\begin{array}{c}\text { sol-ótima } \\
\text { (multiestágio) }\end{array}$ & $\begin{array}{c}\text { sol-Hifi } \\
\text { (multiestágio) }\end{array}$ \\
\hline & $\begin{array}{l}\text { lim sup. } 2757.53 \\
\text { lim. inf. } 2535.00\end{array}$ & 2892.00 & 2731.00 \\
\hline
\end{tabular}




\section{6: $\mathrm{CHW} 2$}

$m=20, L=40, W=70$

\begin{tabular}{|l|l|l|l|l|l|l|l|l|l|l|l|l|l|l|l|l|l|l|l|l|}
\hline Peร̧a & 1 & 2 & 3 & 4 & 5 & 6 & 7 & 8 & 9 & 10 & 11 & 12 & 13 & 14 & 15 & 16 & 17 & 18 & 19 & 20 \\
\hline $\boldsymbol{v}_{i}$ & 140 & 240 & 240 & 260 & 280 & 160 & 180 & 340 & 220 & 380 & 400 & 410 & 420 & 440 & 300 & 460 & 480 & 320 & 500 & 360 \\
\hline $\boldsymbol{u}_{i}$ & 9 & 15 & 15 & 16 & 17 & 19 & 21 & 22 & 23 & 24 & 25 & 26 & 27 & 28 & 29 & 29 & 30 & 31 & 31 & 33 \\
\hline $\boldsymbol{w}_{i}$ & 17 & 24 & 24 & 25 & 27 & 11 & 12 & 32 & 14 & 34 & 35 & 36 & 37 & 38 & 18 & 39 & 41 & 21 & 43 & 23 \\
\hline$b_{i}$ & 1 & 1 & 2 & 4 & 2 & 4 & 3 & 3 & 4 & 4 & 3 & 4 & 3 & 4 & 3 & 4 & 2 & 3 & 4 & 4 \\
\hline
\end{tabular}

\begin{tabular}{|l|l|c|c|}
\hline CHW2 & \multicolumn{1}{|c|}{$\begin{array}{c}\text { sol-lagrangeano } \\
\text { (2-estágios) }\end{array}$} & $\begin{array}{c}\text { sol-ótima } \\
\text { (multiestágio) }\end{array}$ & $\begin{array}{c}\text { sol-Hifi } \\
\text { (multiestágio) }\end{array}$ \\
\hline & $\begin{array}{l}\text { lim.sup. } 1860.29 \\
\text { lim. inf. } 1740.00\end{array}$ & 1860.00 & 1740.00 \\
\hline
\end{tabular}

\section{7: TH1}

$$
m=30, L=55, W=85
$$

\begin{tabular}{|l|l|l|l|l|}
\hline Peça & $\mathrm{v}_{\mathrm{i}}$ & $\mathrm{l}_{\mathrm{i}}$ & $\mathrm{w}_{\mathrm{i}}$ & $\mathrm{b}_{\mathrm{i}}$ \\
\hline 1 & 190 & 10 & 20 & 2 \\
\hline 2 & 220 & 11 & 21 & 1 \\
\hline 3 & 240 & 12 & 22 & 2 \\
\hline 4 & 450 & 12 & 40 & 2 \\
\hline 5 & 280 & 13 & 23 & 3 \\
\hline 6 & 390 & 14 & 24 & 1 \\
\hline 7 & 360 & 15 & 25 & 4 \\
\hline 8 & 350 & 15 & 26 & 3 \\
\hline 9 & 450 & 16 & 28 & 2 \\
\hline 10 & 250 & 17 & 14 & 1 \\
\hline 11 & 460 & 18 & 27 & 2 \\
\hline 12 & 250 & 19 & 15 & 3 \\
\hline 13 & 570 & 20 & 30 & 2 \\
\hline
\end{tabular}




\begin{tabular}{|c|c|c|c|c|}
\hline 14 & 250 & 21 & 13 & 2 \\
\hline 15 & 600 & 22 & 25 & 1 \\
\hline 16 & 660 & 22 & 32 & 3 \\
\hline 17 & 310 & 23 & 14 & 4 \\
\hline 18 & 720 & 24 & 30 & 2 \\
\hline 19 & 790 & 24 & 34 & 4 \\
\hline 20 & 760 & 25 & 30 & 2 \\
\hline 21 & 840 & 25 & 35 & 3 \\
\hline 22 & 900 & 26 & 36 & 4 \\
\hline 23 & 1000 & 26 & 40 & 2 \\
\hline 24 & 980 & 27 & 37 & 3 \\
\hline 25 & 1010 & 28 & 38 & 3 \\
\hline 26 & 550 & 29 & 19 & 5 \\
\hline 27 & 1050 & 29 & 39 & 4 \\
\hline 28 & 280 & 30 & 10 & 1 \\
\hline 29 & 630 & 31 & 21 & 3 \\
\hline 30 & 1320 & 31 & 43 & 4 \\
\hline
\end{tabular}

\begin{tabular}{|l|c|c|c|}
\hline TH1 & $\begin{array}{c}\text { sol-lagrangeano } \\
\text { (2-estágios) }\end{array}$ & $\begin{array}{c}\text { sol-ótima } \\
\text { (multiestágio) }\end{array}$ & $\begin{array}{c}\text { sol-Hifi } \\
\text { (multiestágio) }\end{array}$ \\
\hline & lim.sup. 4560.24 & 4620.00 & 4620.00 \\
\hline & lim. inf. 4450.00 & & \\
\hline
\end{tabular}

\section{8: $\mathbf{T H} 2$}

$$
m=20, L=99, W=99
$$

\begin{tabular}{|l|l|l|l|l|l|l|l|l|l|l|l|l|l|l|l|l|l|l|l|l|}
\hline Peça & 1 & 2 & 3 & 4 & 5 & 6 & 7 & 8 & 9 & 10 & 11 & 12 & 13 & 14 & 15 & 16 & 17 & 18 & 19 & 20 \\
\hline $\boldsymbol{v}_{\boldsymbol{i}}$ & 228 & 406 & 235 & 303 & 333 & 650 & 775 & 648 & 610 & 729 & 937 & 750 & 799 & 968 & 1052 & 999 & 1877 & 1025 & 1204 & 1499 \\
\hline $\boldsymbol{l}_{\boldsymbol{i}}$ & 14 & 14 & 15 & 17 & 18 & 20 & 20 & 21 & 25 & 27 & 29 & 30 & 30 & 33 & 35 & 37 & 38 & 40 & 43 & 44 \\
\hline $\boldsymbol{w}_{\boldsymbol{i}}$ & 16 & 31 & 17 & 19 & 19 & 34 & 39 & 29 & 25 & 27 & 34 & 25 & 27 & 30 & 30 & 27 & 49 & 25 & 28 & 34 \\
\hline $\boldsymbol{b}_{\boldsymbol{i}}$ & 1 & 2 & 3 & 3 & 2 & 2 & 3 & 2 & 2 & 3 & 2 & 2 & 3 & 2 & 2 & 4 & 2 & 2 & 4 & 4 \\
\hline
\end{tabular}




\begin{tabular}{|c|l|c|c|}
\hline TH2 & \multicolumn{1}{|c|}{$\begin{array}{c}\text { sol-lagrangeano } \\
\text { (2-estágios) }\end{array}$} & $\begin{array}{c}\text { sol-ótima } \\
\text { (multiestágio) }\end{array}$ & $\begin{array}{c}\text { sol-Hifi } \\
\text { (multiestágio) }\end{array}$ \\
\hline & $\begin{array}{l}\text { lim. sup. } 9488.82 \\
\text { lim. inf. } 9386.00\end{array}$ & 9700.00 & 9529.00 \\
\hline
\end{tabular}

\section{9: $C W 1$}

$m=25, L=125, W=105$

\begin{tabular}{|l|l|l|l|l|l|l|l|l|l|l|l|l|l|l|l|l|l|l|l|l|l|l|l|l|l|}
\hline Peça & 1 & 2 & 3 & 4 & 5 & 6 & 7 & 8 & 9 & 10 & 11 & 12 & 13 & 14 & 15 & 16 & 17 & 18 & 19 & 20 & 21 & 22 & 23 & 24 & 25 \\
\hline$v_{\boldsymbol{i}}$ & 283 & 256 & 221 & 704 & 648 & 298 & 442 & 640 & 534 & 406 & 469 & 186 & 291 & 665 & 399 & 456 & 201 & 424 & 414 & 629 & 362 & 376 & 414 & 693 & 456 \\
\hline$L_{i}$ & 42 & 28 & 28 & 31 & 69 & 35 & 47 & 78 & 33 & 77 & 35 & 55 & 72 & 37 & 48 & 51 & 58 & 44 & 41 & 59 & 25 & 47 & 56 & 29 & 78 \\
\hline$w_{i}$ & 41 & 65 & 63 & 38 & 24 & 35 & 55 & 22 & 30 & 47 & 41 & 34 & 66 & 64 & 26 & 21 & 40 & 22 & 61 & 36 & 30 & 23 & 65 & 64 & 58 \\
\hline$b_{\boldsymbol{i}}$ & 3 & 1 & 2 & 3 & 2 & 6 & 2 & 1 & 8 & 1 & 4 & 2 & 1 & 3 & 6 & 1 & 2 & 6 & 2 & 2 & 4 & 1 & 2 & 1 & 1 \\
\hline
\end{tabular}

\begin{tabular}{|c|l|c|c|}
\hline CW1 & \multicolumn{1}{|c|}{$\begin{array}{c}\text { sol-lagrangeano } \\
\text { (2-estágios) }\end{array}$} & $\begin{array}{c}\text { sol-ótima } \\
\text { (multiestágio) }\end{array}$ & $\begin{array}{c}\text { sol-Hifi } \\
\text { (multiestágio) }\end{array}$ \\
\hline & $\begin{array}{l}\text { lim.sup. } 6599.21 \\
\text { lim. inf. } 6402.00\end{array}$ & 6402.00 & 6402.00 \\
\hline
\end{tabular}

\section{0: $C W 2$}

$$
m=35, L=145, W=165
$$

\begin{tabular}{|l|l|l|l|l|}
\hline $\boldsymbol{P e c ̧ a}$ & $\boldsymbol{v}_{\boldsymbol{i}}$ & $\boldsymbol{l}_{\boldsymbol{i}}$ & $\boldsymbol{w}_{\boldsymbol{i}}$ & $\boldsymbol{b}_{\boldsymbol{i}}$ \\
\hline $\boldsymbol{1}$ & 315 & 43 & 69 & 1 \\
\hline 2 & 441 & 49 & 34 & 3 \\
\hline 3 & 342 & 84 & 67 & 1 \\
\hline $\mathbf{4}$ & 505 & 74 & 92 & 1 \\
\hline 5 & 691 & 64 & 56 & 1 \\
\hline $\mathbf{6}$ & 531 & 70 & 35 & 2 \\
\hline 7 & 399 & 93 & 47 & 3 \\
\hline
\end{tabular}




\begin{tabular}{|c|c|c|c|c|}
\hline 8 & 418 & 59 & 41 & 1 \\
\hline 9 & 236 & 93 & 104 & 1 \\
\hline 10 & 639 & 68 & 103 & 1 \\
\hline 11 & 452 & 67 & \begin{tabular}{|l|}
78 \\
\end{tabular} & 2 \\
\hline 12 & 237 & 65 & \begin{tabular}{|l|}
79 \\
\end{tabular} & 4 \\
\hline 13 & 348 & 46 & 53 & 2 \\
\hline 14 & 696 & \begin{tabular}{|l|}
72 \\
\end{tabular} & 38 & 3 \\
\hline \begin{tabular}{|l|}
15 \\
\end{tabular} & 250 & 34 & 42 & 1 \\
\hline \begin{tabular}{|l}
16 \\
\end{tabular} & 556 & 78 & 72 & 1 \\
\hline \begin{tabular}{|l}
17 \\
\end{tabular} & 285 & 42 & \begin{tabular}{|l|}
71 \\
\end{tabular} & 2 \\
\hline \begin{tabular}{|l}
18 \\
\end{tabular} & 203 & 51 & 80 & 2 \\
\hline \begin{tabular}{|l}
19 \\
\end{tabular} & \begin{tabular}{|l|}
741 \\
\end{tabular} & 50 & 62 & 4 \\
\hline 20 & 732 & 90 & 92 & 1 \\
\hline \begin{tabular}{|l}
21 \\
\end{tabular} & 611 & 73 & 85 & 2 \\
\hline 22 & 499 & 43 & 46 & 2 \\
\hline 23 & $\mid 184$ & 73 & 62 & 1 \\
\hline 24 & 460 & 68 & 77 & 2 \\
\hline 25 & 324 & \begin{tabular}{|l|}
47 \\
\end{tabular} & 42 & 1 \\
\hline \begin{tabular}{|l|}
26 \\
\end{tabular} & 420 & 88 & 47 & 1 \\
\hline \begin{tabular}{|l|}
27 \\
\end{tabular} & \begin{tabular}{|l}
749 \\
\end{tabular} & 65 & 53 & 1 \\
\hline \begin{tabular}{|l|}
28 \\
\end{tabular} & \begin{tabular}{|l|}
189 \\
\end{tabular} & 69 & 74 & 4 \\
\hline 29 & 279 & 88 & 89 & 1 \\
\hline \begin{tabular}{|l}
30 \\
\end{tabular} & 4445 & 65 & 86 & 1 \\
\hline \begin{tabular}{|l|}
31 \\
\end{tabular} & \begin{tabular}{|l|}
713 \\
\end{tabular} & 36 & 94 & 2 \\
\hline \begin{tabular}{|l|}
32 \\
\end{tabular} & 396 & 34 & 104 & 4 \\
\hline 33 & 150 & 73 & 86 & 1 \\
\hline 34 & 446 & 57 & 81 & 1 \\
\hline 35 & 692 & 74 & 41 & 3 \\
\hline
\end{tabular}




\begin{tabular}{|l|l|c|c|}
\hline CW2 & \multicolumn{1}{|c|}{$\begin{array}{c}\text { sol-lagrangeano } \\
\text { (2-estágios) }\end{array}$} & $\begin{array}{c}\text { sol-ótima } \\
\text { (multiestágio) }\end{array}$ & $\begin{array}{c}\text { sol-Hifi } \\
\text { (multiestágio) }\end{array}$ \\
\hline & $\begin{array}{l}\text { lim. sup. } 5421.73 \\
\text { lim. inf. } 5354.00\end{array}$ & 5354.00 & 5354.00 \\
\hline
\end{tabular}

Note que para CW1 e CW2 o algoritmo proposto nesta dissertação obteve a solução ótima, embora os limitantes superior e inferior não sejam iguais, significando também que a solução ótima foi obtida com cortes 2-estágios. Em particular, para $\mathrm{H}$ obtivemos solução melhor que Hifi et al. 


\section{CAPÍTULO 7}

\section{Conclusões e Perspectivas Futuras}

Esta tese abordou o problema de corte bidimensional guilhotinado restrito em 2estágios, com o objetivo de estudar e desenvolver metodologias para a resolução do problema.

A ênfase do trabalho consistiu na construção de um modelo matemático para a representação do problema. Inicialmente, a preocupação foi o desenvolvimento de um algoritmo exato baseado na relaxação lagrangeana e no método do subgradiente. Em seguida, desenvolvemos heurísticas para encontrar soluções iniciais factíveis. Numa outra etapa, aplicamos uma heurística lagrangeana para factibilizar soluções provenientes do método do subgradiente.

O modelo apresentado no capítulo 3 é um programa não linear e, portanto, um problema de dificil resolução. Para superar essa dificuldade, relaxamos as restrições nãolineares, produzindo subproblemas irrestritos. Definimos então o dual lagrangeano e, para resolvê-lo utilizamos o Método do Subgradiente.

O algoritmo desenvolvido para a resolução do problema foi escrito em Pascal e testados utilizando-se de um microcomputador IBM-PC compatível. Foram gerados aleatoriamente exemplos pequenos e grandes, e duas análises foram feitas. Quando o subgradiente é calculado : 
1. a partir de cada heurística de obtenção de uma solução inicial observamos que para exemplos pequenos há uma grande quantidade de soluções ótimas e quase-ótimas, enquanto que para exemplos grandes as heurísticas gulosa por substituição e gulosa por peça tiveram maior dificuldade em encontrar boas soluções.

2. a partir da melhor heurística de obtenção de solução inicial observamos que mais de $90 \%$ de exemplos pequenos (quando os valores de utilidade são dados pela área) resolvidos pela heurística lagrangeana estão a menos de $5 \%$ da solução ótima, sendo que para pelo menos $50 \%$ dos exemplos pequenos foram obtidas as soluções ótimas.

O estudo da resolução do modelo juntamente com as heurísticas implementadas deverão ser redigidos em forma de artigo e submetido para publicação em revista especializada.

Como perspectivas futuras estudaremos o problema de cortes acoplado ao problema de planejamento de produção. Um importante problema de planejamento da produção é o problema de dimensionamento de lotes que consiste em planejar a quantidade a ser produzida dos itens em vários (ou único) estágios em cada período ao longo de um horizonte de tempo finito, de modo a atender uma certa demanda e otimizar uma função objetivo (por exemplo, minimizar os custos). Estudaremos no projeto de doutorado o problema de dimensionamento de lotes multiestágios com restrições de capacidade.

O problema de dimensionamento de lotes multiestágio ocorre quando um item final possui itens predecessores, que também devem ser programados para produção ou compra. Os itens finais possuem suas próprias demandas, chamadas demandas independentes, enquanto que os itens predecessores podem possuir demanda dependente (utilizados para o consumo interno) e demanda independente. 
Em Billington et al (1983) encontramos uma formulação matemática para o problema de dimensionamento de lotes multiestágio com restrições de capacidade considerando estrutura geral de produto. $\mathrm{O}$ modelo considera tempo de produção (lead time) diferente de zero, tempo e custo de setup. Por lead time entende-se o tempo decorrido entre o instante em que se formaliza uma ordem de fabricação de um item e o instante em que ele se torna disponível.

Procurando especificar as principais operações no processo de produção, ele pode ainda esconder detalhes importantes, isto é, um centro de trabalho pode significar um conjunto de operações as quais não podem ser modelados simplesmente. Por exemplo, considere o problema de dimensionamento de lotes cuja estrutura do processo de produção em cada período de tempo é representada pela figura abaixo:

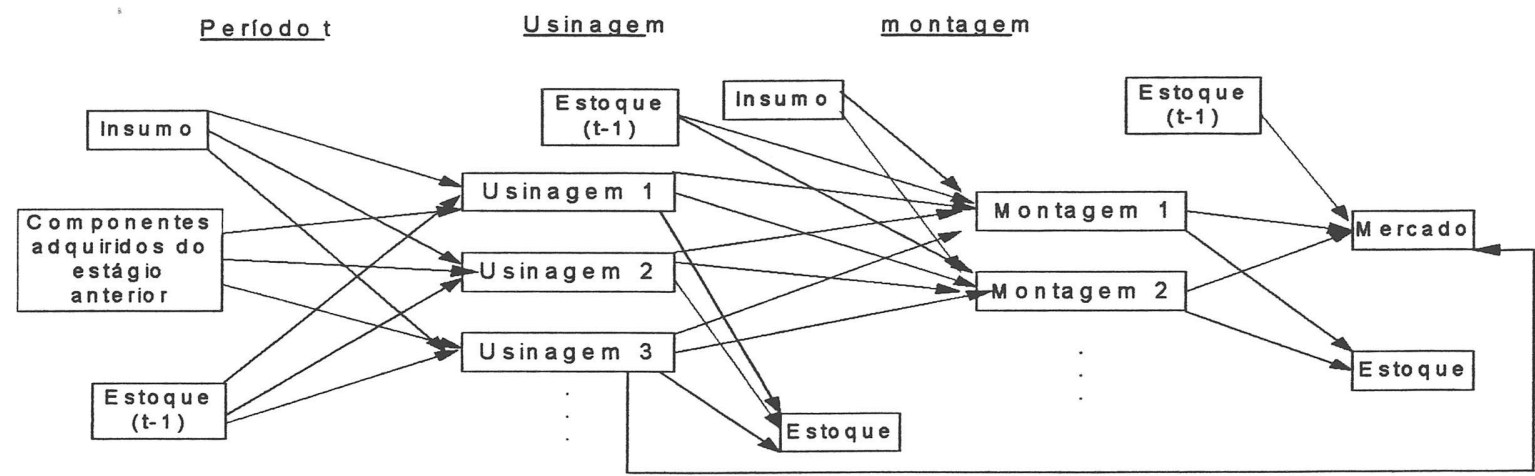

Figura 7.1 Representação esquemática do processo de produção.

O estágio precedente à usinagem consiste no estágio fundição, que envolve uma série de decisões que uma restrição não é capaz de descrever convenientemente. Por exemplo, a produção dos itens que passarão ao estágio usinagem implicam numa sequência de operações, tais como, escolha da liga, preparação dos moldes, etc. que, devido a sua importância no processo, poderiam ter um impacto relevante nas decisões de dimensionamento dos lotes.

Um outro exemplo consiste em indústrias onde a programação da produção envolve um estágio fundamental que consiste em cortar peças grandes (adquiridas de terceiros ou 
produzidas pela própria indústria) de modo a obter itens que serão então processados em estágios subsequentes e montados para compor um produto final, num processo de produção semelhante ao anterior. Tal estágio encerra uma complexidade ainda maior que o exemplo anterior da fundição. Verifica-se ser bastante relevante o custo de perda ocasionado pelo processo de corte. Assim, a decisão de dimensionamento dos lotes das peças grandes, sem levar em conta os custos associados ao estágio corte, pode ocasionar custos totais inaceitáveis na prática.

O problema de selecionar objetos e definir como devem ser cortados consiste por si só um problema de otimização combinatória bastante complexo e que tem motivado intensas pesquisas. A combinação deste com a programação da produção é ainda pouco explorada na literatura, mas a constatação de sua relevância em diversos situações já encontradas na prática o elegem como um interessante problema a ser pesquisado.

Como tema de doutorado os principais objetivos podem ser resumidos em:

1. Modelar matematicamente um problema de programação da produção onde um estágio fundamental consiste no processo de cortagem;

2. Desenvolver e implementar métodos exatos e heurísticos de resolução para o modelo proposto;

3. Estudo de caso com dados reais. 


\section{APÊNDICE}

\section{Método do Subgradiente}

\section{Introdução}

O método do subgradiente é uma das ferramentas mais usadas no campo de programação matemática, especialmente dentro do contexto de Relaxação Lagrangeana e Branch and Bound. O método do Subgradiente é um procedimento iterativo semelhante ao método do gradiente.

\section{Método do Subgradiente Aplicado ao Problema Lagrangeano.}

Considere o programa linear:

$$
\begin{array}{cl}
\min & c^{t} x \\
\text { sujeito } a: & A x \leq b \\
& x \in \Omega
\end{array}
$$

onde $\Omega$ é um poliedro fechado de $\mathfrak{R}^{n}$.

Então o problema lagrangeano (relaxando-se as restrições $A x \leq b, A \in \mathfrak{R}^{m \times n}$ ) é:

$$
h(\lambda)=\min _{x \in \Omega}\left\{c^{t} x+\lambda^{t}(A x-b)\right\}, \quad \lambda \geq 0
$$


Como a solução pode ser reduzida em um número finito de pontos, temos que:

$$
h(\lambda)=\min _{x=x^{1}, x^{2}, \ldots, x^{k}}\left\{c^{t} x+\lambda^{t}(A x-b)\right\}
$$

ou equivalentemente:

$$
\begin{aligned}
& h(\lambda)=\min _{i \in I}\left\{a^{i} \lambda+b_{i}, \quad i=1,2, \ldots, k\right\} \\
& \text { onde } a^{i}=\left(A x^{i}-b\right)^{t} \\
& \qquad b_{i}=c^{t} x^{i} \\
& I=\{1,2, \ldots, k\}
\end{aligned}
$$

O método do subgradiente pode ser visto como um procedimento que tenta maximizar o limitante inferior obtido do problema lagrangeano, isto é, resolver o dual lagrangeano, pela perturbação dos multiplicadores. Logo, estamos interessados no seguinte problema:

$$
\begin{gathered}
\max _{\lambda \geq 0} h(\lambda) \\
\text { onde } h(\lambda)=\min _{i \in I}\left(a^{i} \lambda+b_{i}\right)
\end{gathered}
$$

ou analogamente, se o problema original for de maximização:

$$
\begin{aligned}
& \min _{\lambda \geq 0} h(\lambda) \\
& \text { onde } h(\lambda)=\max _{i \in I}\left(a^{i} \lambda+b_{i}\right), a^{i}=\left(b-A x^{i}\right)^{t} \text { e } b_{i}=c^{t} x^{i}
\end{aligned}
$$

Logo, o procedimento básico do método do subgradiente aplicado ao problema lagrangeano é:

Passo 1: Escolha um vetor multiplicador de lagrange inicial $\left(\lambda^{0}\right), t=0$.

Passo 2: Resolva o problema relaxado (2) obtendo a solução $x^{t}$ e o valor da função objetivo que denominaremos $Z_{L B}$ (ou seja, um limitante inferior pois o problema original é de minimização, observe que no nosso problema obteremos um limitante superior, pois o problema restrito original é de maximização). 
Passo 3: Defina os subgradientes $a^{t}$ para as restrições relaxadas e calcule na solução atual:

$$
a^{t}=b_{t}-A x^{t}
$$

Passo 4: Defina o passo $\theta_{t}$.(Veja discussão abaixo)

Passo 5: Atualize $\lambda_{i}^{t}$ :

$$
\lambda_{i}^{t+1}=\max \left(0, \lambda_{i}^{t}+\theta_{t} a^{t}\right), i=1,2, \ldots, m
$$

e vá para o passo $2, t=t+1$.

Há muitos resultados teóricos que determinam o tamanho do passo a ser utilizado. Aqui daremos duas maneiras de determiná-lo:

- A série divergente $\sum_{t=1}^{\infty} \theta_{t} \rightarrow \infty, \theta_{t} \rightarrow 0$ quando $t \rightarrow \infty$.

- $\theta_{t}=\pi\left(\frac{Z_{U B}-Z_{L B}}{\left\|a^{t}\right\|^{2}}\right)$ onde $0<\pi<2$ e $Z_{U B}$ é um limitante superior da solução ótima de (4), obtido de uma solução factível do problema original.

O algoritmo do subgradiente pode parar quando, em alguma iteração $t$, encontrarmos $a^{t}=0$. Entretanto, na prática isso raramente irá acontecer. Portanto, uma regra de parada consiste em parar depois de um número fixo de iterações, ou se a função não apresenta melhora depois de um certo número de iterações, outras regras de parada são comentadas no Capítulo 3.

Não podemos também esperar do método do subgradiente uma melhora contínua em cada iteração pois a direção do subgradiente não é necessariamente uma direção de subida. O limitante inferior em uma certa iteração pode ser pior que o anterior. Logo, temos que sempre guardar a melhor solução encontrada. 


\section{BIBLIOGRAFIA}

AKINC, U. (1983), “An Algorithm for the knapsack Problem”, IIE Transactions 15, pp. 3136.

BAZARRAA, M. e JARVIS, J. (1977), "Linear Programming and Network Flows", John Wiley \& Sons, New York.

BEASLEY J.E., “Algorithms for unconstrained two-dimensional guillotine cutting”, Journal of the Operational Research Society, 36 (1985) 297-306.

CHRISTOFIDES, N. and WHITLOCK, C. (1977), "An Algorithm for Two Dimensional Cutting Problems", Operations Research 25, pp.30-44.

CHVÀTAL, V. (1980), “Linear Programming”, W.H.Freeman and Company, New York. 
DOWSLAND, K.A. e DOWSLAND, W.B. (1992), "Packing Problems", European Journal of Operational Research, 56:02-14.

DYCKHOFF, H. e FINKE, U. (1992), "Cutting and Packing in Production and Distribuition." Springer-Verlag Co., Heidelberg

EISEMANN, K. (1957), “The Trim Problem”, Management Science 3, pp. 279-284.

GILMORE, P., e GOMORY, R. (1961), “A linear programming approach to the cutting stock problem", Operations Research 9, 849-859.

GILMORE, P., e GOMORY, R. (1963), “A linear programming approach to the cutting stock problem - part II", Operations Research 11, 863-888.

GILMORE, P., e GOMORY, R. (1965), "Multi-stage cutting stock problems of two and more dimensions", Operations Research 14, 1045-1074.

HERZ, J. (1972), "Recursive Computational Procedure for Two Dimensional Stock Cutting”, IBM Journal of Research and Development 16, pp. 462-469.

HIFI, M.., FAYARD, D., ZISSIMOPOULOS, V., (1997) “A General Efficient Approach for Large-Scale Two-Dimensional Cutting Stock Problems",Technical Reports, Université de Paris 1.

LUENBERGER, D. (1984), "Linear and Nonlinear Programming”, Addinson-Wesley Publishing Company, Reading Massachusetts. 
MORÁBITO, R. (1992), "Uma abordagem em Grafo E/OU para o problema do empacotamento: Aplicação ao carregamento de paletes e contêineres", Tese de Doutorado, USP/SC.

MORÁBITO, R., e ARENALES, M. (1994), “An AND/OR-graph approach to the contanier packing problem", International Transactions in Operational Research 1, 59-73.

MORÁBITO, R., e ARENALES, M. (1995), "Performance of two heuristics to solve large scale two-dimensional cutting problems", INFOR 33, 2, 145-155.

MORÁBITO, R., e ARENALES, M. (1995), “An AND/OR-graph approach to the solution of two-dimensional non-guilhotine cutting problems", EJOR, Vol. 84, 599-617.

MORÁBITO, R., e ARENALES, M. (1996), "Staged and Constrained two-dimesnional guilhotine cutting problems: An AND/OR-graph approach", EJOR, Vol. 94, $\mathrm{n}^{\circ} 3,548-560$.

NEMHAUSER, G. L., WOLSEY, L.A. (1988), "Integer and Combinatorial Optimization", Wiley-Interscience Publication.

OLIVEIRA J.F., e FERREIRA J.S., “An improved version of Wang's algorithm for twodimensional cutting problems", European Journal of Operational Research, 44 (1990) 256266.

SANDI, C. (1979), “Combinatorial Optimization”, Wiley, pp. 73-91.

WANG P.Y., "Two algorithms for constrained two-dimensional cutting stock problems", Operations Research, 31/3 (1983) 573-586. 